\title{
Investigating chromosome damage and gammaH2AX response \\ in human lymphocytes and lymphocyte subsets as potential \\ biomarkers of radiation sensitivity
}

\author{
by

\section{Lindsay A. Beaton} \\ B.Eng. Engineering Physics, Carleton University, 2006 \\ M.Sc. Physics, Carleton University, 2009
}

A thesis submitted to the Faculty of Graduate Studies and Research

in partial fulfillment of the requirements for the degree of

\section{Doctor of Philosophy}

in

Physics, Specialization in Medical Physics

\author{
Ottawa-Carleton Institute of Physics \\ Department of Physics \\ CARLETON UNIVERSITY \\ Ottawa, ON, Canada
}

November 2012

(C) 2012, Lindsay A. Beaton 
Library and Archives

Canada

Published Heritage

Branch

395 Wellington Street

Ottawa ON K1A ON4

Canada
Bibliothèque et

Archives Canada

Direction du

Patrimoine de l'édition

395 , rue Wellington

Ottawa ON K1A ON4

Canada
Your file Votre référence

ISBN: 978-0-494-94209-3

Our file Notre référence

ISBN: $978-0-494-94209-3$
NOTICE:

The author has granted a nonexclusive license allowing Library and Archives Canada to reproduce, publish, archive, preserve, conserve, communicate to the public by telecommunication or on the Internet, loan, distrbute and sell theses worldwide, for commercial or noncommercial purposes, in microform, paper, electronic and/or any other formats.

The author retains copyright ownership and moral rights in this thesis. Neither the thesis nor substantial extracts from it may be printed or otherwise reproduced without the author's permission.
AVIS:

L'auteur a accordé une licence non exclusive permettant à la Bibliothèque et Archives Canada de reproduire, publier, archiver, sauvegarder, conserver, transmettre au public par télécommunication ou par l'Internet, prêter, distribuer et vendre des thèses partout dans le monde, à des fins commerciales ou autres, sur support microforme, papier, électronique et/ou autres formats.

L'auteur conserve la propriété du droit d'auteur et des droits moraux qui protege cette thèse. $\mathrm{Ni}$ la thèse ni des extraits substantiels de celle-ci ne doivent être imprimés ou autrement reproduits sans son autorisation.
In compliance with the Canadian Privacy Act some supporting forms may have been removed from this thesis.

While these forms may be included in the document page count, their removal does not represent any loss of content from the thesis.
Conformément à la loi canadienne sur la protection de la vie privée, quelques formulaires secondaires ont été enlevés de cette thèse.

Bien que ces formulaires aient inclus dans la pagination, il n'y aura aucun contenu manquant. 


\section{Abstract}

This thesis examines in vitro irradiated blood samples from prostate cancer patients exhibiting late normal tissue damage after receiving radiotherapy, for lymphocyte response. Chromosomal aberrations, translocations and proliferation rate are measured, as well as $\gamma \mathrm{H} 2 \mathrm{AX}$ response in lymphocytes and lymphocyte subsets. The goal of this thesis is to determine whether the lymphocyte response to in vitro radiation could be used as a marker for radiosensitivity.

Patients were selected from a randomized clinical trial evaluating the optimal timing of Dose Escalated Radiation and short course Androgen Deprivation Therapy. Of 438 patients, $3 \%$ developed Grade 3 late radiation proctitis and were considered to be radiosensitive. Blood was drawn from 10 of these patients along with 20 matched samples from patients with grade 0 proctitis. The samples were irradiated and were analyzed for dicentric chromosomes, excess fragments and proliferation rates (at $6 \mathrm{~Gy}$ ), translocations, stable and unstable damage (at $4 \mathrm{~Gy}$ ), and dose response (up to $10 \mathrm{~Gy}$ ), along with time response after 2 Gy $(0-24$ h). Chromosome aberrations, excess fragments per cell, translocations per cell and proliferation rates were analyzed by brightfield and fluorescent microscopy, while the $\gamma \mathrm{H} 2 \mathrm{AX}$ response in lymphocytes and lymphocyte subsets was analyzed by flow cytometry.

Both groups were statistically similar for all endpoints at $0 \mathrm{~Gy}$. At $6 \mathrm{~Gy}$, there were statistically significant differences between the radiosensitive and control cohorts for three endpoints; the mean number of dicentric chromosomes per cell, the mean number of excess fragments per cell and the proportion of cells in second metaphase. At 
$4 \mathrm{~Gy}$, there were statistically significant differences between the two cohorts for three endpoints; the mean number of translocations per cell, the mean number of dicentric chromosomes per cell and the mean number of deletions per cell. There were no significant differences between the $\gamma \mathrm{H} 2 \mathrm{AX}$ responses of the groups for either the dose or time course as measured with flow cytometry.

Six cytogenetic endpoints, measuring chromosomal aberrations, demonstrated a strong correlation with radiosensitivity and should be studied further as markers of radiation response. These results will contribute to the search for an indicator for identifying radiosensitive patients and for tailoring radiotherapy treatments. 


\section{Preface}

This thesis contains three manuscripts, described below, which, taken together, investigated the lymphocytes of prostate cancer patients for a biomarker of radiation sensitivity. The prostate cancer patients were chosen from a clinical trial as those who exhibited severe late normal tissue effects after radiotherapy treatments. These patients were matched by a control group of prostate cancer patients, chosen from the same clinical trial. The blood samples from each patient were aliquoted into separate volumes for each of three experiments; the dicentric chromosome assay (DCA), the fluorescent in situ hybridization (FISH) assay and the phosphorylated histone $(\gamma \mathrm{H} 2 \mathrm{AX})$ assay. Each manuscript describes one of these experiments, and is presented as a chapter of this thesis.

Chapter 1 presents an introduction to radiosensitivity, as well as background information about the research that has previously been done on the subject.

Chapter 2 includes additional background details about lymphocytes and the different experiments performed. This information is intended to present more detailed methods in addition to the descriptions in each paper's Materials and methods section.

Chapter 3 contains the manuscript entitled "Chromosome damage and cell proliferation rates in in vitro irradiated whole blood as markers of late radiation toxicity after prostate radiotherapy", accepted for publication in the International Journal of Radiation Oncology, Biology, Physics (IJROBP) (September $23^{\text {rd }}, 2012$ ). The manuscript has been edited from the published version following revisions requested by examiners at the defense (December $10^{\text {th }}, 2012$ ). 
Chapter 4 contains the manuscript entitled "Investigating chromosome damage using fluorescent in situ hybridization to identify biomarkers of radiosensitivity in prostate cancer patients", as submitted to the IJROBP (November $19^{\text {th }}, 2012$ ).

Chapter 5 contains the manuscript entitled "Investigating $\gamma H 2 A X$ as a biomarker of radiation sensitivity using flow cytometry methods", as submitted to Radiology Research and Practice (November $4^{\text {th }}, 2012$ ). There is an additional section at the end of the chapter which contains experimental results which were not included in the paper due to word limitations.

Chapter 6 presents a discussion of the discriminant analysis of the three experiments, and includes a discussion of the limitations of the data set.

Chapter 7 presents a general discussion of the results of each experiment, as well as a discussion of future work with regards to biomarkers of radiation sensitivity.

Note that for consistency, the references have been unified throughout the thesis and are listed at the end of the thesis. 


\section{Statement of originality}

As mentioned in the preface, this thesis contains three manuscripts which investigated the lymphocytes of prostate cancer patients for a biomarker of radiation sensitivity. Each manuscript describes one of these experiments, and is presented as a chapter of this thesis.

Chapter 3 contains the manuscript entitled "Chromosome damage and cell proliferation rates in in vitro irradiated whole blood as markers of late radiation toxicity after prostate radiotherapy", accepted for publication in the International Journal of Radiation Oncology, Biology, Physics (IJROBP) (September $23^{\text {rd }}, 2012$ ). I performed the experiments, analyzed the data and wrote the manuscript. Catherine Ferrarotto, MLT, a technologist in the laboratory, helped me to prepare the slides, and count the $6 \mathrm{~Gy}$ samples, as well as the percentage of cells in second metaphase.

Chapter 4 contains the manuscript entitled "Investigating chromosome damage using fluorescent in situ hybridization to identify biomarkers of radiosensitivity in prostate cancer patients", as submitted to the IJROBP (November 19, 2012 ). I performed the experiments, analyzed the data and wrote the manuscript.

Chapter 5 contains the manuscript entitled "Investigating $\gamma H 2 A X$ as a biomarker of radiation sensitivity using flow cytometry methods", as submitted to the Radiology Research and Practice (November $4^{\text {th }}, 2012$ ). I designed and performed the experiments, and wrote the manuscript.

Leonora Marro, a statistician with Health Canada, provided advice and assistance on the statistical analysis in chapters $3-5$, as well as chapter 6 a discussion of the discriminant analysis of the three experiments. 
Dr. Ruth Wilkins, my supervisor, provided advice and guidance for each of the experiments, and assisted with editing and reviewing each manuscript, and the thesis as a whole.

Other authors on the three papers were Dr. Shawn Malone, a radiation oncologist at the Ottawa Hospital Research Institute, and his oncology resident, Dr. Sara Samiee, who were responsible for identifying the appropriate patients (both the sensitive and control patients) and for discussions relating to clinical symptoms and side effects. Scott Grimes, from the Ottawa Hospital Research Institute was the Patient Trials Co-ordinator, and Kyle Malone was responsible for maintaining the patient database. 


\section{Acknowledgements}

I would like to gratefully acknowledge the help and support of the following people, without whom I would not have been able to complete this thesis.

Firstly, I would like to thank my supervisor Dr. Ruth Wilkins, for her positive support and encouragement, and her research insights. She has been an excellent mentor, and I look forward to continuing our work together.

I would also like to thank the other members of the Radiobiology lab at Health Canada, for making it such a great place to work. I would especially like to mention and thank Catherine Ferrarotto for teaching me to count chromosomes, her help with counting the 6 Gy slides and the $\mathrm{M} 1 / \mathrm{M} 2$ ratios and our many early morning discussions. I would also thank Sylvie Lachapelle and Barbara Fenske for their indispensable support and discussions.

Leonora Marro, a statistician with Health Canada, was invaluable in providing advice on the statistical analysis of the different experiments, as well as helping to analyse the data.

I would like to thank Dr. Shawn Malone, a radiation oncologist at the Ottawa Hospital Research Institute, and his oncology resident, Dr. Sara Samiee, who were responsible for identifying the appropriate patients and for discussions relating to clinical symptoms and side effects.

I would also like to thank the faculty and staff of the Carleton University Physics department; they have been supportive and encouraging, especially Eva Lacelle who always has the best interests of the students at heart. 
My friends have been a great source of fun and inspiration. I am excited for all of our new adventures!

I owe my family, Mark, Evelyn and Dale Beaton, Kyle and Jill Cashman, and Geoff and Cathy Green, a great deal of thanks, for keeping me grounded, and for their love and support.

And finally, a very special thanks to Chris Green, mo chridhe. 


\section{Table of Contents}

ABSTRACT …......................................................................................................... II

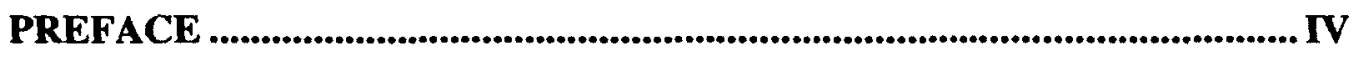

STATEMENT OF ORIGINALITY ................................................................ VI

ACKNOWLEDGEMENTS .................................................................. VIII

TABLE OF CONTENTS ..........................................................................................

LIST OF ABBREVIATIONS ..................................................................... XVI

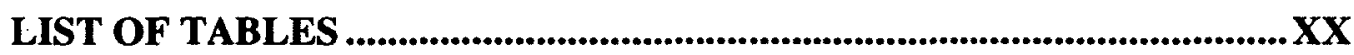

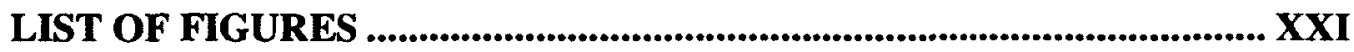

1. GENERAL INTRODUCTION….......................................................................1

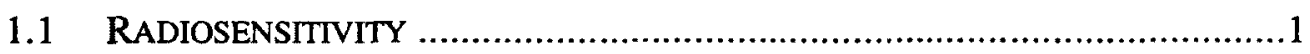

1.1.1 Radiosensitive diseases and individual radiosensitivity ........................1

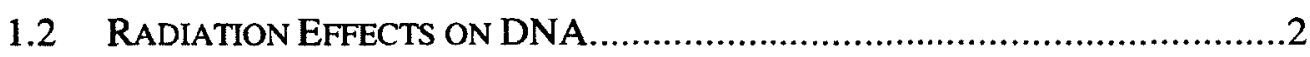

1.2.1 DNA damage: single- and double-strand breaks .................................

1.2.2 DNA repair: mechanisms and pathways..............................................

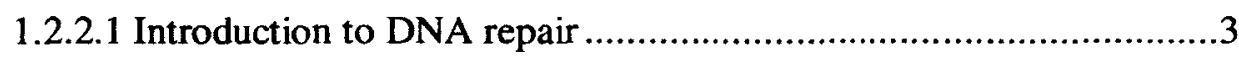

1.2.2.2 Homologous recombination (HR) ...............................................

1.2.2.3 Non-homologous end joining (NHEJ) ..........................................

1.2.2.4 Summary of DNA repair mechanisms ...........................................

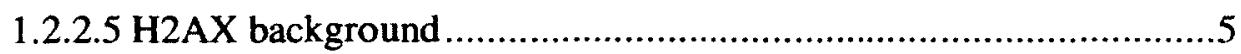

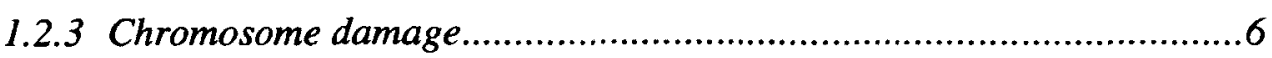


1.2.3.1 Chromosome Structure .......................................................

1.2.3.2 Radiation-induced chromosome aberrations ..............................9

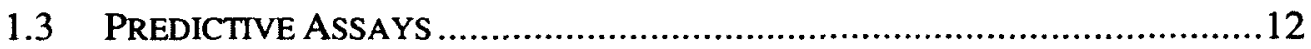

1.3.1 Skin Cells .................................................................................. 12

1.3.2 Lymphocyte apoptosis ......................................................... 13

1.3 .3 Lymphocyte response ....................................................... 14

1.3 .4 Other assays ................................................................. 15

1.4 THESIS STATEMENT .......................................................

1.4.1 Thesis statement ................................................................ 16

1.4.2 Collaboration with the Ottawa Hospital Cancer Center ...................17

1.4 .3 A note on prostate cancer..................................................... 18

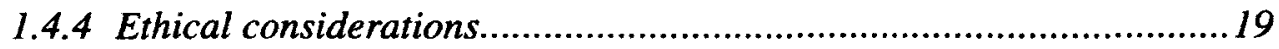

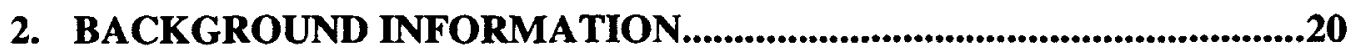

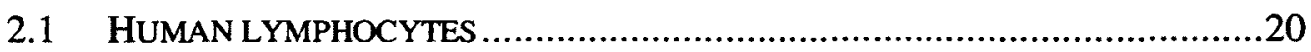

2.1.1 The make-up of a venous blood sample .......................................20

2.1.2 Persistence of damage ............................................................20

2.2 EXPERIMENTAL TECHNIQUES TO DETECT DNA DAMAGE .....................21

2.2.1 Dicentric Chromosome Assay ...............................................21

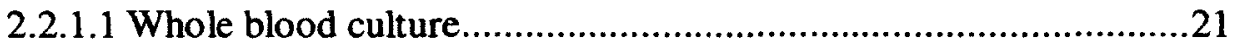

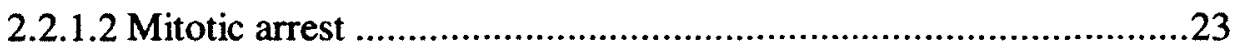

2.2.1.3 Hypotonic shock and soft fixation ......................................24

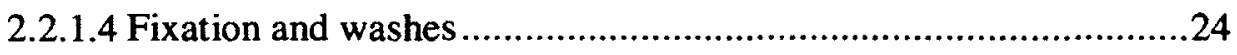

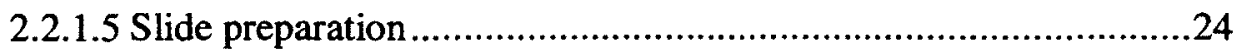


2.2.1.6 Fluorescence plus Giemsa staining ..................................25

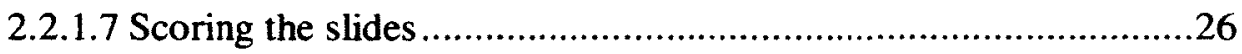

2.2.2 Fluorescence In Situ Hybridization (FISH) .............................27

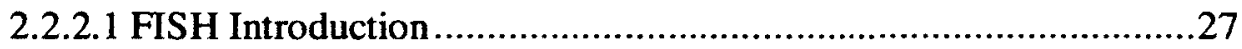

2.2.2.2 Cell culture, mitotic arrest, hypotonic shock and fixation and slide

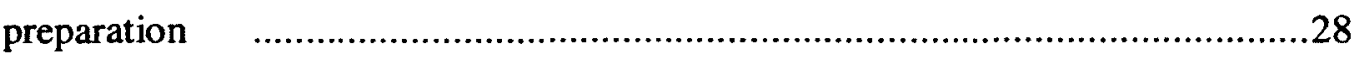

2.2.2.3 Slide preparation and chromosome painting .........................28

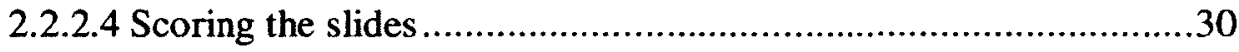

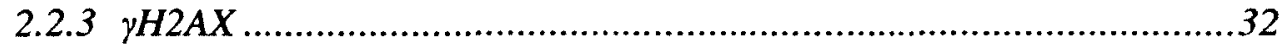

2.2.3.1 Methods of measuring $\gamma \mathrm{H} 2 \mathrm{AX}$ : spot counting and flow cytometry..

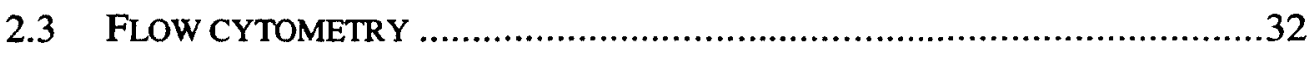

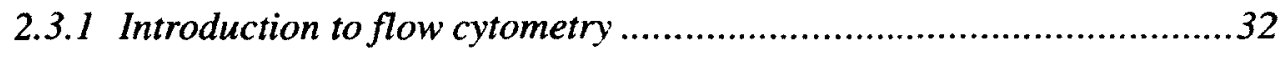

2.3.2 Key elements of flow cytometry ............................................. 33

3. THE DICENTRIC CHROMOSOME ASSAY (DCA) STUDY ..............37

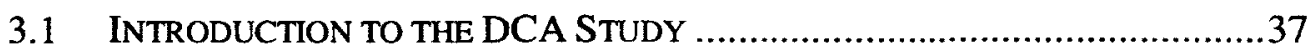

3.2 CHROMOSOME DAMAGE AND CELL PROLIFERATION RATES IN IN VITRO IRRADIATED WHOLE BLOOD AS MARKERS OF LATE RADIATION TOXICITY AFTER PROSTATE

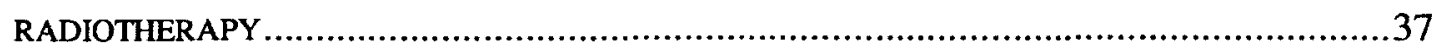

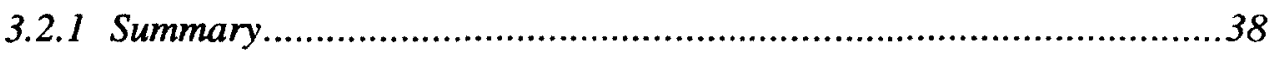

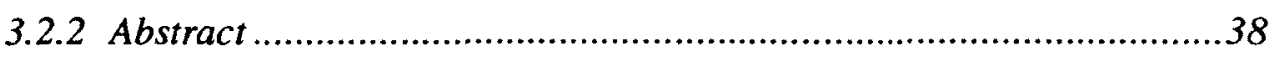

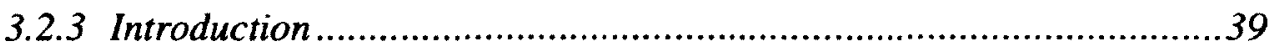

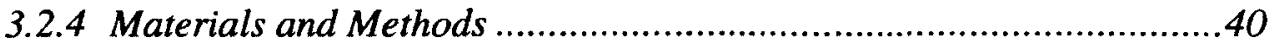




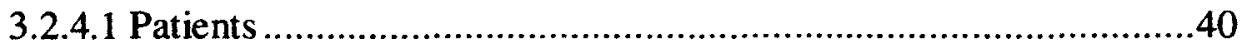

3.2.4.2 In vitro Irradiation Protocol..............................................42

3.2.4.3 Culture and Fixation .........................................................43

3.2.4.4 Dicentric Chromosome Assay (DCA) ...................................44

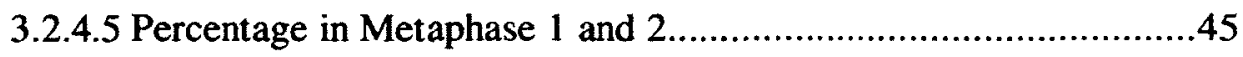

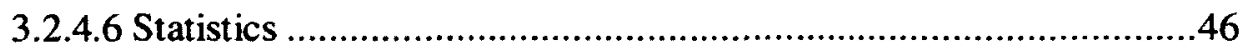

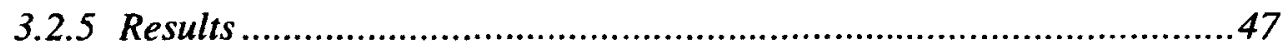

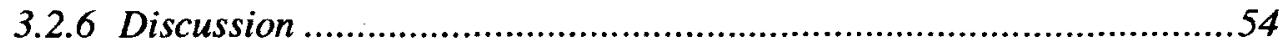

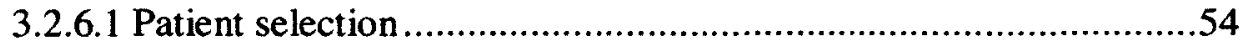

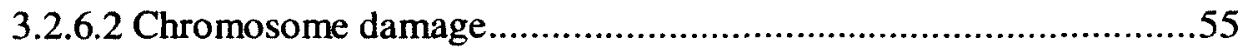

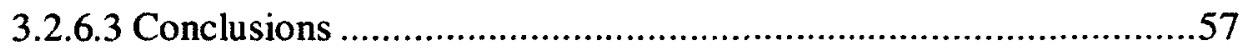

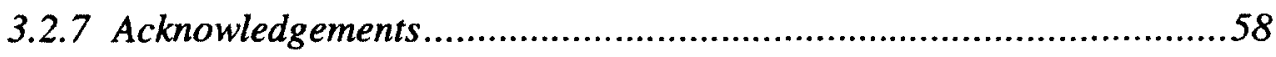

\section{THE FLUORESCENT IN SITU HYBRIDIZATION ASSAY STUDY ...59}

4.1 INTRODUCTION TO THE FLUORESCENT IN SITU HYBRIDIZATION (FISH)

STUDY

4.2 INVESTIGATING CHROMOSOME DAMAGE USING FLUORESCENT IN SITU HYBRIDIZATION TO IDENTIFY BIOMARKERS OF RADIOSENSITIVITY IN PROSTATE CANCER PATIENTS

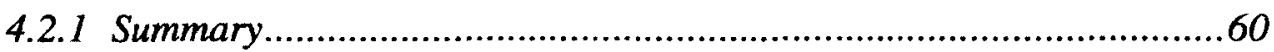

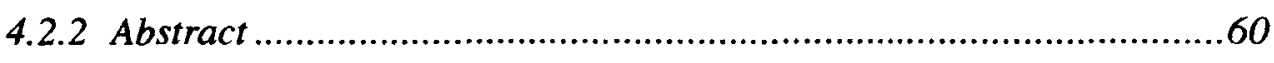

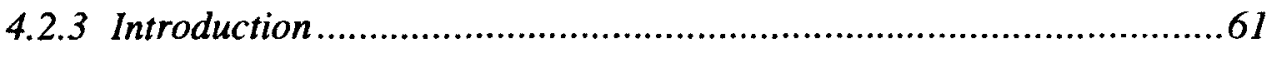

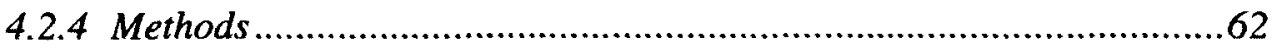

4.2.4.1 Patient Selection and Sample Collection .............................62 
4.2.4.3 Slide preparation and staining ........................................64

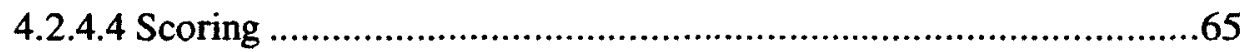

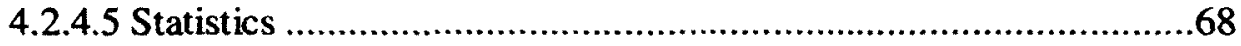

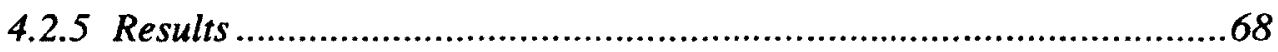

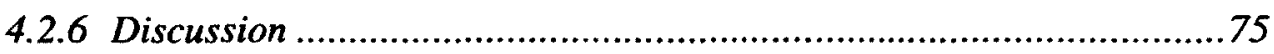

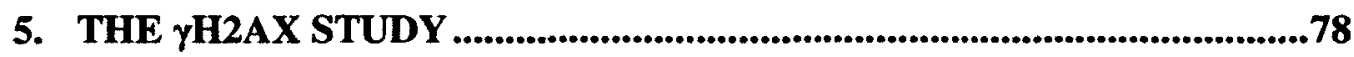

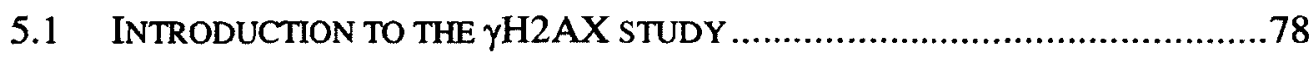

5.2 INVESTIGATING $\gamma$ H2AX AS A BIOMARKER OF RADIATION SENSITIVITY

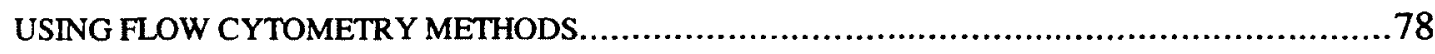

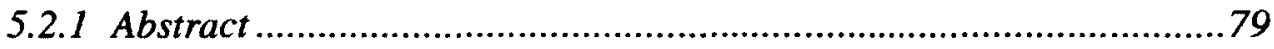

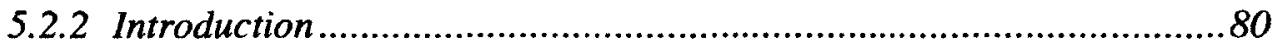

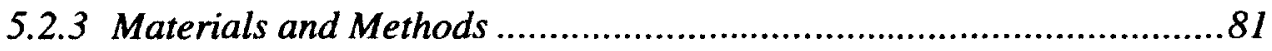

5.2.3.1 Patient Selection and Sample Collection ................................81

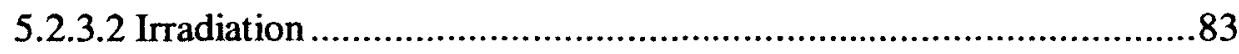

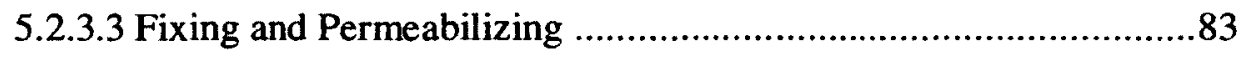

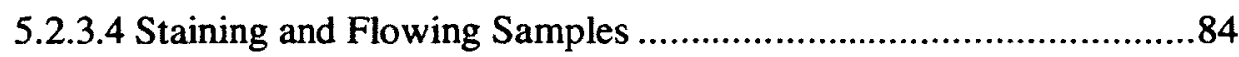

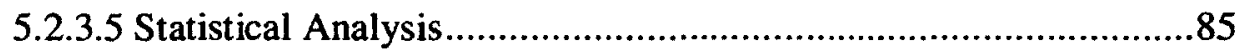

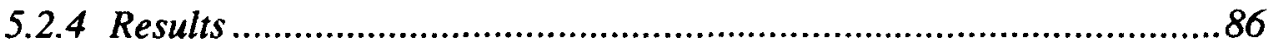

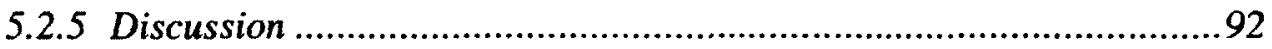

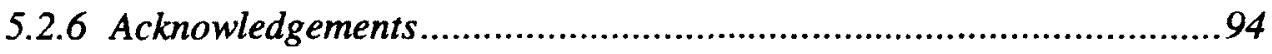

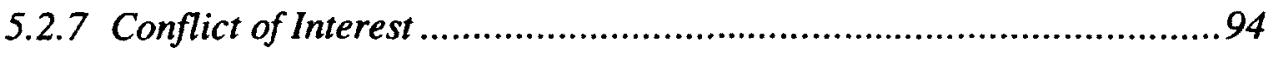

5.3 FURTHER NOTES WITH RESPECT TO THE $\gamma \mathrm{H} 2 \mathrm{AX}$ EXPERIMENT.................95 


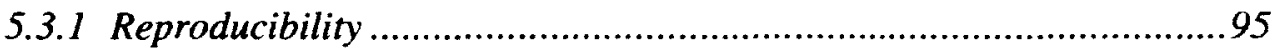

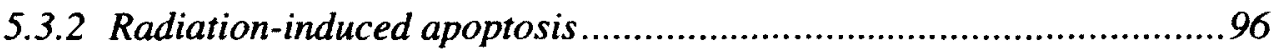

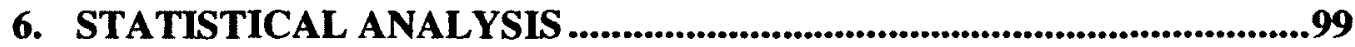

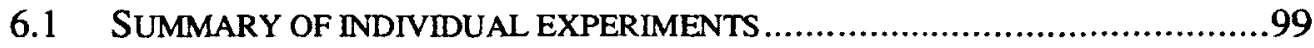

6.2 BUILDING A CLASSIFIER: DISCRIMINANT ANALYSIS .........................101

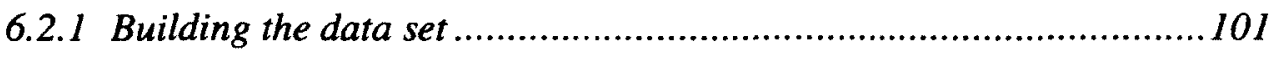

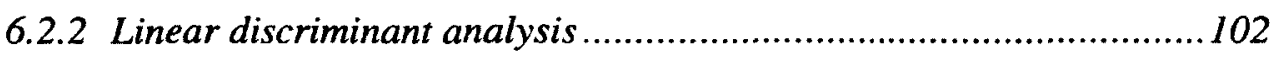

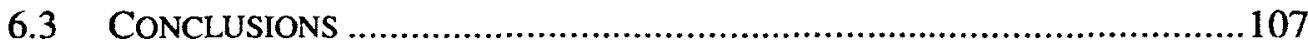

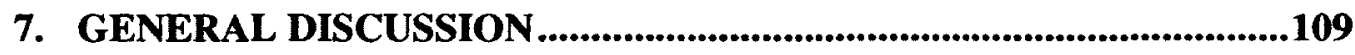

7.1 SUMMARY OF THESIS FINDINGS AND LIMITING FACTORS ....................109

7.1.1 Null results and suggested improvements .................................111

7.1.2 Patient selection and limitations of sample size ...........................112

7.1.3 Confounding factors: treatment errors and treatment target volume114

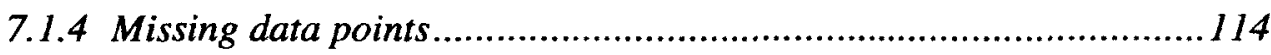

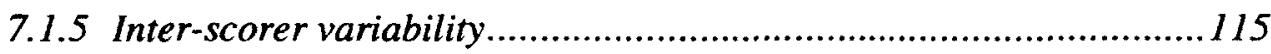

7.2 FURTHER WORK WITH ASSORTED PATIENT POPULATIONS...................115

7.3 APPLICATION OF ASSAY(S) IN THE CLINIC ..................................116

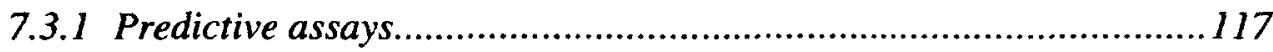

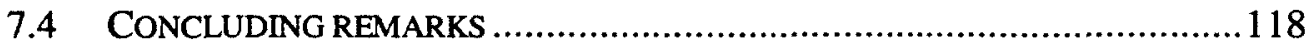

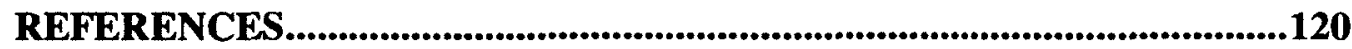

APPENDIX A - LATE RADIATION MORBIDITY SCORING SCHEMA 


\section{List of abbreviations}

ADT

ANOVA

APC

AT

ATM

AVM

BrdU

CD19

CD4

CD8

CTV

DAPI

DC

DCA

DNA

DSB

EORTC

ESTRO

FA

FBS

FISH
Androgen Deprivation Therapy

ANalysis Of VAriance

AlloPhycoCyanin

Ataxia Telangiectasia

Ataxia Telangiectasia, Mutated

Arterial Venal Malformation

BromodeoxyUridine (5-bromo-2'-deoxyuridine)

Cluster of Differentiation 19

Cluster of Differentiation 4

Cluster of Differentiation 8

Clinical Target Volume

4',6-DiAmidino-2-Phenyllndole

Dose Course

Dicentric Chromosome Assay

DeoxyriboNucleicAcid

Double Strand Break

European Organization for Research on the Treatment of Cancer

European Society for Therapeutic Radiology and Oncology

Fanconi Anemia

Fetal Bovine Serum

Fluorescent in situ Hybridization 


\begin{tabular}{|c|c|}
\hline FITC & Fluorescein IsoThioCyanate \\
\hline FMO & Fluorescent Minus One \\
\hline FPG & Fluorescence Plus Giemsa \\
\hline fsc & forward scatter \\
\hline FSD & Focal Spot Distance \\
\hline g & gravity \\
\hline $\mathrm{G}_{0}$ & G zero phase (resting phase) of a cell cycle \\
\hline $\mathrm{G}_{1}$ & Presynthetic Gap \\
\hline $\mathbf{G}_{2}$ & Postsynthetic Gap \\
\hline GENE-PARE & GENEtic Predictors of Adverse Radiotherapy Effects \\
\hline GENEPI & GENEtic pathways for the Prediction of the effects of Irradiation \\
\hline GLMM & Generalized linear mixed models \\
\hline HR & Homologous Recombination \\
\hline IAEA & International Atomic Energy Agency \\
\hline IGRT & Image-Guided Radiation Therapy \\
\hline IJROBP & International Journal of Radiation Oncology, Biology, Physics \\
\hline $\mathrm{KCl}$ & Potassium Chloride \\
\hline LED & Light Emitting Diode \\
\hline LMDS & Locally Multiply Damaged Sites \\
\hline LMM & Linear Mixed effects Models \\
\hline M1 & First Metaphase \\
\hline M2 & Second Metaphase \\
\hline N/A & Not Available \\
\hline
\end{tabular}




\begin{tabular}{|c|c|}
\hline $\mathrm{Na}_{2} \mathrm{HPO}_{4}$ & Sodium phosphate dibasic \\
\hline NBS & Nijmegan Breakage Syndrome \\
\hline NHEJ & NonHomologous End Joining \\
\hline PAINT & Protocol for Aberration Identification and Nomenclature Terminology \\
\hline PBS & Phosphate Buffered Saline \\
\hline PC7 & Phycoerythrin Cyanin 7 \\
\hline PE & Phycoerythrin \\
\hline pen-strep & penicillin-streptomycin \\
\hline PFGE & Pulsed Field Gel Electrophoresis \\
\hline PHA & PhytoHemAgglutinin \\
\hline PMT & PhotoMultiplier Tube \\
\hline QUANTEC & Quantitative Analysis of Normal Tissue Effects in the Clinic \\
\hline RCBD & Randomized Complete Block Design \\
\hline RPMI & Roswell Park Memorial Institute \\
\hline RT & Room Temperature \\
\hline RTOG & Radiation Therapy Oncology Group \\
\hline SCID & Severe Combined Immunodeficiency Disease \\
\hline SD & Standard Deviation \\
\hline $\mathrm{SF}_{2}$ & Surviving Fraction after 2 Gy \\
\hline SRS & Stereotactic RadioSurgery \\
\hline SSB & Single-Strand Break \\
\hline SSC & Saline-Sodium Citrate \\
\hline Ssc & side-scattered light \\
\hline
\end{tabular}


Time Course

TCPS

Tri-Council Policy Statement

TST

TBS containing $4 \%$ FBS (v/v) and $0.1 \%$ Triton X-100 (w/v)

$\mathrm{v} / \mathrm{v}$

volume per volume

$w / v$

weight per volume

$\gamma \mathrm{H} 2 \mathrm{AX}$

(gamma-H2AX) Phosphorylated Histone-2 variant X 


\section{List of Tables}

Table 3-1: Clinical features of control and radiosensitive groups

Table 3-2: Counted data for individual patients, including chromosome damage and cell proliferation information

Table 3-3: Comparison of control to radiosensitive groups for three measurements

(dicentrics per cell, excess fragments per cell and fM2). .53

Table 4-1: Poisson regression analysis results comparing the sensitive and control cohorts for multiple endpoints (per cell) after $4 \mathrm{~Gy}$ in vitro irradiation. .70

Table 5-1: Clinical features of control and radiosensitive groups

Table 5-2: Comparing control to sensitive groups for the dose course experiment.

Table 5-3: Comparing control to sensitive groups for time course experiments after exposure to 2 Gy in vitro radiation.

Table 5-4: Comparing control to sensitive groups for special ratios (DC and TC). 98

Table 6-1: Summary of the final test statistics from the DCA and FISH endpoints comparing the two status groups (control and sensitive).

Table 6-2: Descriptive statistics and test of equality of group means 102

Table 6-3: Standardized canonical discriminant function coefficients. 103

Table 6-4: Cross validation summary using linear discriminant function. 105 


\section{List of Figures}

Figure 1-1: Stylized schematic of DNA structure and the compaction levels .................8

Figure 1-2: Schematic illustrating assorted configurations of chromosome aberrations ..11

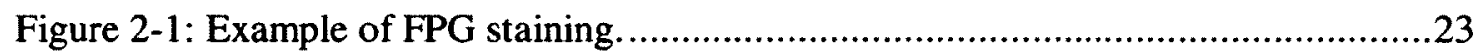

Figure 2-2: Two metaphase spreads illustrating (a) no visible damage and (b) 1 dicentric chromosome (solid arrow) and 1 acentric fragment (dashed arrow) ............27

Figure 2-3: Example of the scoring of a 0 and $4 \mathrm{~Gy}$ spread ....................................

Figure 2-4: Intensity of forward light scatter versus intensity of side light scatter acquisition dot plot of a blood sample

Figure 3-1: Example of chromosome damage in a solid stained, M1 spread

Figure 3-2: Harlequin staining: visible with FPG staining, with one sister chromatid being darker than the other .46

Figure 3-3: Spread of the data for each of three endpoints (a) dicentrics per cell, (b) excess fragments per cell, and (c) proportion of cells in M2. Each point represents one patient.

Figure 4-1: Examples of metaphase spreads stained for chromosome 1 (red), 2 (green) and 4 (yellow)

Figure 4-2: Plot illustrating the spread and mean (with standard deviation) of colour junctions per cell for unirradiated and 4 Gy samples in both sensitive (open diamond) and control (closed circle) cohorts.

Figure 4-3: Plots illustrating the spread and mean (with standard deviation) of stable damage in both the sensitive (open diamond) and control (closed circle) cohorts. 
Figure 4-4: Plots illustrating the spread and mean (with standard deviation) of unstable damage in both the sensitive (open diamond) and control (closed circle)

cohorts

Figure 4-5: Plots illustrating the spread and mean (with standard deviation) of damage as scored per (a) chromosome 1 (b) chromosome 2 and (c) chromosome 4, in both the sensitive (open diamond) and control (closed square) cohorts.........74

Figure 5-1: Dose course results for lymphocytes (a) and each subset (b, c, d)..............91

Figure 5-2: Time course results for lymphocytes (a) and each subset (b, c, d)..............92

Figure 5-3: Plot of dose course point ( $2 \mathrm{~Gy}, 1 \mathrm{~h}$ ) versus time course point $(2 \mathrm{~Gy}, 1 \mathrm{~h}$ ) for each patient, for each of the lymphocyte and lymphocyte subset (CD4, CD8 and $\mathrm{CD} 19)$ populations. .96

Figure 6-1: Scatter plot of the two most significant factors of the linear discriminant function, excess fragments per cell and $\mathrm{fM} 2$, after $6 \mathrm{~Gy}$ 106 


\section{General Introduction}

\subsection{Radiosensitivity}

Interpatient heterogeneity in normal tissue response to radiation varies widely and is an ongoing challenge to radiotherapy treatment regimes. There is a need to balance the eradication of the tumour with the protection (or minimization of damage) of healthy tissue; this balance is the key to radiotherapy treatments. Ionizing radiation doses are limited to minimize normal tissue toxicity (both acute and chronic effects), and the daily fractionated dose is based on the average response of patients in general [1-3]. Despite the best efforts in planning, one treatment does not suit every patient: some patients continue to have more severe adverse effects, and the development of a biomarker of radiation sensitivity would allow for the personalization of individual radiotherapy plans.

\subsubsection{Radiosensitive diseases and individual radiosensitivity}

An often cited example of radiosensitive disease is ataxia telangiectasia (AT); a multisystem syndrome with numerous clinical characteristics, one of which is severe radiation sensitivity. The discovery of the gene leading to this syndrome, ataxia telangiectasia, mutated (ATM), led to a much greater understanding of not only the disease, but also of the molecular response to DNA damage. ATM is critical in the signal cascade that responds to DNA double-strand breaks (DSBs). McKinnon published a review of ATM and AT in 2004 [4] which describes both the disease, and the implications to cellular DNA damage response that results from the gene mutation. Similarly, other radiosensitive diseases, such as Severe Combined Immunodeficiency 
Disease (SCID) [5], Nijmegan Breakage Syndrome (NBS) and Fanconi Anemia (FA) [6] have provided insights into, among other things, genetic mutations and DNA repair pathways.

Patients with AT, SCID, NBS and FA experience severe normal tissue toxicity from typical radiation doses used for radiotherapy. While these diseases are at the extreme end of a radiosensitive response, otherwise apparently healthy patients also exhibit a varying response to similar treatments [7;8]. While some variation is not unexpected, due to the random nature of radiation injury, it is a long-held belief that much of the variation is due to a patient's individual radiosensitivity [9]. The results of a 2002 study by Raaphorst et al. [10] suggested that there was an underlying genetic radiosensitivity in the arterial venal malformation (AVM) patients studied. As well in 2002, Andreassen et al. [11] came to similar conclusions, encouraging large-scale international studies to identify the genetic basis of individual radiosensitivity.

\subsection{Radiation Effects on DNA}

Ionizing radiation acts on a biological target either directly, by ionizing the target atoms themselves, or indirectly, by the production of free radicals, which subsequently damage the target. DNA is believed to be the primary target for the biological effects of ionizing radiation. Stone et al. [1] provide a review of the effects of radiation on normal tissue, and Denham and Hauer-Jensen [12] provide a review of organized normal tissue responses during and after radiation therapy, the effect of radiation therapy on the responses. The following sections, 1.2.1-3 describe DNA damage, DNA repair and the resulting chromosome damage in more detail. 


\subsubsection{DNA damage: single- and double-strand breaks}

DNA has a well-known double-helix structure, consisting of two strands of sugar moieties and phosphate groups, interconnected by pairs of complementary bases (adenine and thymine, guanine and cytosine). When exposed to ionizing radiation, these strands can be broken, directly or indirectly. In healthy DNA, a single-strand break (SSB) is relatively inconsequential, since the complementary base provides a template for the DNA repair mechanism. Conversely, if two SSBs are in close proximity (separated by no more than a few base pairs), these may result in what is called a double-strand break (DSB). In reality, the damage can be quite complicated, potentially made up of complex breaks encompassing base damage as well as DSBs (known as locally multiply damaged sites (LMDS)). It is a much more complex process to repair a DSB or LMDS as compared to an SSB, and DSBs in chromosomes are considered to be critical to genomic stability $[13 ; 14]$.

\subsubsection{DNA repair: mechanisms and pathways}

\subsubsection{Introduction to DNA repair}

DNA damage occurs in somatic cells on a regular basis, from both radiation and chemicals. In general, the cell is well-equipped with multiple, complex mechanisms to repair the DNA damage. It is unrepaired or misrepaired damage that leads to cell death or mutation. When a cell dies, it is reabsorbed into the surrounding environment, but mutations may lead to alterations or impairments of cellular function, which could in turn lead to systemic issues such as carcinogenesis or late normal tissue reactions. 
Simple damage, such as a SSB, is readily repaired as the opposing DNA strand acts as a template. Two such mechanisms are base excision repair and nucleotide excision repair. More complex damage, such as DSBs or LMDS, lack a corresponding template, and are considered to be especially genotoxic [15]. There are two major repair pathways: homologous recombination (HR) and nonhomologous end joining (NHEJ). These two pathways will be briefly described in sections 1.2 .2 .2 and 1.2.2.3.

\subsubsection{Homologous recombination (HR)}

HR is considered to be an error-free mechanism for the repair of DSB [16]. The mechanism is most active through the late phase of DNA synthesis and into the $G_{2}$ phase of the cell cycle when the sister chromatid is present [17]. The sister chromatid provides a matching template for the repair of the broken strands. The final result is two intact copies of the DNA.

\subsubsection{Non-homologous end joining (NHEJ)}

Compared to HR, NHEJ is known to be inaccurate and prone to misrepair leading to mutations [17]. The NHEJ pathway is also active during all phases of the cell cycle [18]. NHEJ is capable of joining the broken ends of DNA directly, even in the absence of a homologous DNA sequence. But it is this capability that often leads to misrepair: the genome is only properly repaired if the matching ends are correctly rejoined. If the ends do not match, they are first resected before being re-ligated. Resection of the broken ends of the DNA can lead to small alterations in the genome. If there are very few strand breaks, there is a higher probability that the original ends will be reattached, but in the 
presence of a DSB-causing agent such as ionizing radiation, the probability drops, as more DSBs are formed.

\subsubsection{Summary of DNA repair mechanisms}

It is still unknown how cells determine which of these two pathways to use to repair complex damage. A recent study by Mladenov and Iliakis [19] suggest that the cells are programmed to preferentially utilize the NHEJ pathway. The authors also suggest that when the NHEJ pathway is compromised, alternative NHEJ pathways are utilized, rather than HR. Regardless, it is clear that DNA repair mechanisms play an important role in genomic stability. If there are genetic defects in either of the pathways, there would be subsequent chromosome instability, as evidenced by chromosomal aberrations [17]. The details of DNA repair mechanisms are beyond the scope of this thesis, but it is important to note their underlying significance and the role that they have in chromosomal aberrations.

\subsubsection{H2AX background}

A DSB triggers a cascade of biochemical processes, one of the first of which is the phosphorylation of $\mathrm{H} 2 \mathrm{AX}(\gamma \mathrm{H} 2 \mathrm{AX})$. DNA is wrapped around proteins known as histones in order to form nucleosomes in chromosomes. There are five major classes of histones known as $\mathrm{H} 1, \mathrm{H} 2 \mathrm{~A}, \mathrm{H} 2 \mathrm{~B}, \mathrm{H} 3$ and $\mathrm{H} 4 . \mathrm{H} 2 \mathrm{AX}$ is an electrophoretic isoform of $\mathrm{H} 2 \mathrm{~A}$, and is believed to be directly involved in the efficient recognition and repair of DSBs [20]. Celeste et al. [21] proposed that $\gamma \mathrm{H} 2 \mathrm{AX}$, while not the primary signal for DSB repair complexes, concentrated proteins in the vicinity of the DSB. Two ideas put 
forth by Fernandez-Capitello et al. [22] proposed that $\gamma \mathrm{H} 2 \mathrm{AX}$ increases the likelihood of assembling a functional repair complex, as well as preventing the premature separation of broken ends, potentially safeguarding the possibility of tumorigenic chromosome rearrangements. Rogakou et al. [23] determined that $\gamma \mathrm{H} 2 \mathrm{AX}$ is detectable within minutes of the induction of damage, and that the amount of phosphorylation amplifies to a plateau within an hour and is proportional to the dose of ionizing radiation.

Since the discovery of $\gamma \mathrm{H} 2 \mathrm{AX}$, a phospho-specific anti- $\gamma \mathrm{H} 2 \mathrm{AX}$ antibody has been developed which allows the visualization of $\gamma \mathrm{H} 2 \mathrm{AX}$ foci. Using this antibody, Rogakou et al. [24] determined that the $\gamma \mathrm{H} 2 \mathrm{AX}$ foci were adjacent to DSB sites. Furthermore, Sedelnikova et al. [25] found that there was a one-to-one correlation between the presence of a $\gamma \mathrm{H} 2 \mathrm{AX}$ focus and a DSB. Several detailed reviews have been published about $\gamma \mathrm{H} 2 \mathrm{AX}$ and the characteristics of foci formed at DNA DSBs [26;27].

\subsubsection{Chromosome damage}

\subsubsection{Chromosome Structure}

Over the course of a cell cycle, a cell goes through a number of different stages. For the most part, DNA is found unwound in the nucleus during a phase known as interphase, a part of which is the synthesis phase during which the chromosome material is duplicated (synthesized). There are also two gap phases, the first known as $G_{1}$, a presynthetic gap which occurs before synthesis, and the second known as $G_{2}$, a postsynthetic gap. After $\mathrm{G}_{2}$ phase, the chromatin begins to condense; the DNA double helix is folded and packed into very tight coils until it eventually forms a metaphase chromosome. Figure 1-1 illustrates a classic schematic for the organization of a 
metaphase chromosome, adapted from Alberts et al. [28]. Once fully condensed, a metaphase chromosome has a well characterized appearance, with a constriction known as a centromere, with $\mathrm{p}$ - and $\mathrm{q}$-arms extending from the centromeres, as shown in the mitotic chromosome of figure 1-1. Conventional study of chromosome aberrations is generally done with metaphase chromosomes, where the structure of the chromosome can be visualized. 

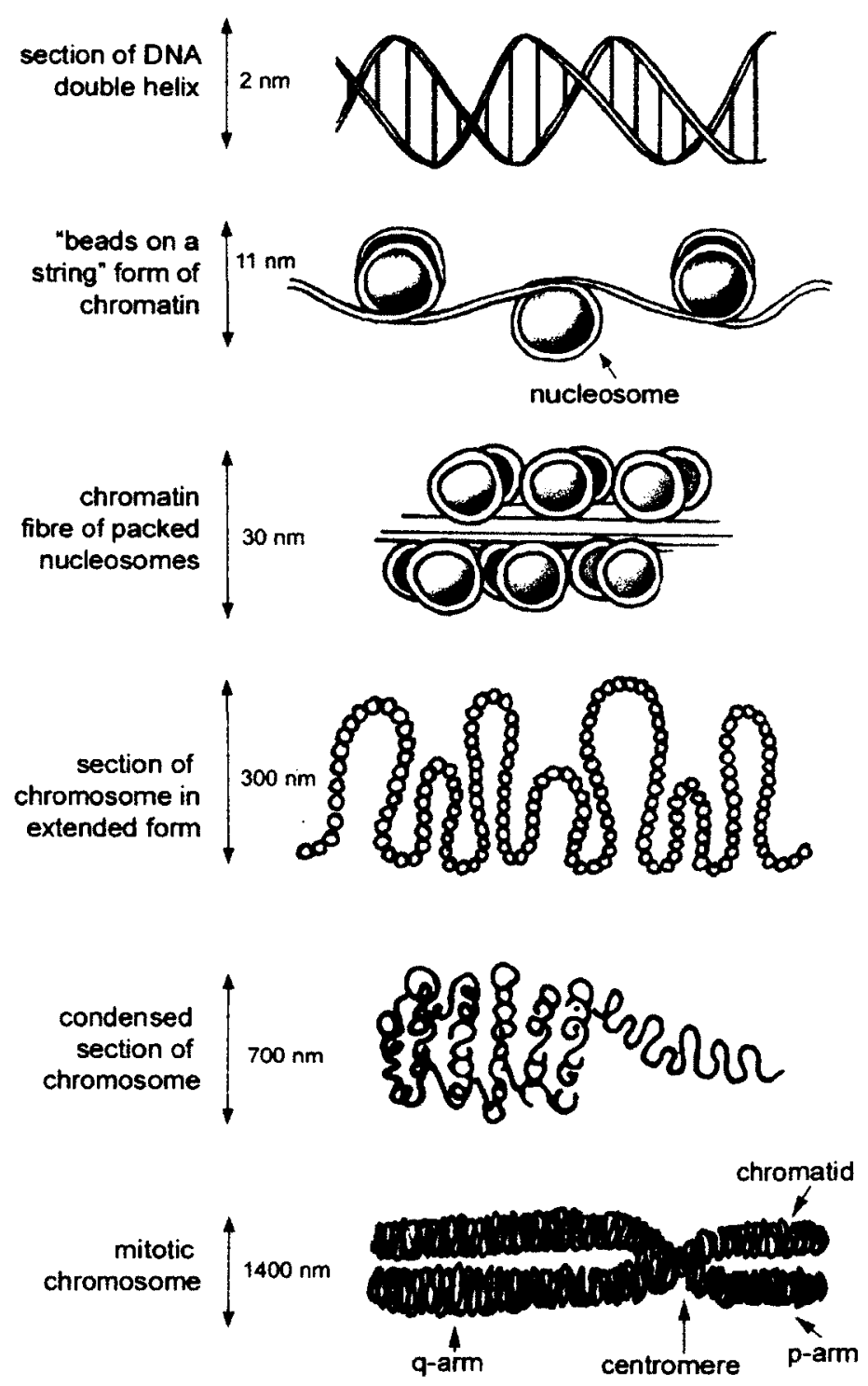

Figure 1-1: Stylized schematic of DNA structure and the compaction levels, ranging from the DNA double helix to the mitotic chromosome, adapted from Alberts et al. [28]. Also labelled are the nucleosomes, which are proteins around which the DNA is wrapped, a chromatid, as well as the centromere, the constriction where the two chromatid arms meet, and the p-and q-arms (the shorter and longer arms, respectively) of the chromatid. 


\subsubsection{Radiation-induced chromosome aberrations}

As previously discussed, exposure to ionizing radiation may result in DNA DSBs. With respect to the structure of the chromosome, DSBs can result in chromosome breaks. If the DSB is properly repaired, there remains no visible damage, but if the breaks are either misrepaired, or not repaired at all, this can result in a chromosome aberration.

There are different types of chromosome aberrations, and those relevant to this thesis are described below. Chromosome aberrations can be classified as either stable or unstable damage. If the damage is unstable, it is considered to be lethal, as the cell should be unable to divide. Unstable damage includes dicentric chromosomes, rings and the associated acentric fragments. Stable damage involves chromosome aberrations that do not lead to reproductive cell death but could lead to mutations, and includes translocations, deletions, insertions and inversions. Figure 1-2 schematically illustrates assorted configurations of chromosome damage. When two chromosomes, each with a DSB, are misrepaired and the two centric fragments rejoin while the two acentric fragments rejoin, the result is a dicentric chromosome and an associated acentric fragment. If a single chromosome has a DSB in each arm, the sticky ends of the arms might attach to each other, while the leftover acentric fragments join together. This would

result in a centric ring and acentric fragment. It is also possible to have the formation of acentric rings. A translocation occurs in chromosomes, each with a DSB, when the broken ends are swapped. A deletion occurs when two DSBs occur in the same arm of a chromosome and the end of the chromosome reattaches to the centric part of the chromosome, leaving out a small piece of chromosome material. An insertion occurs if there is a deletion in one chromosome which is subsequently inserted into the cut of a 
second chromosome, again caused by a DSB. An inversion occurs when a chromosome suffers from multiple DSBs and is rearranged end-to-end with itself. There are different ways of visualizing stable and unstable damage, and these assays will be discussed in Chapter 2: Background Information. 


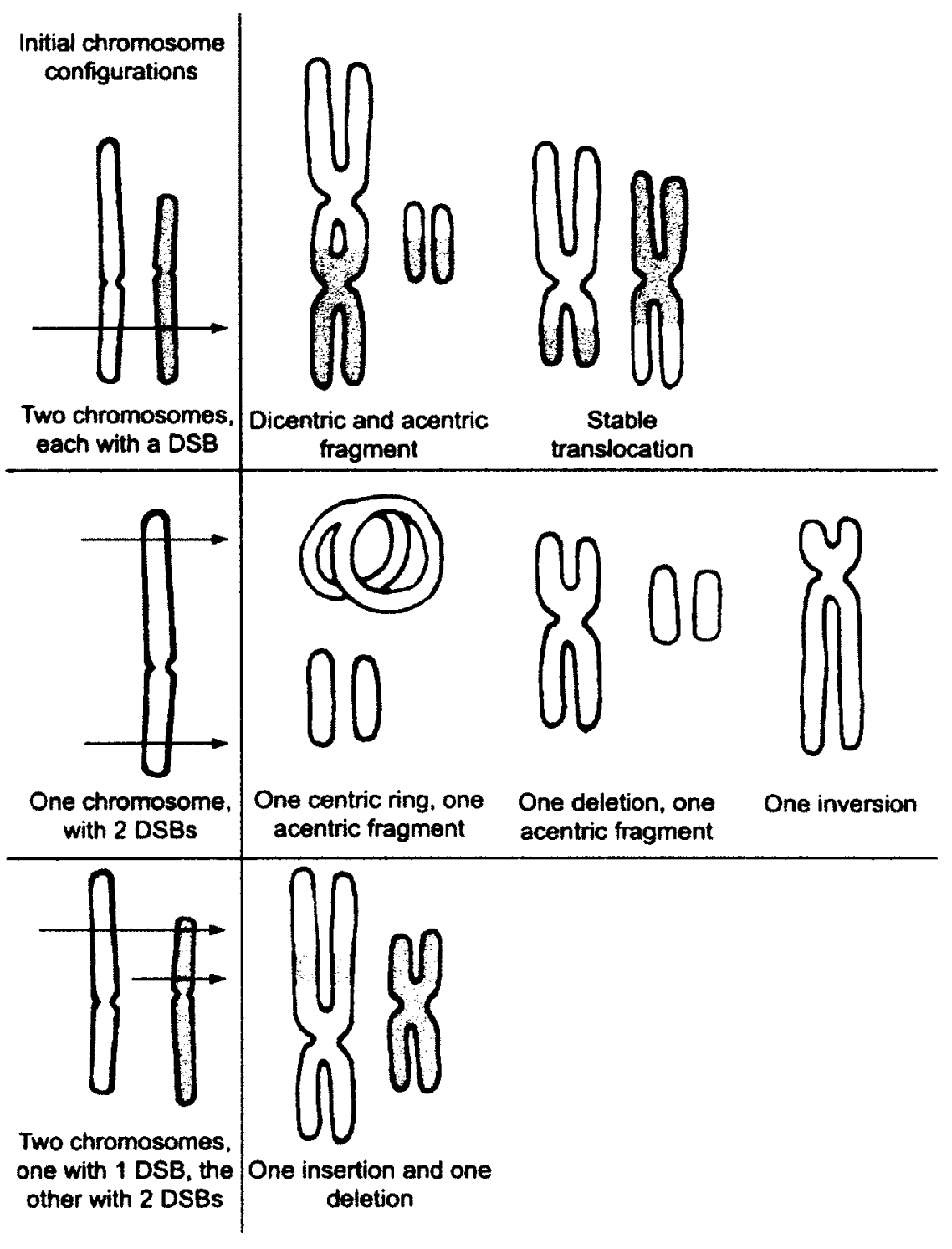

Figure 1-2: Schematic illustrating assorted configurations of chromosome aberrations. To the left of the line the initial chromosome configurations illustrate chromosomes in a presynthesis phase $\left(\mathrm{G}_{0}\right.$ or $\mathrm{G}_{1}$ phase), and assume irradiation damage and misrepair occur prior to synthesis. Damage that occurs during or post-synthesis ( $S$ or $G_{2}$ phase) results in chromatid type aberrations and are not illustrated. 


\subsection{Predictive Assays}

In order to properly identify a biomarker, there must be a correlation of cellular radiosensitivity to clinical effects. Numerous studies have investigated a variety of endpoints in an effort to find a reliable biomarker of radiosensitivity. The clonogenic assay, a measurement of colony formation, has historically been the standard for measuring cellular survival, but more recently, other assays investigating chromosome damage, DNA damage and genetic response are also being pursued. Some of the studies, as described below, showed mixed results.

\subsubsection{Skin Cells}

Much effort has been devoted to using skin cells, both fibroblasts and keratinocytes, as markers of radiosensitivity. Burnet et al. [29] did some early work on fibroblast sensitivity with clonogenic cell survival assays $\left(\mathrm{SF}_{2}\right)$ and found some correlations to acute effects. Geara et al. [30] looked at $\mathrm{SF}_{2}$ and found a highly significant correlation with the maximum grade of late effects but found no significant correlation between fibroblast radiosensitivity and maximum grade of acute effects or between lymphocyte radiosensitivity and either acute or late effects. Two studies by Kiltie et al. [31;32] found mixed results. The first, examining keratinocytes of previously treated breast cancer patients using Pulsed Field Gel Electrophoresis (PFGE) to measure DNA damage showed no correlation with the severity of late normal tissue reactions. The second similar study, studying fibroblasts from breast cancer patients using PFGE, found a relationship between residual radiation-induced DNA damage in fibroblasts and the severity of the late normal tissue damage. Conversely, Peacock et al. [33], who also 
investigated fibroblast radiosensitivity with $\mathrm{SF}_{2}$ assays in breast cancer patients, found no significant correlations. In addition, Brock et al. [34] studied the correlation between fibroblast radiosensitivity with $\mathrm{SF}_{2}$ and the degree of acute or late normal skin damage after radiotherapy (for breast cancer); the results suggested a partial dependency on intrinsic cellular radiosensitivity but the relationship was ambiguous. They did note a trend toward correlation between fibroblast $\mathrm{SF}_{2}$ and the clinical response pertaining to the late skin reactions only.

\subsubsection{Lymphocyte apoptosis}

In 1999, examining lymphocyte response to in vitro radiation as a predictor of radiosensitivity, Crompton et al. [35] found that hypersensitive patients (post-treatment) had significantly less radiation-induced apoptosis as compared to the average agematched donors. In addition, they also found that a group of 9 ataxia telangiectasia patients had even less radiation-induced apoptosis. Barber et al. [36], in a comparative study involving apparently normal individuals, as well as AT homo- and heterozygotes and breast cancer patients exhibiting a range of late side effects, treated in the previous 8 13 years, found no correlation of rates of apoptosis with the severity of breast fibrosis, retraction or telangiectasia. They put forth the possibility that the reduced rate of apoptosis observed in the breast cancer cases may be associated with genetic predisposition towards breast cancer, but concluded that lymphocyte apoptosis assays were unlikely to be of use in predicting normal tissue tolerance to radiotherapy.

Wilkins et al. [37] found that the ratios of lymphocyte subpopulations had an effect on the apoptotic response of human lymphocytes, which might be linked to 
radiosensitivity. A large prospective study by Ozsahin [38] examined blood samples from 399 curatively irradiated patients and concluded that radiation-induced T-lymphocyte apoptosis after $8 \mathrm{~Gy}$ in vitro radiation could significantly predict late normal tissue toxicity. Moreover, Schnarr et al. [39] found similar results, noting that after 8 Gy in vitro radiation, lymphocyte apoptosis had the potential to predict which patients would be spared late normal tissue toxicity after radiotherapy. Henriquez-Hernandez et al. [40] studied the inverse relationship between initial DNA damage and radiation-induced apoptosis and proposed that patients with lower levels of DNA damage, combined with higher levels of radiation-induced apoptosis, were at low risk of suffering from late normal tissue toxicity.

\subsubsection{Lymphocyte response}

Other studies, such as those of Hoeller et al. [41], Borgmann et al. [42] and Chua et al. [43], have examined the response of lymphocytes to in vitro radiation for correlations with late normal tissue toxicity, with some promising results.

As will be discussed in Chapters 3 and 5, Chua et al. [43] found significant results correlating DNA residual damage and chromosomal damage to late normal tissue toxicity in breast cancer. Hoeller et al. [41] also found significant results when comparing lymphocyte response to risk of fibrosis after radiotherapy in breast cancer patients.

While Bourton et al. [44] found a significant correlation between residual $\gamma \mathrm{H} 2 \mathrm{AX}$ response and the severity of late normal tissue toxicity in an patients with a variety of cancer types, two studies by Werbrouck et al. [45;46], examining the $\gamma \mathrm{H} 2 \mathrm{AX}$ response in isolated T-lymphocytes, from gynaecological and head and neck cancer patients 
respectively, concluded that the scoring of $\gamma \mathrm{H} 2 \mathrm{AX}$ foci after in vitro radiation did not correlate with late normal tissue complications. They did find a correlation between the $\mathrm{G}_{2}$ chromatid break assay and late clinical radiation sensitivity. For more information about the $\mathrm{G}_{2}$-assay, chromatin dynamics and cell-cycle dependencies, see a review by Terzoudi et al. 2011 [47]. A proposed standardized $\mathrm{G}_{2}$-assay is described by Pantelias and Terzoudi [48]

\subsubsection{Other assays}

Banath et al. [49], investigated the $\gamma \mathrm{H} 2 \mathrm{AX}$ response in irradiated cervical cancer cell lines, and suggested the possibility that cell line-dependent differences in the loss of $\gamma \mathrm{H} 2 \mathrm{AX}$ after irradiation were partially related to intrinsic radiosensitivity.

Much research has also been done with molecular biology such as with serum markers, single nucleotide polymorphism association studies and gene expression [5053]. These studies are also limited by both size and by inclusion of patients with different side effects (toxicities). The scope of these studies is beyond that of this thesis, but for more information, West et al. [54] published a review regarding ongoing worldwide initiatives with respect to banking of tissues and adverse event reporting. West et al. highlight a number of ongoing studies investigating molecular profiles that might predict patient response to radiotherapy, and report on a European Society for Therapeutic Radiology and Oncology (ESTRO) project (GENEPI - GENEtic pathways for the Prediction of the effects of Irradiation). Given the difficulty in acquiring an appropriate sample size in a given clinical trial to make conclusive statements, the collection of 
information in a shared database such as GENEPI will help establish more robust assays [55].

GENE-PARE (GENEtic Predictors of Adverse Radiotherapy Effects), described by Ho et al. [56] is another example of a biorepository made up of frozen lymphocytes and DNA isolated from patients treated with radiotherapy which aims to help predict markers for the development of adverse effects after radiotherapy.

Finnon et al. [57] recently published a study examining the correlation of in vitro lymphocyte radiosensitivity and gene expression with late normal tissue reactions in patients who had undergone curative breast cancer radiotherapy. After studying several endpoints (gene expression, apoptosis, residual DNA DSBs as measured by residual $\mathrm{H}$ 2AX signal, as well as chromosomal damage as measured by the $\mathrm{G}_{2}$ assay and the micronucleus assay), the authors concluded that despite significant inter-sample variation, sensitive patients could not be distinguished from controls.

\subsection{THESIS STATEMENT}

\subsubsection{Thesis statement}

The hypothesis of this thesis is that chromosome aberrations and $\gamma \mathrm{H} 2 \mathrm{AX}$ response in lymphocytes and lymphocyte subsets can provide one or more biomarkers of radiation sensitivity.

This thesis consists of three studies comparing the in vitro radiosensitivity of lymphocytes from patients treated in the above mentioned clinical trial exhibiting grade 3 late radiation toxicity with the lymphocytes from patients with minor or no late radiation side effects. 
The primary goal of the three studies was to examine lymphocytes of the patients mentioned above in order to identify one or more biomarkers of radiosensitivity. The biomarkers(s) of radiosensitivity could be used in a predictive assay for radiation response in order to identify patients for whom conventional radiotherapy would be detrimental. These patients could then be considered for a reduced dose or an alternative therapy to radiation.

\subsubsection{Collaboration with the Ottawa Hospital Cancer Center}

The studies involved in this thesis were part of a collaboration with Dr. Shawn Malone at The Ottawa Hospital Cancer Center, who provided access to patients from the clinical trial "A Randomized Phase III Trial of Optimal Sequencing of Hormone Therapy and Radiation Therapy in Patients with T1-T3 Prostate Cancer". The clinical trial began in 2001 and was designed to evaluate the optimal sequencing of radiation therapy and hormonal therapy in the treatment of patients with carcinoma of the prostate and has been approved by the Ottawa Hospital Research Ethics Board (and Health Canada). The main objective of this clinical trial is to assess the optimal timing of radiotherapy on various clinical outcomes. Complications of prostate cancer radiotherapy include gastrointestinal, urinary and sexual side effects. From the study cohort of 438) patients, 13 were identified as having Grade 3 late rectal toxicity as measured using the RTOG/EORTC late toxicity scale [58]. See Appendix A for a copy of the toxicity scale. 


\subsubsection{A note on prostate cancer}

Prostate treatments generally include 3D conformal planning, and often involve escalated radiation doses. Different radiotherapy treatment regimens include brachytherapy (where a radioisotope is inserted into the tumour tissue) and external beam therapy. External beam therapy might also include image-guided radiation therapy (IGRT), where multiple images are acquired throughout the treatment to track the tumour. The use of IGRT allows for improved accuracy in the delivery of ionizing radiation while at the same time providing improved sparing of the normal tissue [59]. External beam therapy also allows for alternative fractionation schemes, one of which is known as hypofractionation, where higher radiation doses are delivered in fewer fractions over the course of treatment [60]. The use of alternative fractionation schemes, some of which are considered to be more aggressive, might affect the incidence of acute and late normal tissue reactions $[61 ; 62]$.

Thorough planning goes into the treatment protocol to minimize the volume of normal tissue irradiated by high doses. Some of the normal tissues at risk during prostate radiotherapy treatments are bladder, anterior rectum and the prostatic urethra. Gardner et al. [63] studied the long-term normal tissue response after high-dose conformal prostate treatments. They reported that treatment was followed by a high rate of low grade rectal bleeding but a low rate of grade 2 or higher gastrointestinal morbidity. 


\subsubsection{Ethical considerations}

The studies included in this thesis were approved by The Ottawa Hospital Research Ethics Board and Health Canada's Research Ethics Board, adhering to the principles of the Tri-Council Policy Statement Ethical Conduct for Research Involving Humans (TCPS); informed consent was granted by patients to the clinical trials staff at the Ottawa Hospital and participation in the study did not affect their treatment (which occurred at least a year prior to participation in the study). The anonymity of donors was maintained during the study, and only after completion of the studies was more information provided about the average patient characteristics. 


\section{Background Information}

\subsection{Human lymphocytes}

\subsubsection{The make-up of a venous blood sample}

When a venous blood sample is taken from an individual, this whole blood contains a varied mixture of red blood cells, plasma and white blood cells. Only the white blood cells (leukocytes) contain a nucleus and DNA material. Within these leukocytes, a subset of cells called human peripheral lymphocytes (lymphocytes) is of particular interest for biodosimetry and our studies.

The concentration of lymphocytes in a blood volume varies between individuals, but the normal range is considered to be $4.0-10.0 \times 10^{6}$ lymphocytes per $\mathrm{mL}$. The lymphocytes themselves are made up of two types of cells, B and T cells, which can be further differentiated into subtypes, for example, CD4 and CD8 T cells and CD19 B cells. These subtypes can further be subcategorized, but for the purposes of this thesis, we will focus only on the CD4, CD8 and CD19 subtypes.

\subsubsection{Persistence of damage}

It should also be noted that lymphocytes can be long-lived. Lymphocytes with unstable damage have been shown to live on average between 22 weeks to 3.5 years. Lymphocytes with stable damage can live an average of 20 years [64]. Thus it is not unexpected to find a small level of background damage in blood samples taken from patients who have been exposed to high doses of radiotherapy treatments. 


\subsection{Experimental techniques to detect DNA damage}

While the methods for each study are described in the appropriate chapter, the following sections include background information and more detail about the methods where it is missing in the manuscripts.

\subsubsection{Dicentric Chromosome Assay}

The dicentric chromosome assay (DCA) is well-established as a method to score the number of dicentric chromosomes in a patient sample. The assay is often used for biodosimetry, as it provides a very accurate measurement of dose received by an individual [65].

\subsubsection{Whole blood culture}

For all experiments, venous blood samples were drawn into lithium-heparinized vacutainers to avoid in vitro coagulation. Upon receiving the patient samples, blood was aliquoted into $1.7 \mathrm{~mL}$ samples, and irradiated with $6 \mathrm{~Gy}$. After irradiation, the samples were incubated at $37^{\circ} \mathrm{C}$ on a rocker for 2 hours, and then $1.5 \mathrm{~mL}$ of each sample were put into culture. Typical culture conditions require culture medium, serum, a stimulant and a blocking agent.

Different culture media are available for lymphocyte culture, and are well characterized. For our experiments, Roswell Park Memorial Institute medium (RPMI1640) was used. The medium was supplemented with L-glutamine and the antibiotics penicillin and streptomycin (the combined L-glutamine and antibiotics (1x concentration, 
$2 \mathrm{mM}$ ) were added at $1 \%$ final volume). Fetal bovine serum (FBS) (15\% final volume) was also added to the culture medium to provide nutrients to the cells.

Phytohaemagglutinin (PHA) was added to the culture medium, at a volume of $1.8 \%$ in flask, as a stimulant. Lymphocytes are generally found in a quiescent phase (also called the $G_{0}$ phase or resting phase), and need to be stimulated to undergo in vitro mitosis. PHA has been shown to act as a stimulant for lymphocytes to undergo mitosis [66]. Note that of the two types of lymphocytes, B and $T$ cells, it is the $T$ cells, particularly the CD4 and CD8 subtypes that are stimulated by PHA [67].

Bromodeoxyuridine (BrdU) was also included in the DCA cultures (at $5 \mu \mathrm{g} / \mathrm{mL}$ in flask), which allowed for fluorescence plus Giemsa (FPG) staining. BrdU is an analogue for thymidine, one of the base pairs of the DNA. The analogue is taken up in replicating DNA resulting in one strand of each chromatid of the chromosome containing BrdU. If, after first mitosis, the cell goes through a subsequent replication in the presence of BrdU, the chromosome will then contain one chromatid with both strands of DNA containing BrdU while the DNA in the other chromatid will only contain one BrdU labelled strand. The chromosomes will then present with harlequin staining when stained with Giemsa; this is used to visualize chromosomes in first or second metaphase (M1 with uniform staining or M2 with harlequin staining respectively) [68]. Figure 2-1 is an example of harlequin staining. 

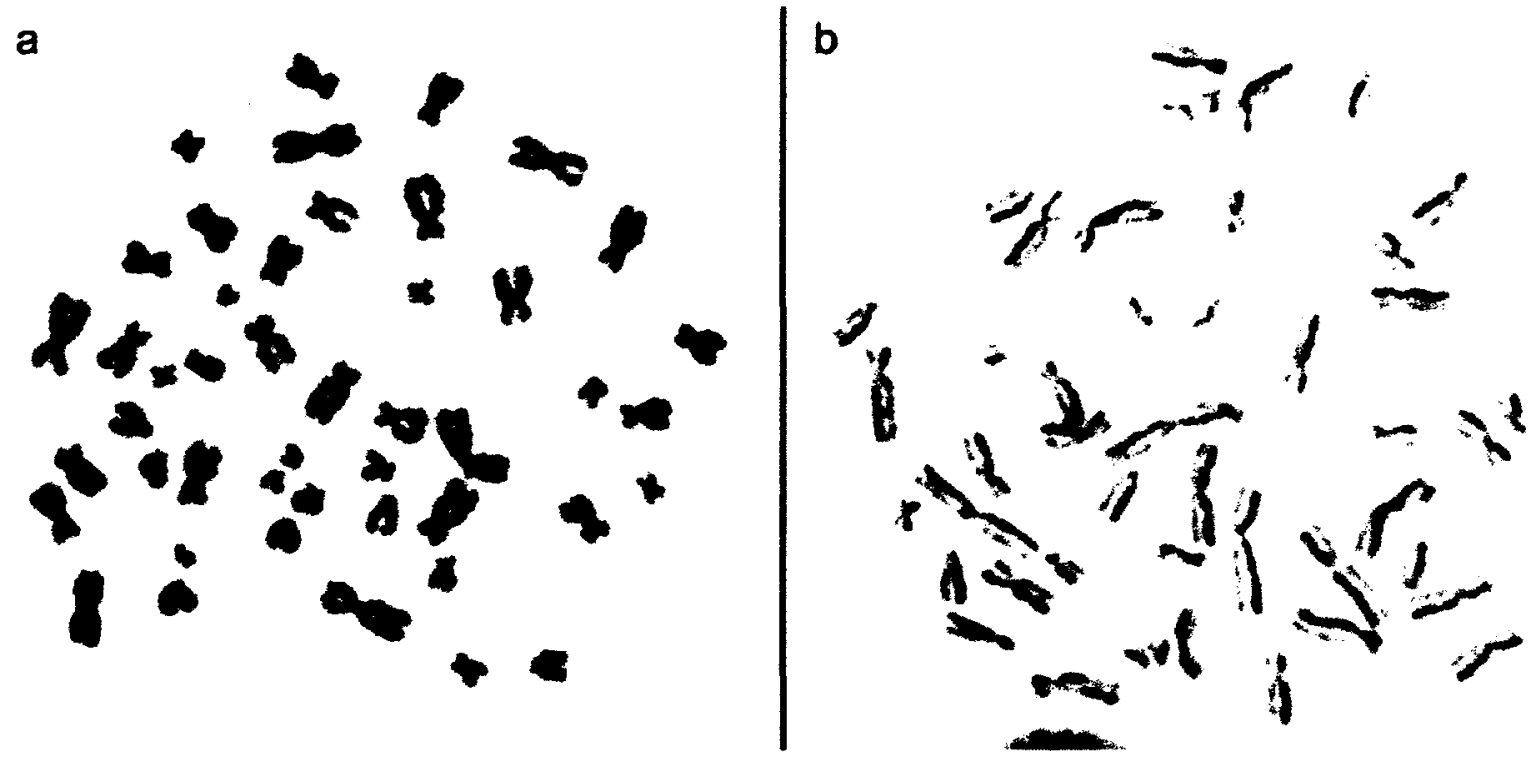

Figure 2-1: Example of FPG staining, with (a) monochrome staining of a first metaphase spread and (b) harlequin staining of a second metaphase spread. Spreads were captured at 1000x magnification on a Metafer Slide Scanning System (Metasystems Group Inc.,

Watertown MA).

\subsubsection{Mitotic arrest}

After $44 \mathrm{~h}$ of incubation at $37^{\circ} \mathrm{C}$, Colcemid (final concentration of $0.10 \mu \mathrm{g} / \mathrm{mL}$ ) was added to the culture, and the samples left to incubate another $4 \mathrm{~h}$. By adding Colcemid to the cultures, most cells are arrested in first metaphase, and therefore only a small fraction has entered second metaphase. After the full $48 \mathrm{~h}$ incubation time, the cells were mixed and transferred to $15 \mathrm{~mL}$ polypropylene tubes. The samples were centrifuged at $200 \mathrm{~g}$ for 8 minutes. 


\subsubsection{Hypotonic shock and soft fixation}

After centrifugation, the medium was aspirated, leaving approximately $2 \mathrm{~mL}$ in the tube, and the pellet resuspended. $10 \mathrm{~mL}$ of hypotonic solution $(0.075 \mathrm{M} \mathrm{KCl}$, at room temperature (RT)) was slowly added to the tubes, and mixed twice by inversion. The samples were left to incubate for 12 minutes at RT, inverted to mix again, and then $2 \mathrm{~mL}$

of freshly prepared Modified Carnoy's ( 3 methanol: 1 acetic acid) fixative was slowly added so the fixative was layered on top of the hypotonic solution. The samples were mixed by inversion, and left to incubate 10 minutes at RT. They were centrifuged at $200 \mathrm{~g}$ for another 8 minutes.

\subsubsection{Fixation and washes}

The aspirate-fix-incubate-spin process was repeated twice again. After the fourth centrifugation, the supernatant was aspirated, leaving behind approximately $0.5 \mathrm{~mL}$. The pellet was resuspended and $10 \mathrm{~mL}$ of fresh fix added to the cell suspension and mixed by inversion. The samples were then placed in the $-20^{\circ} \mathrm{C}$ freezer until slide preparation.

\subsubsection{Slide preparation}

From the freezer, samples were centrifuged at $200 \mathrm{~g}$ for 8 minutes. Most of the fixative was aspirated, leaving approximately $0.5 \mathrm{~mL}$, and the pellet resuspended.

The slides were prepared using a Hanabi Metaphase Spreader (ADSTECHANABI, Funabashi-city, Japan). The slides were placed on the Hanabi cassette and warmed for approximately 5 minutes. When the internal environment settings of the Hanabi were ready, $15 \mu \mathrm{L}$ of cell suspension sample was dropped onto the slide through 
a window on the top. The window was closed and the Hanabi set to dry. Once dry, the slides were moved to a slide warmer at $37^{\circ} \mathrm{C}$. The slides were checked for optimal spreading and metaphase concentration by examining them under an inverted light microscope. The concentration of the cell suspension was adjusted as required by the addition of fresh fix if the concentration of metaphase cells was too high, or else by centrifugation and aspiration of the excess fix if the concentration of the cells was too sparse.

\subsubsection{Fluorescence plus Giemsa staining}

Prior to Fluorescence Plus Giemsa (FPG) staining [69], prepared slides were warmed on a slide warmer at $37^{\circ} \mathrm{C}$. As well, the Giemsa stain (Harleco Original Giemsa formulation) was filtered with Whatman \#1 filter to avoid stain debris on the slides.

The slides were stained by immersion for 2 minutes in Hoechst $33258(20 \mu \mathrm{g} / \mathrm{mL})$ in a covered Coplin jar. Run-off liquid was blotted, the slides place on a $60^{\circ} \mathrm{C}$ slide warmer, flooded with $0.6 \mathrm{M} \mathrm{Na}_{2} \mathrm{HPO}_{4}(\mathrm{pH} 9)$ and a cover slip was applied. The slides were incubated under $365 \mathrm{~nm}$ UV light at a height of approximately $8 \mathrm{~cm}$ for 8 minutes. The coverslips were carefully removed and the slides rinsed three times in distilled water. The slides were blotted dry and stained by immersion with $10 \%$ Giemsa solution in phosphate buffer ( $\mathrm{pH} \mathrm{6.8)}$ for 10 minutes in a Coplin jar. The slides were again rinsed with distilled water and left to dry on a slide warmer at $37^{\circ} \mathrm{C}$ for at least an hour before mounting with Permount, covering with a coverslip and being left to dry at RT overnight. 


\subsubsection{Scoring the slides}

For analysis the slides were first scanned at low magnification $(100 \mathrm{x})$ to find spreads that were mitotic with approximately 46 pieces. The scanning was done methodically, either manually by the scorer, or else automatically using a Metafer Slide Scanning System (Metasystems Group Inc., Watertown MA). Once a mitotic spread was identified, the scorer would then switch to a higher magnification, either $630 \mathrm{x}$ or $1000 \mathrm{x}$, to score the spread. If the spread had harlequin staining or fewer than 46 centromeres, it was rejected. Otherwise, the spread was scored for damage; dicentric chromosomes and rings, with their acentric fragments, as well as any excess acentric fragments. Tricentrics were scored as two dicentrics, with two associated acentric fragments, and likewise for higher number multicentrics. Figure 2-2 illustrates two spreads, one with 46 pieces and no visible damage, and the other with 46 pieces, 1 dicentric and 1 acentric fragment. 


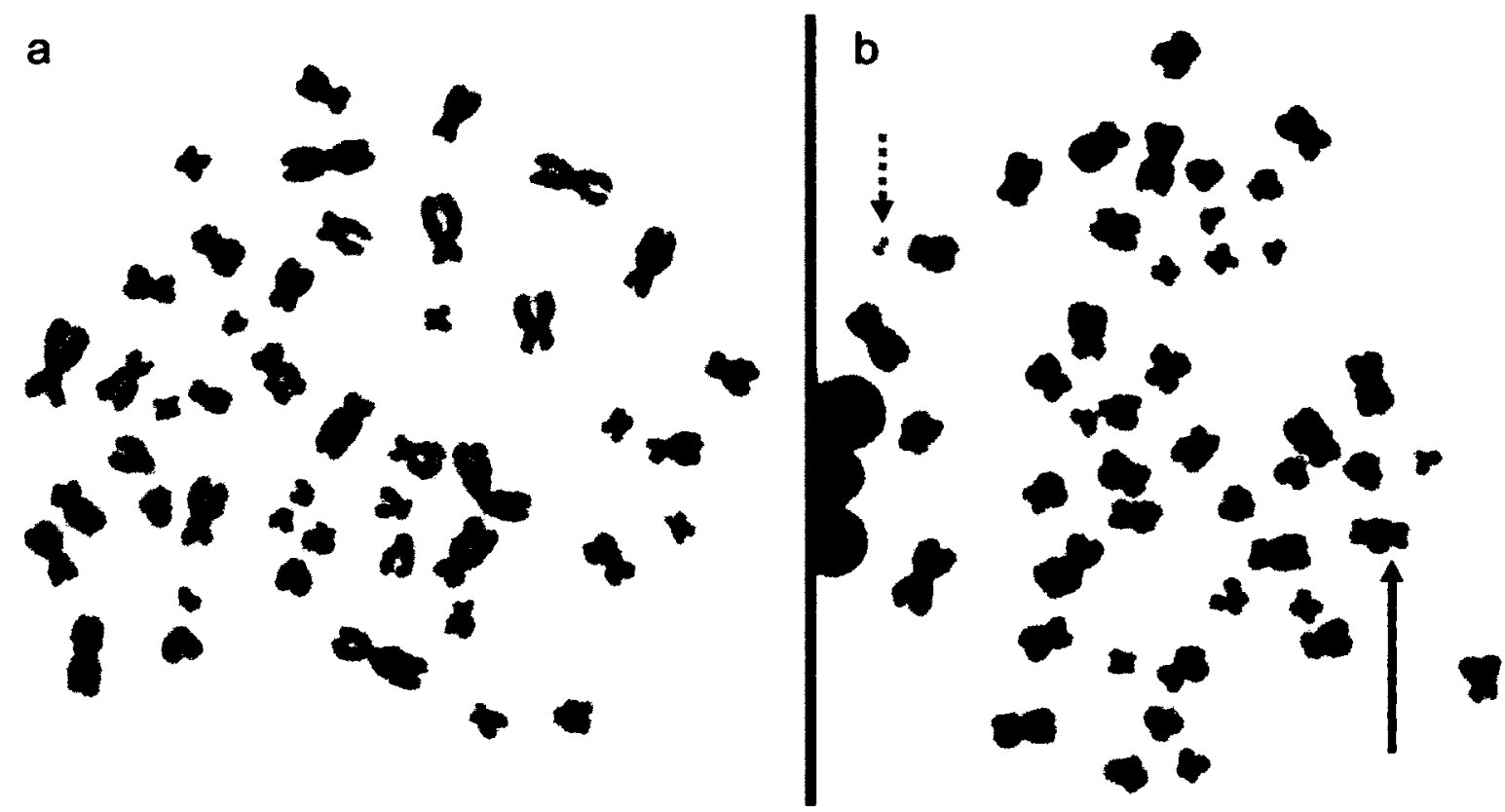

Figure 2-2: Two metaphase spreads illustrating (a) no visible damage and (b) 1 dicentric chromosome (solid arrow) and 1 acentric fragment (dashed arrow). Spreads were captured at 1000x magnification on a Metafer Slide Scanning System (Metasystems Group Inc., Watertown MA).

At least 100 spreads were scored for each $0 \mathrm{~Gy}$ sample, or in the case of the $6 \mathrm{~Gy}$ samples, at least 100 dicentrics were scored.

\subsubsection{Fluorescence In Situ Hybridization (FISH)}

\subsubsection{FISH Introduction}

While the DCA is useful for scoring unstable damage such as dicentric chromosomes and rings, without karyotyping or banding, it does not provide any information about the presence of stable damage, such as translocations, deletions, insertions or inversions. Karyotyping and banding are laborious techniques, and the development of the FISH assay [70] provides an effective alternative for the visualization 
of stable chromosome damage. FISH is a method which uses specific DNA sequences as probes which paint the probed sequence with various coloured fluorochromes. The fluorochromes can then be visualized using fluorescent microscopy. If stable damage is present, it is visible as a rearrangement of the coloured fragments.

\subsubsection{Cell culture, mitotic arrest, hypotonic shock and fixation and slide preparation}

The processing of the FISH samples is very similar to that of the DCA, and follows the same methods as outlined in sections 2.2 .1 .1 through 2.2 .1 .5 , with only a few minor alterations. For the FISH samples, the samples were irradiated at $4 \mathrm{~Gy}$. BrdU was not used, and the percentage of cells in second metaphase was assumed to be low (approximately $5 \%$, based on prior knowledge).

\subsubsection{Slide preparation and chromosome painting}

Generally, only a portion of the chromosome population is painted for $\mathrm{FISH}$, and these are the larger chromosomes, as they represent a larger percentage of the DNA content. For our assay, a three colour kit was used, which specifically painted chromosomes 1, 2 and 4, which represent $21.87 \%$ of the genome [71].

Starting with frozen samples, the samples were washed twice with $10 \mathrm{~mL}$ fresh fix (as described in section 2.2.1.4 Fixation and washes) at RT. Slides were prepared using the same method as for the DCA except that the concentration of cells required for FISH was slightly more dense, to ensure that sufficient spreads would be available to score. The slides were left to dry on a slide warmer to $37^{\circ} \mathrm{C}$ overnight. 
On the following day, each slide was immersed in $2 x \operatorname{SSC}(\mathrm{pH} 7.0$ ) for 2 minutes in a glass Coplin jar at RT, then dehydrated by immersion in a series of ethanol baths (70\%, 85\% and $100 \%$ ) for 2 minutes each at RT. The slides were transferred to a $37^{\circ} \mathrm{C}$ warming tray for another 2 minutes.

$15 \mu \mathrm{L}$ of pre-warmed probe (Cytocell 1,2,4 Direct Probe, Rainbow Scientific; Windsor CT) was applied to the center of the slide and then covered with a pre-warmed coverslip. The edges of the coverslip were sealed with rubber cement and left to dry completely on the plate warmer. The use of the rubber cement ensures that the probe does not evaporate during the denaturation and hybridization stages. Once dry, the slides were placed in a thermocycler where they were denatured at $75^{\circ} \mathrm{C}$ for 2 minutes, and then hybridized at $37^{\circ} \mathrm{C}$ for 24 hours.

Post-hybridization, the rubber cement was carefully removed, and the slide washed in $0.4 \mathrm{X}$ saline-sodium citrate (SSC), (pH 7.0) at $72^{\circ} \mathrm{C}$ for 2 minutes. Note that care was taken to not allow the slide to dry out once the coverslip was removed. The slide was drained, washed in $2 \mathrm{X} \mathrm{SSC}, 0.05 \%$ Tween-20, pH 7.0 at RT for 30 seconds, drained again and $15 \mu \mathrm{L}$ of DAPI (4,6-diamidino-2-phenylindole) antifade (Cytocell 1,2,4 Direct Probe, Rainbow Scientific) applied to the center of the slide. A coverslip was added and the edges sealed with clear lacquer to prevent the slides from drying out. The slides were kept in the dark to allow the colour to develop for a minimum of 10 minutes. Slides were kept in a $-20^{\circ} \mathrm{C}$ freezer for storage. Also note that all procedures with the probe were done under reduced light to limit degradation of the fluorochromes in the probe solution. 


\subsubsection{Scoring the slides}

There are a number of different nomenclature systems which are used to describe FISH aberrations. Because some of the spreads can become quite complex, the PAINT system [72] was used. It is a descriptive system, and each piece is described without relying on the presence of another piece, which makes it efficient to use and verify. The PAINT system also used the term "colour junction" which refers to the junction of two different colours, where it is clear that a DSB had to have occurred. Some key elements of the system include the colour and centromeres designations. The letters are assigned as A for achromatic (no colour), $\mathrm{R}$ for red, $\mathrm{G}$ for green and $\mathrm{Y}$ for yellow; and a capital letter is used for the piece with a centromere, and a small letter for that without. Figure $2-3$ is an example of the nomenclature used for a 4 Gy spread. 


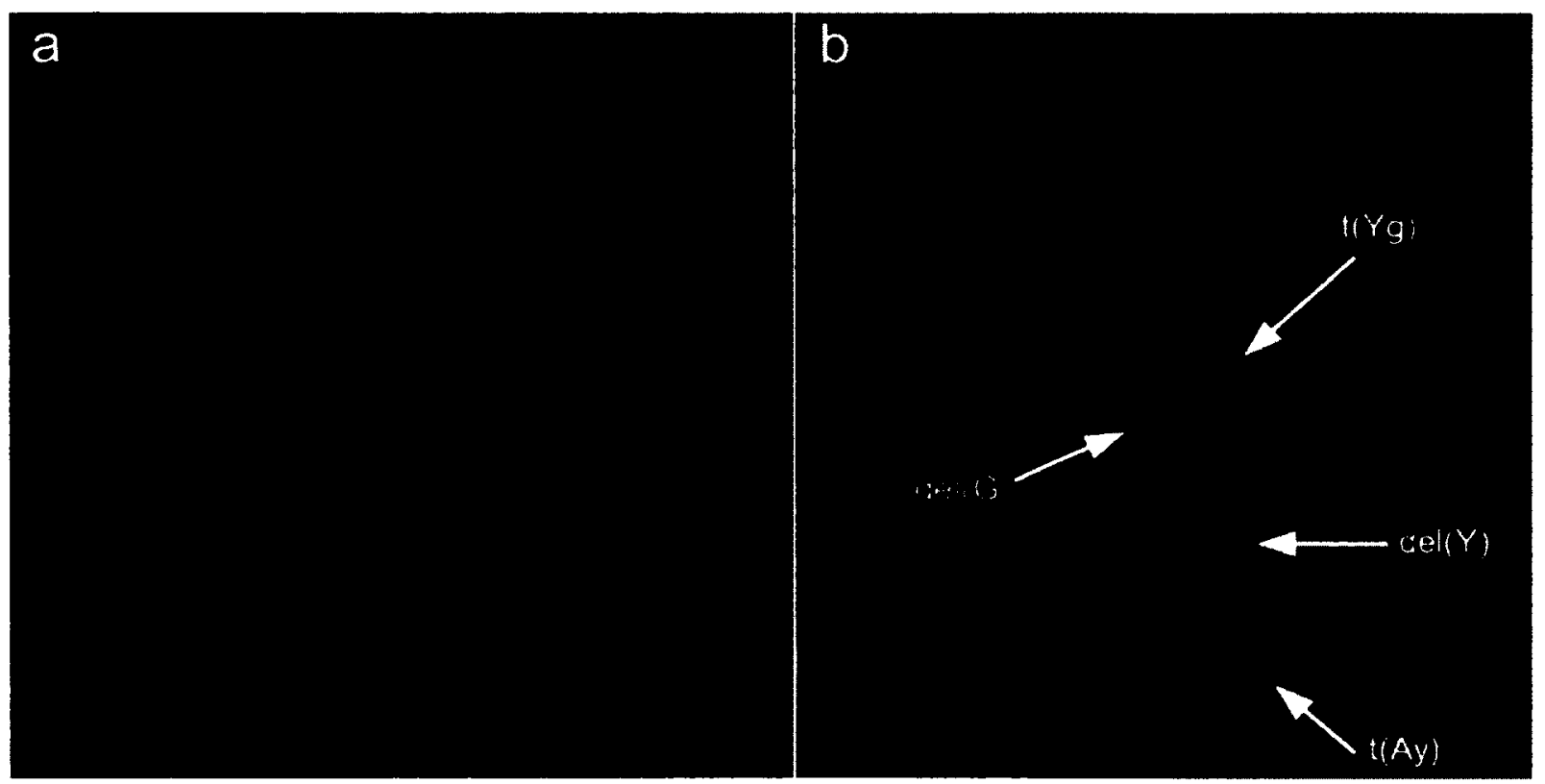

Figure 2-3: Example of the scoring of a 0 and 4 Gy spread. (a) 0 Gy spread: no visible damage (b) 4 Gy spread: complete chromosomes include 2 copies of chromosome 1 (red), and 1 chromosome 2 (green). The spread also includes the following damage; a deletion of chromosome 2 (del(G)), a deletion of chromosome 4 (yellow) (del(Y)), a yellow-achromatic translocation ( $(\mathrm{Ay}))$ and a green-yellow translocation $(\mathrm{t}(\mathrm{Yg}))$. Spreads were captured at $1000 x$ magnification on a Metafer Slide Scanning System (Metasystems Group Inc., Watertown MA)

At least 1000 spreads were scored for the 0 Gy samples, and in the case of the 4 Gy samples, at least 100 colour junctions were scored. 


\subsection{3 $\gamma \mathrm{H} 2 \mathrm{AX}$}

\subsubsection{Methods of measuring $\gamma H 2 A X$ : spot counting and flow cytometry}

Given the ability to visualize individual $\gamma \mathrm{H} 2 \mathrm{AX}$ foci (as mentioned in Chapter 1 section 1.2.2.5 $H 2 A(X)$ background), and the close correlation to DSBs, assays were quickly developed to measure $\gamma \mathrm{H} 2 \mathrm{AX}$ as a measure of DNA damage. $\gamma \mathrm{H} 2 \mathrm{AX}$ can be measured by fluorescent microscopy, by counting the number of foci per cell. While this method is able to detect low levels of damage, it is time consuming. Alternatively, flow cytometry could be used to measure the fluorescent intensity of the $\gamma \mathrm{H} 2 \mathrm{AX}$ foci which is very fast but less sensitive than foci counting. Olive et al. [73] used flow cytometry techniques to measure $\gamma \mathrm{H} 2 \mathrm{AX}$ intensity to determine if $\gamma \mathrm{H} 2 \mathrm{AX}$ could provide information on tumour and normal tissue sensitivity to radiation. From the same research group, Banath et al. [49] examined radiation sensitivity and the kinetics of DNA repair in irradiated cervical cancer cell lines and concluded that differences in $\gamma \mathrm{H} 2 \mathrm{AX}$ response was in part related to intrinsic radiosensitivity.

The method used for sample preparation is described in detail in chapter 5.

\subsection{Flow cytometry}

\subsubsection{Introduction to flow cytometry}

Flow cytometry is the rapid measurement of cells as they pass an interrogation point in a fluid stream. The key feature is that cells in single file pass this interrogation point, generally a set of lasers, and as they pass, the scattered, transmitted and fluorescent light is measured by a series of highly tuned optical elements. 


\subsubsection{Key elements of flow cytometry}

Sample preparation is the most important step in flow cytometry due to the fluidics. The sample must consist of a single cell suspension which can be guided by the laminar flow through the flow stream in a single file, "bead-on-a-string" arrangement. If the sample does not consist of single cells, the result is a noisier signal, however, some of these noisy events (for example, doublets, which are two cells attached) can be gated out in the post-processing.

Cells are stained by incubation with a fluorescent dye or an antibody that is conjugated with a fluorochrome. The staining must be specific and proportional to the feature being measured. Non-specific binding is misleading and can be an issue. Titration of the fluorochrome is important so as to ensure a bright signal that is not oversaturated. Use of controls (single colour and fluorescent minus one (FMO)) are important also for setting gates and defining negative and positive populations.

Fluorochrome and antibody combinations are important to minimize optical cross-talk, which occurs when fluorochromes with overlapping spectra are used simultaneously. Optical filtration and electronic compensation are used to correct for signal bleed through, but there is a reduction in sensitivity with increased use of compensation. Another issue to be wary of is energy transfer between fluorochromes. If the energy absorbed by one dye is transferred to a second dye, the signal of the first dye is quenched, and the second dye fluoresces instead. Again, FMOs and a thoughtful selection of dyes will help mitigate this.

Optical elements consist of multiple lasers or light emitting diodes (LEDs) and band- and long-pass filters used in combination with dichroic mirrors. As the lasers and 
LEDs excite the fluorochromes, the emitted light is split according to wavelength and each band of colour is deflected to the appropriate photomultiplier tubes (PMTs).

Light scatter and transmission characteristics are used to provide information on the size (based on forward scatter) and granularity (based on side scatter) of the particles flowing past the point of interrogation. For example, in figure $2-4$, the side-scattered light (ssc) is plotted against the forward-scattered light (fsc). The sample consisted of lymphocytes, monocytes, granulocytes, platelets and cellular debris. Lymphocytes have minimal granularity and are relatively small in size, and are easily selected based on these characteristics. On the other hand, granulocytes are very granular and are larger in size, and the monocytes are larger in size as compared to the lymphocytes but less granular than most of the granulocytes. 


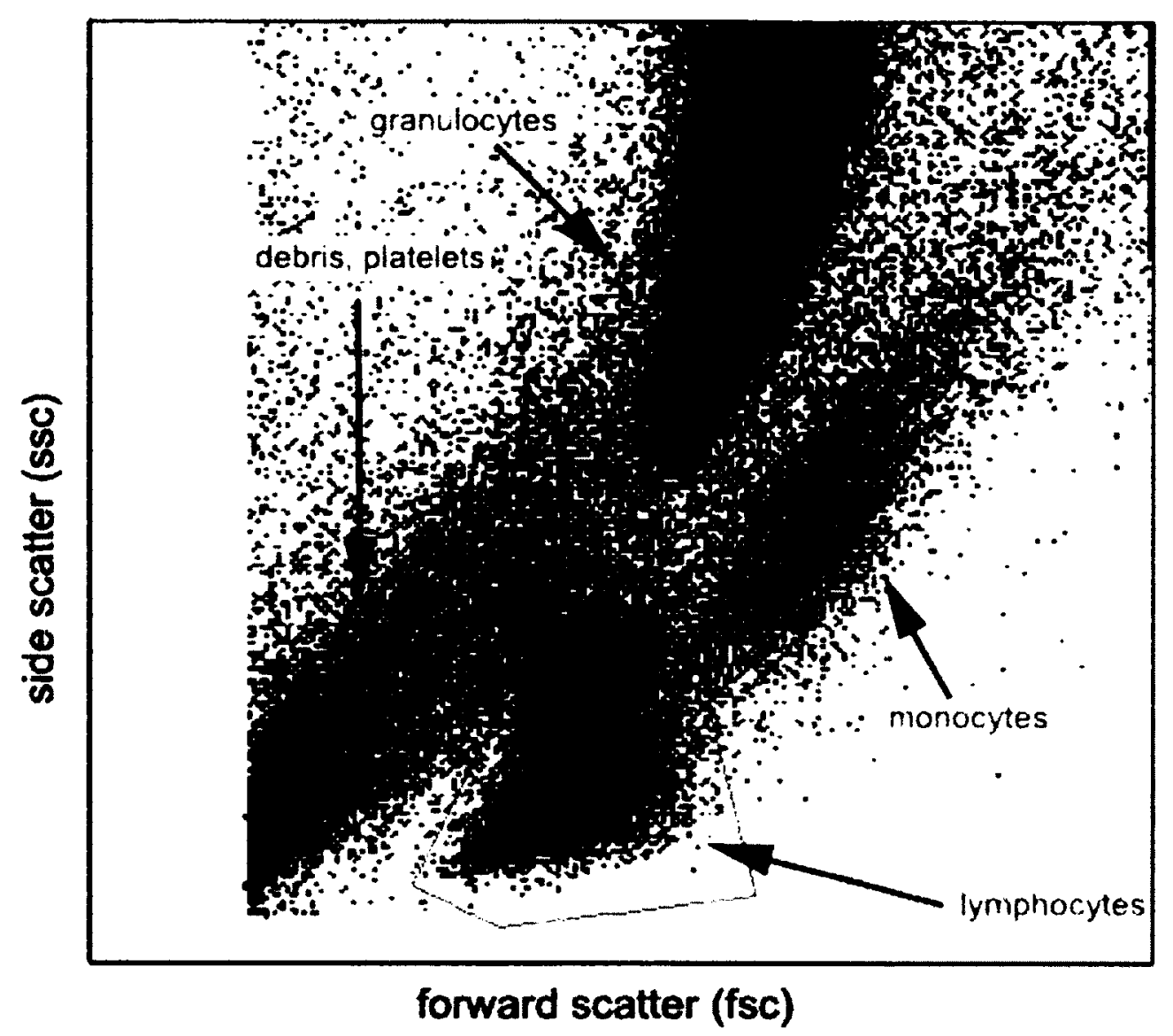

Figure 2-4: Intensity of forward light scatter versus intensity of side light scatter acquisition dot plot of a blood sample. Various clusters represent different cell types, and characteristic populations are identified (lymphocytes, monocytes, granulocytes and debris/platelets). A gate is drawn around the cell population of interest (LYMPHS)

The light scatter characteristics, along with the intensity of the fluorescent colours detected, provide the information about the sample, and because of the speed of the assay, many more cells can be rapidly analyzed, as compared to microscopic assays. In this way, the flow cytometer is said to provide good population statistics. As described 
subsequently in chapter 6 , these functions allow simultaneous detection of $\gamma \mathrm{H} 2 \mathrm{AX}$ in lymphocytes, as well as in the CD4, CD8 and CD19 subsets. 


\section{The Dicentric Chromosome Assay (DCA) Study}

\subsection{Introduction to the DCA Study}

This chapter contains the manuscript entitled "Chromosome damage and cell proliferation rates in in vitro irradiated whole blood as markers of late radiation toxicity after prostate radiotherapy", accepted for publication in the International Journal of

Radiation Oncology, Biology, Physics (IJROBP) (September $23^{\text {rd }}, 2012$ ). The manuscript has been edited from the published version following revisions requested by examiners at the defense (December $10^{\text {th }}, 2012$ ). As well, the references, which have been unified for the entire thesis are presented at the end of the thesis, in section 7.0 References.

\subsection{Chromosome damage and cell proliferation rates in in vitro irradiated whole} blood as markers of late radiation toxicity after prostate radiotherapy Authors: Lindsay A. Beaton, M.Sc.(1), Catherine Ferrarotto, MLT(1), Leonora Marro, M.Sc.(1), Sara Samiee, M.D.(2), Shawn Malone, M.D.(2), Scott Grimes(2), Kyle Malone (2), Ruth C. Wilkins, Ph.D.(1)

(1) Environmental and Radiation Health Sciences Directorate, Health Canada, 775 Brookfield Rd., Ottawa, ON, Canada

(2) The Ottawa Hospital, Ottawa Hospital Research Institute, University of Ottawa, 501 Smyth Rd, Ottawa, ON, Canada 


\subsubsection{Summary}

This study examines three cytogenetic endpoints in in vitro irradiated whole blood from prostate cancer patients exhibiting late normal tissue damage. These patient samples were matched by prostate cancer patients who exhibited no late normal tissue damage. Statistical analysis is described in detail, and significant results were found in all three endpoints.

\subsubsection{Abstract}

Background and Purpose: In vitro irradiated blood samples from prostate cancer patients exhibiting late normal tissue damage were examined for lymphocyte response by measuring chromosomal aberrations and proliferation rate.

Material and Methods: Patients were selected from a randomized trial evaluating the optimal timing of Dose Escalated Radiation and short course Androgen Deprivation Therapy. Of 438 patients, 3\% developed Grade 3 late radiation proctitis and were considered to be radiosensitive. Blood samples were taken from 10 of these patients along with 20 matched samples from patients with grade 0 proctitis. The samples were irradiated at $6 \mathrm{~Gy}$ and, along with controls, were analyzed for dicentric chromosomes and excess fragments per cell. Cells in first and second metaphase were also enumerated to determine the lymphocyte proliferation rate.

Results: At $6 \mathrm{~Gy}$, there were statistically significant differences between the radiosensitive and control cohorts for three endpoints; the mean number and standard deviation $(S D)$ of dicentric chromosomes per cell $(3.26 \pm 0.31,2.91 \pm 0.32 ; p=0.0258)$, the mean number and SD of excess fragments per cell $(2.27 \pm 0.23,1.43 \pm 0.37 ; \mathrm{p}<$ 
$0.0001)$ and the mean proportion and SD of cells in second metaphase $(0.27 \pm 0.10,0.46$ $\pm 0.09 ; \mathrm{p}=0.0007)$

Conclusions: These results may be a valuable indicator for identifying radiosensitive patients and for tailoring radiotherapy treatments.

\subsubsection{Introduction}

Radiotherapy is a common treatment modality for a broad range of malignancies. Depending on the type of cancer, radiation can be used either as a mono-therapy or in combination with other treatments such as surgery and chemotherapy. With modern radiotherapy techniques, clinicians have been able to minimize the risk of normal tissue toxicity [74]. Despite improvements in radiotherapy techniques, a percentage of patients suffer moderate to severe late side effects that can impact on patient quality of life. Normal tissue damage might present as acute (early responding) and/or chronic (late responding) $[75 ; 76]$. Acute side effects are typically reversible and self-limited whereas late effects occur years after treatment and are often irreversible. Furthermore, the severity of these late effects can limit the total dose and dose per fraction that can be administered during treatment [3]. For prostate cancer treatment, up to $10 \%$ of patients experience grade 3 late rectal toxicity [77].

It has become clear that inter-patient variability and the incidence of late side effects could be partially due to individual patient radiosensitivities [7]. The need for a greater understanding of the variations in radiosensitivity has led to many attempts to identify biomarkers that could be used to predict an individual's radiosensitivity in order to personalize patient treatment protocols. A number of potential predictive assays for 
normal tissue toxicity have been explored including but not limited to clonogenic survival after 2 Gy $\left(\mathrm{SF}_{2}\right)$ assays $[30 ; 34 ; 78]$, chromosomal damage assays [79;80], genomic profiles (see Andreassen 2005 for a review [50]) and, more recently, lymphocyte assays.

Lymphocyte assays provide attractive potential benefits, such as being less invasive and having a shorter turnaround time compared to fibroblast or genetic assays. West et al. [81] suggested that lymphocytes were more radiosensitive in patients suffering more severe reactions to radiotherapy. Preliminary results from Hoeller et al. [41] found that an increased annual rate of fibrosis might be predicted from a high cellular radiosensitivity as measured by the number of lethal chromosome aberrations in in vitro irradiated lymphocytes. Those results were followed by a pair of studies by Borgmann et al. [42] that indicated a significant correlation between chromosome deletions in vitro and normal tissue side effects in breast cancer patients.

The goal of this study was to evaluate the in vitro lymphocyte response in a cohort of prostate cancer patients enrolled in a prospective phase III clinical trial to identify possible biomarkers of radiosensitivity. Dicentric chromosomes and excess acentric fragments were analyzed, and the lymphocyte proliferation rate was studied.

\subsubsection{Materials and Methods}

\subsubsection{Patients}

438 prostate cancer patients have been entered onto a phase 3 clinical trial (OTT0101, OHREB \#2001014-01H) evaluating the optimal sequencing of radiation and 6 months Androgen Deprivation Therapy (ADT) in cT1-T3 prostate cancer. Low risk prostate cancer patients were excluded from the trial. All patients received 6 months ADT 
and were randomized to radiation at Day 1 or after 4 months of ADT. The clinical trial received Research Ethics Board approval from the Ottawa Hospital. Patients for the companion in vitro radiosensitivity study were recruited from OTT-0101 clinical trial. Of the patients entered in the phase III clinical trial, $3 \%$ had developed Grade 3 late radiation proctitis. Toxicity was prospectively scored using the RTOG/EORTC Late Toxicity Scale [58] scoring schema. Of the identified patients with Grade 3 late proctitis (sensitive), 10 patients agreed to participate in the in vitro radiosensitivity study. These patients were matched with 20 Grade 0 patients (control) from the same prospective clinical trial. For the control group (Grade 0 proctitis) the patients had been followed for a minimum of 3 years after radiotherapy and prior to trial entry on the radiosensitivity study. Clinical characteristics of the patient groups are given in Table 3-1. In the sensitive cohort severe late grade 3 proctitis developed 9 to 41 months post therapy (mean 21 months). Patients gave informed consent to give a venous blood sample. The blood samples were drawn at the hospital, and blinded before being transferred to the radiobiology laboratory. The patient status was revealed once sample analysis was complete. The in vitro radiosensitivity study was approved by The Ottawa Hospital Research Ethics Board and Health Canada's Research Ethics Board. 
Table 3-1: Clinical features of control and radiosensitive groups

\begin{tabular}{ccccccc}
\hline $\begin{array}{c}\text { Clinical } \\
\text { Group }\end{array}$ & $\begin{array}{c}\text { Age at } \\
\text { diagnosis } \\
\text { (mean and } \\
\text { range) }\end{array}$ & $\begin{array}{c}\text { Pre-Existing } \\
\text { Cardiovascular } \\
\text { Disease/ } \\
\text { Hypertension }\end{array}$ & $\begin{array}{c}\text { Pre- } \\
\text { existing } \\
\text { Type II } \\
\text { Diabetes }\end{array}$ & $\begin{array}{c}\text { Smoker/ } \\
\text { Ex- } \\
\text { Smoker }\end{array}$ & $\begin{array}{c}\text { Mean follow } \\
\text { up time post- } \\
\text { treatment } \\
\text { (years) }\end{array}$ & $\begin{array}{c}\text { Mean } \\
\text { time to } \\
\text { onset of } \\
\text { grade 3 } \\
\text { proctitis } \\
\text { (range) }\end{array}$ \\
\hline Control & $69(60-77)$ & $8 / 20$ & $3 / 20$ & $8 / 20$ & 6 & N/A \\
\hline Sensitive & $73(68-76)$ & $6 / 10$ & $1 / 10$ & $4 / 10$ & 7 & $\begin{array}{c}21 \\
\text { months } \\
\text { (9-41 } \\
\text { months) }\end{array}$ \\
\hline
\end{tabular}

All patients were treated with a 6 Field 3D Conformal Radiotherapy technique using 10 to $18 \mathrm{MV}$ photons. Clinical Target Volume (CTV) 1 included the prostate and proximal seminal vesicles. CTV2 was the prostate only. Planning Target Volume (PTV) 1 was the CTV1 $+1 \mathrm{~cm}$ (except at the prostate-rectal interface where it was $7 \mathrm{~mm}$ ). PTV2 was the CTV2 $+1 \mathrm{~cm}$ except at the prostate-rectal interface where it was $7 \mathrm{~mm}$. PTV1 was treated to 56 Gy in 28 fractions ( 2 Gy per fraction) and PTV2 to an additional 20 Gy in 10 fractions ( 2 Gy per fraction). All patients (sensitive and control) met the DV70 rectal dose constraints proposed in QUANTEC. Gold fiducial markers were used for image guidance on the linear accelerator. Median patient age was 70 years, ranging from 60 to 77 years. The average follow up time for these patients has been 6.2 years, ranging from 1.8 to 9.2 years.

\subsubsection{In vitro Irradiation Protocol}

Venous blood, drawn into $10 \mathrm{~mL}$ lithium-heparinized vacutainers (BD, Mississauga, ON), was aliquoted for each assay. Blood samples were irradiated on their sides at room temperature (RT) in a cabinet X-ray machine (XRAD 320, Precision X-ray, 
North Branford CT) at $250 \mathrm{kVp}$ and $12.5 \mathrm{~mA}$ with a $2 \mathrm{~mm} \mathrm{Al}$ filter. The dose-rate was 1.7 Gy/min calibrated using a Radcal 9010 ion chamber (Radcal, Monrovia CA) calibrated at the National Research Council, Ottawa, $\mathrm{ON}\left(\mathrm{N}_{\mathrm{K}}=0.992 \mathrm{~Gy} / \mathrm{G} \mathrm{y}_{\text {reading }}\right.$ at 250 $\mathrm{kV}$, assuming air kerma to be equal to dose).

\subsubsection{Culture and Fixation}

Aliquots of $1.7 \mathrm{~mL}$ of whole blood were transferred into two sterile $2 \mathrm{~mL}$ cryogenic vials (Corning Life Sciences, Lowell MA) and irradiated at RT at 0 or 6 Gy. After irradiation, the samples were incubated at $37^{\circ} \mathrm{C}$ on a rocker for $2 \mathrm{~h}$ prior to culturing.

After incubation, $1.5 \mathrm{~mL}$ of blood was transferred into the T25 vented culture flasks (VWR, Mississauga, ON) containing $13.5 \mathrm{~mL}$ RPMI 1640 media (Invitrogen, Burlington ON) supplemented with 1\% L-Glutamine pen-strep (Sigma-Aldrich, Oakville ON, 100x), 15\% inactivated FBS (Sigma-Aldrich), 2\% PHA (Invitrogen) and $0.5 \% 5-$ Bromo-2'-deoxyuridine (BrdU) (Sigma-Aldrich, $1 \mathrm{mg} / \mathrm{mL}$ ). The flasks were incubated in a $5 \% \mathrm{CO}_{2}, 37^{\circ} \mathrm{C}$ incubator. $150 \mu \mathrm{L}$ Colcemid (Invitrogen, $10 \mu \mathrm{g} / \mathrm{mL}$ ) was added to the 0 Gy samples at $44 \mathrm{~h}$, and similarly was added to the $6 \mathrm{~Gy}$ samples after $68 \mathrm{~h}$. The samples were incubated for another $4 \mathrm{~h}$.

At $48 \mathrm{~h}(0 \mathrm{~Gy})$ and $72 \mathrm{~h}(6 \mathrm{~Gy})$, the suspensions were transferred to $15 \mathrm{~mL}$ polypropylene tubes, centrifuged at $200 \mathrm{~g}$ for 8 minutes and the pellet was resuspended in hypotonic $0.075 \mathrm{M} \mathrm{KCl}$ solution at $\mathrm{RT}$ and incubated for 12 minutes. Samples were subsequently fixed and washed repeatedly with 3:1 methanolacetic acid and placed in a $20^{\circ} \mathrm{C}$ freezer for a minimum of 30 minutes prior to slide preparation. 


\subsubsection{Dicentric Chromosome Assay (DCA)}

Slides were prepared by dropping $15 \mu \mathrm{L}$ of cell suspension onto frosted glass microscope slides (Fisher Scientific, Ottawa, ON) in a Hanabi metaphase spreader (Adstec, Funabashi-city, Chiba Japan) and then placed on a slide warmer at $37^{\circ} \mathrm{C}$ overnight.

The slides were stained using the fluorescence plus Giemsa (FPG) method [65] to allow discrimination between cells in first and second metaphase (M1 and M2 respectively). Briefly, slides were stained for 2 minutes in $20 \mu \mathrm{g} / \mathrm{mL}$ Hoechst 33258 , placed on a slide warmer at $60^{\circ} \mathrm{C}$ and flooded with $0.6 \mathrm{M} \mathrm{Na}_{2} \mathrm{HPO}_{4}(\mathrm{pH} 9)$ before being mounted with glass coverslips. After being incubated under $365 \mathrm{~nm}$ UV light for 8 minutes, the coverslips were removed and the slides rinsed three times with distilled water. The slides were stained with $10 \%$ Giemsa solution in phosphate buffer $(\mathrm{pH}$ 6.8) for 10 minutes. They were again rinsed with distilled water and left to air dry on a slide warmer at $37^{\circ} \mathrm{C}$ for at least an hour before being mounted with Permount.

The slides were visualized under brightfield microscopy on a Metafer Slide Scanning System (Metasystems Group Inc., Watertown MA) and an Olympus BX50 (Olympus Corporation, Richmond Hill, ON). A minimum of 200 metaphase spreads were scored for the $0 \mathrm{~Gy}$ samples for each patient and a minimum of 100 dicentrics scored for the 6 Gy samples. Only spreads in M1 were scored, and each spread had to have 46 centromeres to be countable. As shown in figure 3-1, the M1 spreads were scored for dicentrics and acentric fragments. Chromosomes with more than 2 centromeres were counted as multiple dicentrics. For example a tricentric was counted as 2 dicentrics. Excess acentric fragments were determined by subtracting the number of fragments 
associated with dicentrics (on a one-to-one ratio) from the total count of acentric fragments.

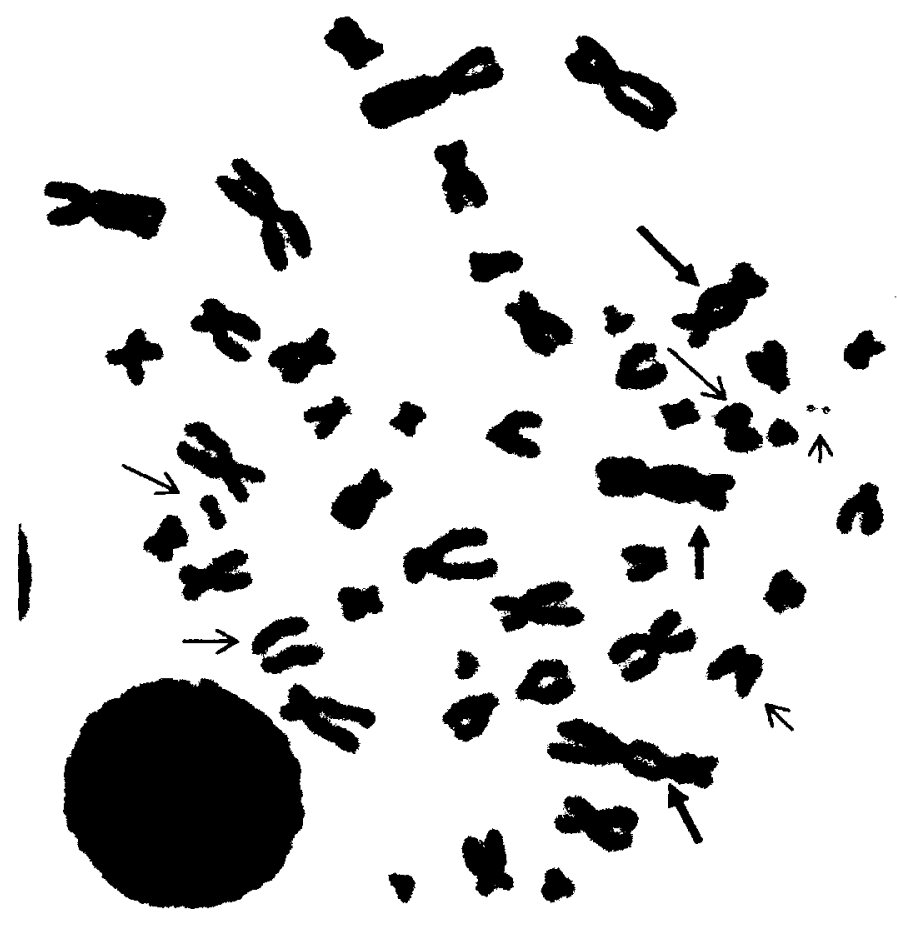

Figure 3-1: Example of chromosome damage in a solid stained, M1 spread. The highly damaged 6 Gy spread (captured at 1000x) contains examples of dicentric chromosomes (bold arrows) and acentric fragments (thin arrows). This spread would be counted as 2 dicentrics, 1 tricentric and 5 acentric fragments, resulting in a final tally of 4 dicentrics with associated fragments and 1 excess fragment.

\subsubsection{Percentage in Metaphase 1 and 2}

The same slides as were prepared for DCA 0 Gy and 6 Gy were scanned at $600 \mathrm{x}$ and a minimum of 150 metaphase spreads per dose per patient were counted as either being in M1 or M2, determined by the use of FPG staining. M1 spreads are identified by 
their monochrome staining (figure 3-1), while M2 spreads have a unique harlequin appearance (figure 3-2) [65].

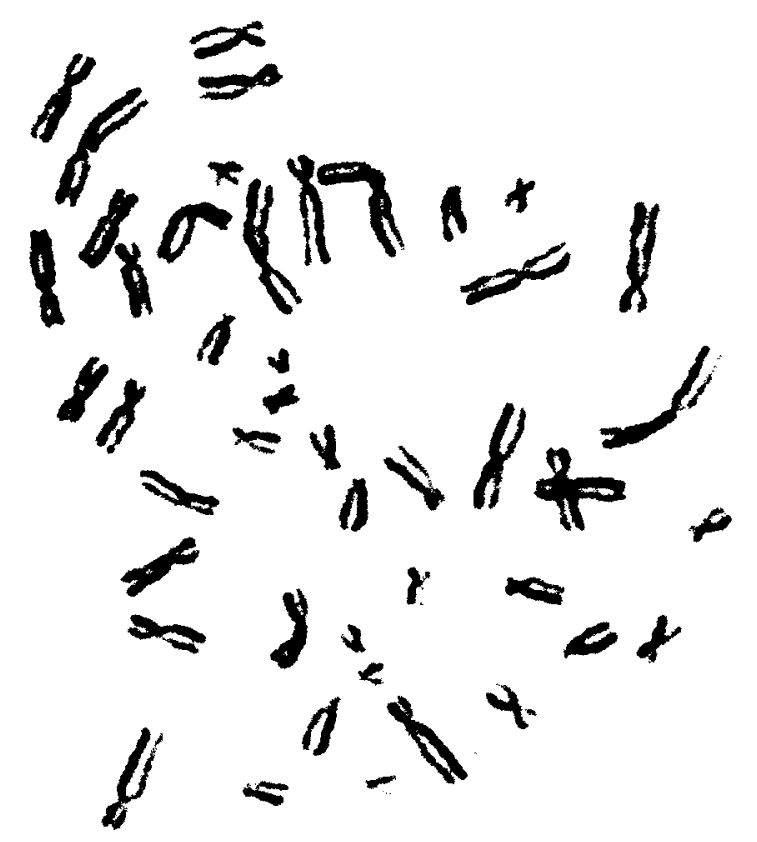

Figure 3-2: Harlequin staining: visible with FPG staining, with one sister chromatid being darker than the other. This M2 spread (captured at 1000x) would not be scored for chromosome damage, but would be counted for the proportion of cells in M1 or M2.

\subsubsection{Statistics}

The study design was a randomized complete block design and generalized linear mixed models (GLMM) with Poisson errors applied to model the outcomes dicentrics per cell and excess fragments per cell as these are rates and typically follow a Poisson distribution. GLMM include both fixed and random effects, to account for between treatment and status group variability (fixed effects) and within subject variability (random effect). Treatment and status are considered to be the fixed effects of the model 
along with their interaction to account for differences between treatment groups with respect to patient status. The random effect in the GLMM was subject to control for correlation within as well as between samples in the two dose groups, since each participant's blood was exposed to all treatment levels. Subjects were considered to be nested within status groups (control and sensitive), since the two status groups consisted of independent samples. The number of cells in $\mathrm{M} 2$, as a fraction of the total cells counted (fM2) was analyzed in a similar approach with the errors in the GLMM model following a binomial distribution.

When the overall F-test demonstrated a difference between status groups ( $p<$ 0.05 ), then multiple comparison tests were applied to compare the two status groups at each dose level. Bonferroni corrections were applied for pair-wise comparisons in order to adjust the Type I error rate to be less than 0.05 . In the present study for each endpoint of analysis there were four possible pair-wise comparisons ( 2 treatment levels at 2 status groups). Therefore, the p-value from each pair-wise comparison was multiplied by a correction factor of 4 .

\subsubsection{Results}

The two patient groups had comparable initial clinical characteristics (Table 3-1). Table 3-2 presents the primary data for each patient; including dicentric chromosomes and cell proliferation information. Table 3-3 presents the average and standard deviation (SD) of dicentrics and excess fragments per cell as well as the average proportion and SD of M2 cells per cell. The data for each patient (dicentrics chromosomes per cell, excess fragments per cell and proportion of spreads in M2) are shown in figure 3-3 to illustrate 
the distribution. As shown in table 3-3, there was no difference between the sensitive and control status groups at 0 Gy for any of the 3 endpoints, while there was an overall difference between the sensitive and control status groups when comparing dicentrics per cell, the excess fragments per cell, and the proportion of cells in M2 after exposure to 6 Gy. 
Table 3-2: Counted data for individual patients, including chromosome damage and cell proliferation information. Status is defined as 0 for controls and 1 for sensitive patients. M1 and M2 represent the number of cells counted as first or second metaphase respectively.

\begin{tabular}{ccccccccccccc}
\hline & & \multicolumn{1}{c}{ Chromosome Damage } & \multicolumn{5}{c}{ Cell Proliferation Rates } \\
\hline ID & Status & $\begin{array}{c}\text { Dose } \\
\text { (Gy) }\end{array}$ & $\begin{array}{c}\text { \# Cells } \\
\text { Counted }\end{array}$ & $\begin{array}{c}\text { \# } \\
\text { Dic }\end{array}$ & $\begin{array}{c}\text { \# Excess } \\
\text { Frags }\end{array}$ & Dic/Cell & $\begin{array}{c}\text { Excess } \\
\text { Frags/Cell }\end{array}$ & M1 & M2 & $\begin{array}{c}\text { Total } \\
\text { Counted }\end{array}$ & fM1 & fM2 \\
\hline P01 & 0 & 0 & 200 & 2 & 0 & 0.010 & 0.000 & 223 & 16 & 239 & 0.93 & 0.07 \\
\hline P02 & 0 & 0 & 200 & 2 & 2 & 0.010 & 0.010 & 200 & 15 & 215 & 0.93 & 0.07 \\
\hline P03 & 0 & 0 & 200 & 0 & 4 & 0.000 & 0.020 & 224 & 14 & 238 & 0.94 & 0.06 \\
\hline P04 & 1 & 0 & 200 & 4 & 5 & 0.020 & 0.025 & 185 & 4 & 189 & 0.98 & 0.02 \\
\hline P05 & 0 & 0 & 0 & - & - & - & - & 129 & 25 & 154 & 0.84 & 0.16 \\
\hline P06 & 1 & 0 & 200 & 1 & 1 & 0.005 & 0.005 & 289 & 11 & 300 & 0.96 & 0.04 \\
\hline P07 & 0 & 0 & 200 & 3 & 0 & 0.015 & 0.000 & 190 & 10 & 200 & 0.95 & 0.05 \\
\hline P08 & 1 & 0 & 200 & 5 & 8 & 0.025 & 0.040 & 178 & 10 & 188 & 0.95 & 0.05 \\
\hline P09 & 0 & 0 & 200 & 1 & 1 & 0.005 & 0.005 & 200 & 9 & 209 & 0.96 & 0.04 \\
\hline P10 & 1 & 0 & 200 & 8 & 5 & 0.040 & 0.025 & 183 & 6 & 189 & 0.97 & 0.03 \\
\hline P11 & 1 & 0 & 200 & 3 & 4 & 0.015 & 0.020 & 189 & 23 & 212 & 0.89 & 0.11 \\
\hline P12 & 1 & 0 & 200 & 1 & 1 & 0.005 & 0.005 & 204 & 15 & 219 & 0.93 & 0.07 \\
\hline P13 & 0 & 0 & 200 & 0 & 3 & 0.000 & 0.015 & 273 & 6 & 279 & 0.98 & 0.02 \\
\hline P14 & 1 & 0 & 200 & 4 & 2 & 0.020 & 0.010 & 194 & 9 & 203 & 0.96 & 0.04 \\
\hline P15 & 1 & 0 & 200 & 1 & 2 & 0.005 & 0.010 & 204 & 7 & 211 & 0.97 & 0.03 \\
\hline P16 & 0 & 0 & 200 & 2 & 2 & 0.010 & 0.010 & 155 & 12 & 167 & 0.93 & 0.07 \\
\hline P17 & 0 & 0 & 200 & 3 & 0 & 0.015 & 0.000 & 228 & 21 & 249 & 0.92 & 0.08 \\
\hline P18 & 0 & 0 & 200 & 5 & 3 & 0.025 & 0.015 & 174 & 7 & 181 & 0.96 & 0.04 \\
\hline & & & & & & & & & & & & \\
\hline
\end{tabular}

Table 3-2 continued on the next page 
Table 3-2 Continued

\begin{tabular}{|c|c|c|c|c|c|c|c|c|c|c|c|c|}
\hline \multirow[b]{2}{*}{ ID } & \multirow[b]{2}{*}{ Status } & \multirow[b]{2}{*}{$\begin{array}{l}\text { Dose } \\
\text { (Gy) }\end{array}$} & \multicolumn{5}{|c|}{ Chromosome Damage } & \multicolumn{5}{|c|}{ Cell Proliferation Rates } \\
\hline & & & $\begin{array}{l}\text { \# Cells } \\
\text { Counted }\end{array}$ & $\begin{array}{c}\# \\
\text { Dic }\end{array}$ & $\begin{array}{c}\text { \# Excess } \\
\text { Frags }\end{array}$ & Dic/Cell & $\begin{array}{c}\text { Excess } \\
\text { Frags/Cell }\end{array}$ & M1 & M2 & $\begin{array}{c}\text { Total } \\
\text { Counted }\end{array}$ & fM1 & fM2 \\
\hline P19 & 1 & 0 & 200 & 1 & 0 & 0.005 & 0.000 & 157 & 7 & 164 & 0.96 & 0.04 \\
\hline $\mathrm{P} 20$ & 0 & 0 & 200 & 1 & 0 & 0.005 & 0.000 & 204 & 26 & 230 & 0.89 & 0.11 \\
\hline P21 & 1 & 0 & 200 & 1 & 1 & 0.005 & 0.005 & 194 & 17 & 211 & 0.92 & 0.08 \\
\hline P22 & 0 & 0 & 200 & 2 & 1 & 0.010 & 0.005 & 161 & 31 & 192 & 0.84 & 0.16 \\
\hline P23 & 0 & 0 & 200 & 5 & 1 & 0.025 & 0.005 & 188 & 43 & 231 & 0.81 & 0.19 \\
\hline P24 & 0 & 0 & 200 & 1 & 1 & 0.005 & 0.005 & 197 & 10 & 207 & 0.95 & 0.05 \\
\hline $\mathrm{P} 25$ & 0 & 0 & 200 & 2 & 8 & 0.010 & 0.040 & 248 & 12 & 260 & 0.95 & 0.05 \\
\hline $\mathrm{P} 26$ & 0 & 0 & 200 & 4 & 10 & 0.020 & 0.050 & 175 & 11 & 186 & 0.94 & 0.06 \\
\hline $\mathrm{P} 27$ & 0 & 0 & 200 & 1 & 0 & 0.005 & 0.000 & 207 & 25 & 232 & 0.89 & 0.11 \\
\hline $\mathrm{P} 28$ & 0 & 0 & 200 & 3 & 1 & 0.015 & 0.005 & 200 & 21 & 221 & 0.90 & 0.10 \\
\hline P29 & 0 & 0 & 200 & 11 & 6 & 0.055 & 0.030 & 163 & 12 & 175 & 0.93 & 0.07 \\
\hline $\mathrm{P} 30$ & 0 & 0 & 200 & 7 & 7 & 0.035 & 0.035 & 178 & 1 & 179 & 0.99 & 0.01 \\
\hline $\mathrm{P} 01$ & 0 & 6 & 33 & 100 & 60 & 3.030 & 1.818 & 126 & 70 & 196 & 0.64 & 0.36 \\
\hline P02 & 0 & 6 & 35 & 100 & 50 & 2.857 & 1.429 & 79 & 129 & 208 & 0.38 & 0.62 \\
\hline $\mathrm{P} 03$ & 0 & 6 & 35 & 104 & 74 & 2.971 & 2.114 & 72 & 60 & 132 & 0.55 & 0.45 \\
\hline $\mathrm{P} 04$ & 1 & 6 & 35 & 103 & 72 & 2.943 & 2.057 & 134 & 51 & 185 & 0.72 & 0.28 \\
\hline P05 & 0 & 6 & 32 & 100 & 41 & 3.125 & 1.281 & 100 & 79 & 179 & 0.56 & 0.44 \\
\hline P06 & 1 & 6 & 34 & 103 & 76 & 3.029 & 2.235 & 169 & 68 & 237 & 0.71 & 0.29 \\
\hline P07 & 0 & 6 & 31 & 101 & 50 & 3.258 & 1.613 & 121 & 79 & 200 & 0.61 & 0.40 \\
\hline
\end{tabular}

Table 3-2 continued on the next page 
Table 3-2 Continued

\begin{tabular}{ccccccccccccc}
\hline & \multicolumn{10}{c}{ Chromosome Damage } & \multicolumn{5}{c}{ Cell Proliferation Rates } \\
\hline ID & Status & $\begin{array}{c}\text { Dose } \\
\text { (Gy) }\end{array}$ & $\begin{array}{c}\text { \# Cells } \\
\text { Counted }\end{array}$ & $\begin{array}{c}\text { \# } \\
\text { Dic }\end{array}$ & $\begin{array}{c}\text { \# Excess } \\
\text { Frags }\end{array}$ & Dic/Cell & $\begin{array}{c}\text { Excess } \\
\text { Frags/Cell }\end{array}$ & M1 & M2 & $\begin{array}{c}\text { Total } \\
\text { Counted }\end{array}$ & fM1 & fM2 \\
\hline P08 & 1 & 6 & 27 & 100 & 66 & 3.704 & 2.444 & 164 & 29 & 193 & 0.85 & 0.15 \\
\hline P09 & 0 & 6 & 36 & 100 & 44 & 2.778 & 1.222 & 107 & 111 & 218 & 0.49 & 0.51 \\
\hline P10 & 1 & 6 & 27 & 100 & 61 & 3.704 & 2.259 & 159 & 21 & 180 & 0.88 & 0.12 \\
\hline P11 & 1 & 6 & 31 & 104 & 75 & 3.355 & 2.419 & 143 & 59 & 202 & 0.71 & 0.29 \\
\hline P12 & 1 & 6 & 28 & 100 & 70 & 3.571 & 2.500 & 148 & 52 & 200 & 0.74 & 0.26 \\
\hline P13 & 0 & 6 & 35 & 103 & 56 & 2.943 & 1.600 & 142 & 62 & 204 & 0.70 & 0.30 \\
\hline P14 & 1 & 6 & 34 & 101 & 76 & 2.971 & 2.235 & 117 & 43 & 160 & 0.73 & 0.27 \\
\hline P15 & 1 & 6 & 31 & 101 & 55 & 3.258 & 1.774 & 130 & 41 & 171 & 0.76 & 0.24 \\
\hline P16 & 0 & 6 & 27 & 101 & 52 & 3.741 & 1.926 & 157 & 67 & 224 & 0.70 & 0.30 \\
\hline P17 & 0 & 6 & 36 & 103 & 63 & 2.861 & 1.800 & 105 & 59 & 164 & 0.64 & 0.36 \\
\hline P18 & 0 & 6 & 40 & 100 & 65 & 2.500 & 1.625 & 86 & 92 & 178 & 0.48 & 0.52 \\
\hline P19 & 1 & 6 & 35 & 101 & 88 & 2.886 & 2.514 & 101 & 72 & 173 & 0.58 & 0.42 \\
\hline P20 & 0 & 6 & 30 & 102 & 60 & 3.400 & 2.000 & 104 & 69 & 173 & 0.60 & 0.40 \\
\hline P21 & 1 & 6 & 31 & 100 & 69 & 3.226 & 2.226 & 83 & 65 & 148 & 0.56 & 0.44 \\
\hline P22 & 0 & 6 & 35 & 103 & 48 & 2.943 & 1.371 & 81 & 101 & 182 & 0.45 & 0.55 \\
\hline P23 & 0 & 6 & 35 & 101 & 38 & 2.886 & 1.086 & 98 & 90 & 188 & 0.52 & 0.48 \\
\hline P24 & 0 & 6 & 36 & 102 & 43 & 2.833 & 1.194 & 82 & 100 & 182 & 0.45 & 0.55 \\
\hline P25 & 0 & 6 & 35 & 102 & 42 & 2.914 & 1.200 & 96 & 92 & 188 & 0.51 & 0.49 \\
\hline P26 & 0 & 6 & 35 & 101 & 49 & 2.886 & 1.400 & 86 & 91 & 177 & 0.49 & 0.51 \\
\hline P27 & 0 & 6 & 43 & 102 & 44 & 2.372 & 1.023 & 78 & 98 & 176 & 0.44 & 0.56 \\
\hline & & & & & & & & & & \\
\hline
\end{tabular}

Table 3-2 continued on the next page 
Table 3-2 Continued

\begin{tabular}{cccccccccccccc}
\hline & \multicolumn{1}{c}{ Chromosome Damage } & \multicolumn{4}{c}{ Cell Proliferation Rates } \\
\hline ID & Status & $\begin{array}{c}\text { Dose } \\
\text { (Gy) }\end{array}$ & $\begin{array}{c}\text { \# Cells } \\
\text { Counted }\end{array}$ & $\begin{array}{c}\text { \# } \\
\text { Dic }\end{array}$ & $\begin{array}{c}\text { \# Excess } \\
\text { Frags }\end{array}$ & Dic/Cell & $\begin{array}{c}\text { Excess } \\
\text { Frags/Cell }\end{array}$ & M1 & M2 & $\begin{array}{c}\text { Total } \\
\text { Counted }\end{array}$ & fM1 & IM2 \\
\hline P28 & 0 & 6 & 35 & 101 & 29 & 2.886 & 0.829 & 109 & 79 & 188 & 0.58 & $\mathbf{0 . 4 2}$ \\
\hline P29 & 0 & 6 & 39 & 100 & 37 & 2.564 & 0.949 & 91 & 94 & 185 & 0.49 & 0.51 \\
\hline P30 & 0 & 6 & 42 & 102 & 47 & 2.429 & 1.119 & 115 & 72 & 187 & 0.61 & 0.39 \\
\hline
\end{tabular}


Table 3-3: Comparison of control to radiosensitive groups for three measurements (dicentrics per cell, excess fragments per cell and $\mathrm{fM} 2$ ). Entries in table represent the mean (standard deviation) for each endpoint and dose combination. Significance levels are denoted by asterisks, where $*, * *$ and $* * *$ correspond to p-values $\leq 0.05,0.01$ and 0.001 respectively.

\begin{tabular}{ccc}
\hline \multirow{2}{*}{ Treatment Group } & \multicolumn{2}{c}{ Dose } \\
\cline { 2 - 3 } & \multicolumn{2}{c}{ 0 Gy Gy } \\
\hline Control & $\left(\mathrm{n}=19^{1}\right) 0.01(0.01)$ & $(\mathrm{n}=20) 2.91(0.32)$ \\
\hline Radiosensitive & $(\mathrm{n}=10) 0.01(0.01)$ & $(\mathrm{n}=10) 3.26(0.31)$ \\
\hline $\mathrm{F}_{(1,27)}(\mathrm{p}$-value $)$ & $0.00(0.9952)$ & $5.57(0.0258)^{*}$ \\
\hline Control & \multicolumn{2}{c}{ Excess fragments per cell } \\
\hline Radiosensitive & $(\mathrm{n}=19) 0.01(0.02)$ & $(\mathrm{n}=20) 1.43(0.37)$ \\
\hline $\mathrm{F}_{(1,27)}(\mathrm{p}$-value $)$ & $(\mathrm{n}=10) 0.01(0.01)$ & $(\mathrm{n}=10) 2.27(0.23)$ \\
\hline & $0.06(0.8036)$ & $33.92(<0.0001)^{* * *}$ \\
\hline Control $(\mathrm{n}=20)$ & & $\mathrm{fM} 2$ \\
\hline Radiosensitive $(\mathrm{n}=10)$ & $0.08(0.05)$ & $0.46(0.09)$ \\
\hline $\mathrm{F}_{(1,28)}(\mathrm{p}-\mathrm{value})$ & $0.05(0.03)$ & $0.27(0.10)$ \\
\hline
\end{tabular}

'Note that for 1 patient, there were no countable spreads in the 0 Gy sample, while there were at $6 \mathrm{~Gy}$. 

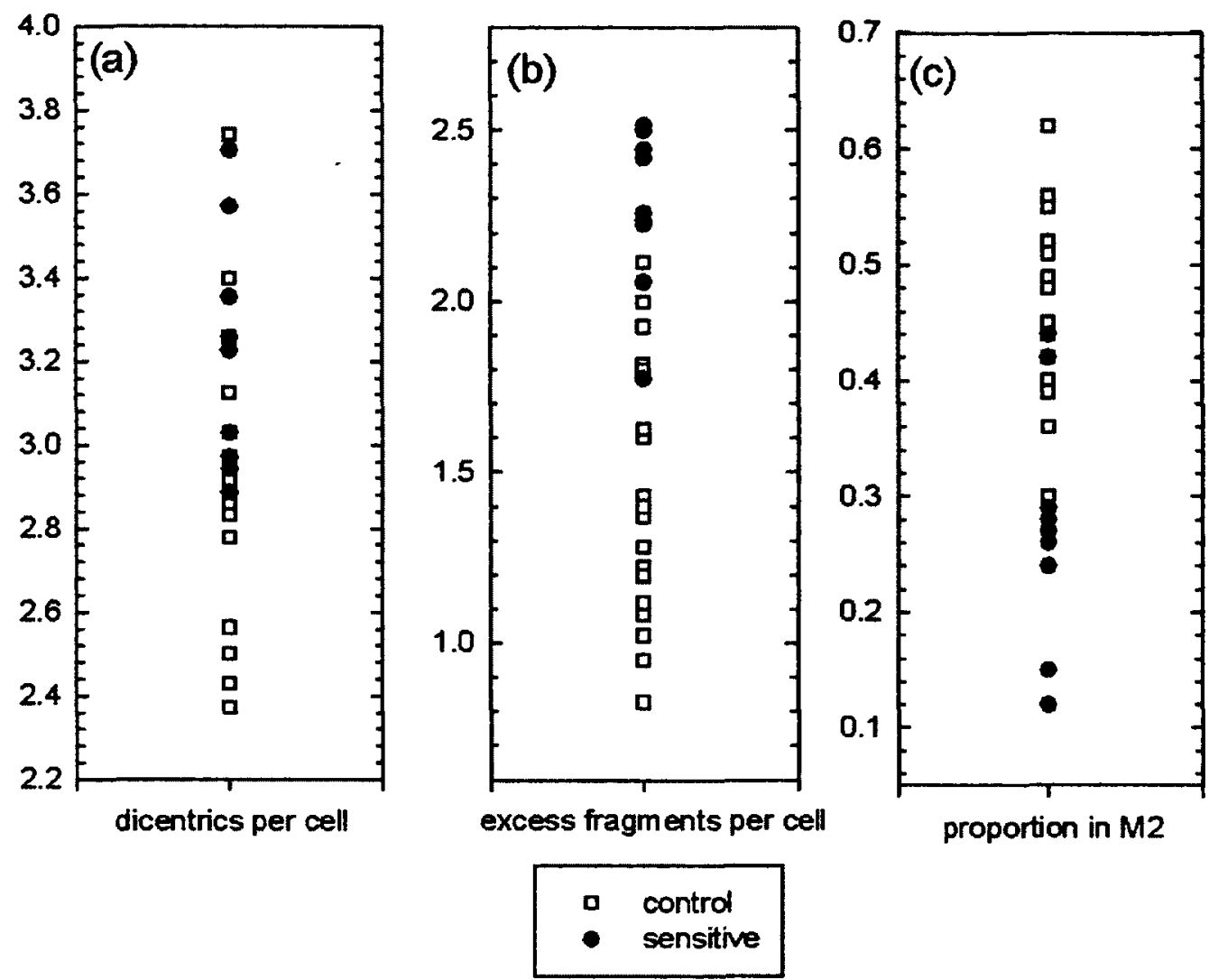

Figure 3-3: Spread of the data for each of three endpoints (a) dicentrics per cell, (b) excess fragments per cell, and (c) proportion of cells in M2. Each point represents one patient.

\subsubsection{Discussion}

\subsubsection{Patient selection}

Patients were selected from a prospective clinical trial in which cT1-T3 prostate cancer patients were treated with a uniform radiotherapy target volume, dose, and treatment technique. The patients were prospectively scored for toxicity using validated toxicity scales. These clinical factors help to minimize potential biases in our clinical- 
translational research study. The clinical cohort represents a unique study population that is well controlled to minimize inter-patient variability.

\subsubsection{Chromosome damage}

In our preliminary work, there were insufficient countable chromosome spreads in the $6 \mathrm{~Gy}$ samples after $48 \mathrm{~h}$ incubations. Since high doses of radiation can delay the cell cycle, the incubation time for the $6 \mathrm{~Gy}$ samples was increased from the standard $48 \mathrm{~h}$ to $72 \mathrm{~h}$. This ensured that adequate numbers of cells had reached metaphase. With the use of FPG staining, only spreads in M1 were counted.

In the $0 \mathrm{~Gy}$ samples, although there was no difference in the number of dicentric chromosomes between the control and the sensitive samples, both groups had increased numbers of dicentric chromosomes (10 per 1000 cells for both groups) as compared to the expected level in a normal healthy population $(-0.5-1.0$ dicentrics per 1000 cells $)$ [65;82]. While this could indicate repair deficiencies in cancer patients as compared to healthy populations, it is inconclusive in this study, as patients have already been exposed to high doses of radiation during their radiotherapy. Nonetheless, this is similar to the findings of Vodicka et al. [83], who measured a difference in the frequencies of aberrant cells and chromosomal aberrations when comparing newly diagnosed cancer patients to healthy individuals.

After $6 \mathrm{~Gy}$, however, a significant increase in both dicentric chromosomes and excess fragments was found in the blood samples from the sensitive patients as compared to the control group. These results are in agreement with those of both Borgmann et al. [42] and Chua et al. [43]. Similar to both of these studies, our study looked at the number 
of excess fragments in in vitro irradiated samples. The biggest difference in this method was the use of FPG staining to identify and count cells in M1 only. Borgmann et al. found a correlation between the lymphocyte assay at $6 \mathrm{~Gy}$ and clinical radiosensitivity, and Chua et al. found that the mean excess fragments per cell was 3.10 for sensitive cases as compared to 1.95 for controls, $(p=0.026)$, while the mean values (and SD) in this study were $2.27 \pm 0.23$ and $1.43 \pm 0.37$ respectively $(\mathrm{p} \leq 0.0001)$.

FPG staining not only enabled the identification of M1 metaphase spreads, but had the added value of allowing the evaluation of the rate of cell cycling by determining the proportion of M1 and M2 metaphase spreads for each patient. There was, in fact, a significant difference between the two groups: the sensitive cohort had a lower proportion of cells in M2 (mean $=27 \%$ ) while the control cohort had a higher proportion (mean = $46 \%$ ). This is indicative of a difference in cell cycling time, and it was clear that the control cells were cycling faster than the sensitive cells. This could be due to the sensitive population having more difficulty with cellular repair and is worth investigating further. While there are studies examining tumour radiosensitivity as a function of tumour proliferation rate, there is little evidence in the literature linking cell proliferation rate with late normal tissue toxicity.

The use of the FPG staining also provided a more stringent result. As there is a difference between the cell cycling times in the two populations and as there is a higher likelihood that undamaged cells will cycle into M2, patients with a higher M2\% will have a diluted score of the amount of damage per cell if M2 cells are included in the analysis (since there are more healthy cells in the total count). As shown in the results of our study, at $6 \mathrm{~Gy}$, there was a significant difference between the M2:M1 ratio of the control 
and sensitive populations and therefore by using the FPG method, we were able to ensure that only spreads in Ml were scored. This stricter scoring schema increased the significance of the differences between the two populations at $6 \mathrm{~Gy}$ for both dicentric chromosomes per cell, as well as excess fragments per cell when compared to earlier studies. Based on these results, it is recommended that future work with this assay also adopt the practice of using FPG staining. While there is some overlap between sensitive and control patients, the radiation response of many of the patients could be identified using these endpoints. Future studies should examine the usefulness of combining multiple endpoints to improve the predictive power of cytogenetics.

\subsubsection{Conclusions}

Although cytogenetics has been used as a marker of radiation exposure for many years, to date there has been limited use as a marker of radiation sensitivity. These prostate cancer results, which further validate the results found by Borgmann et al. and Chua et al. in breast cancer patients, add strength to the suggestion that cytogenetic analysis may be a useful predictor of radiosensitivity. The use of FPG staining to denote cells in first or second metaphase was used to ensure that only spreads in first metaphase were counted for chromosome damage and increased the significance of these findings. It also proved useful to measure the fraction of cells in M2 as a second biomarker to differentiate between the sensitive and control populations.If a patient is identified as radiosensitive, it is recommended that follow up testing be done to verify their sensitivity. The use of multiple endpoints would help verify a patient's sensitivity, These biomarkers may be valuable in the future for tailoring radiotherapy treatments. Further work will be 
done to validate the results in other types of patients who have shown a radiosensitive response.

\subsubsection{Acknowledgements}

The authors thank Colin Malone for his work with the patient database. This project was partially funded by the Ottawa Regional Cancer Foundation. 


\section{The Fluorescent in situ Hybridization Assay Study}

\subsection{Introduction to the fuorescent in situ hybridization (FISH) Study}

This chapter contains the manuscript entitled "Investigating chromosome damage using fluorescent in situ hybridization to identify biomarkers of radiosensitivity in prostate cancer patients", as submitted to the IJROBP (November $19^{\text {th }}, 2012$ ). The manuscript has been edited from the submitted version following revisions requested by examiners at the defense (December $10^{\text {th }}, 2012$ ). The references have been unified for the entire thesis, and are presented at the end of the thesis, in section 7.0 References.

\subsection{Investigating chromosome damage using fluorescent in situ hybridization to} identify biomarkers of radiosensitivity in prostate cancer patients

Authors: Lindsay A. Beaton, M.Sc.(1,2), Leonora Marro, M.Sc.(1), Sara Samiee, M.D.(3), Shawn Malone, M.D.(3), Scott Grimes(3), Kyle Malone(3), Ruth C. Wilkins, Ph.D.(1)

(1) Environmental and Radiation Health Sciences Directorate, Health Canada, 775 Brookfield Rd., Ottawa, ON, Canada

(2) Department of Physics, Carleton University, 1125 Colonel By Dr., Ottawa, ON, Canada

(3) The Ottawa Hospital, Ottawa Hospital Research Institue, University of Ottawa, 501 Smyth Rd., Ottawa, ON, Canada 


\subsubsection{Summary}

This study examined cytogenetic endpoints, as measured using fluorescent in situ hybridization (FISH), in in vitro irradiated whole blood from prostate cancer patients previously treated with external beam radiotherapy and exhibiting late normal tissue damage. These patient samples, previously studied by the authors, were matched by a selection of prostate cancer patients who exhibited no late normal tissue damage. Significant results were found in three endpoints.

\subsubsection{Abstract}

Background and Purpose: Whole chromosome fluorescence in situ hybridization (FISH) allows for the detection and identification of chromosome translocations in metaphase spreads. In order to evaluate FISH as a method for predicting radiosensitivity, this study has examined the incidence of translocations, after exposure to in vitro radiation, in both normally responding patients and those exhibiting late effects after radiotherapy treatment.

Materials and Methods: Patients were selected from a randomized trial evaluating the optimal timing of Dose Escalated Radiation (76 Gy) and short course Androgen Deprivation Therapy for intermediate-risk prostate cancer. Of 438 patients entered on trial with mature follow-up (mean 78 months), 3\% developed grade 3 late proctitis. Blood samples were taken from this radiosensitive cohort (10 patients) along with matched control patients (6 patients) with no late proctitis. Whole blood samples were exposed to 0 or $4 \mathrm{~Gy}$ and cultured according to the IAEA recommended methods. Colour junctions were evaluated in the resulting metaphases by painting chromosomes 1,2 , and 4 in red, 
green and yellow respectively and scoring according to the PAINT system. At least 1000 metaphase spreads, or up to 100 colour junctions per sample were scored.

Results: While both groups were statistically similar at $0 \mathrm{~Gy}$, after an in vitro dose of $4 \mathrm{~Gy}$, the radiosensitive group had significantly higher rates of damage in the number of colour junctions per cell ( $p=0.01$ ), the number of deletions per cell $(p=0.01)$ and the number of dicentrics per cell $(p=0.02)$.

Conclusions: These results confirm previous studies and indicate that the analysis of translocations using FISH after in vitro irradiation correlates with clinical response to radiation. This cytogenetic assay should be considered as a predictor of radiosensitivity.

\subsubsection{Introduction}

The onset of late normal tissue effects after radiotherapy treatments is a limiting factor in current radiotherapy regimes and has significant repercussions for the patient's quality of life [76]. For many years, different endpoints have been studied in an effort to identify reliable biomarkers of individual patient radiosensitivity, with mixed results [33;80;85]. More recently, studies have focused on lymphocyte assays and chromosome damage $[41 ; 43 ; 86]$.

Given that unstable damage induced by a higher dose of in vitro irradiation, such as dicentric chromosomes and excess acentric fragments, has been shown to correlate with the onset of late normal tissue effects [87], further work was done to investigate whether stable damage such as chromosome translocations would also be evidenced after a similar high dose of in vitro irradiation. 
Fluorescence in situ hybridization (FISH), a technique which uses specific probes for the painting of individual chromosomes, allows for the easy visualization and scoring of damage in painted chromosomes of interest in metaphase spreads. These painted chromosomes also allow for the differentiation between stable (translocations, insertions and deletions) and unstable damage (dicentric chromosomes, rings and acentric fragments). A recent study by Huber et al. [88] has shown a significant relationship between translocations after in vitro exposure and the time dependent occurrence of side effects of the skin with patients during the radiotherapy period (acute effects).

This study has examined the incidence of translocations, after exposure to in vitro radiation, in both normally responding patients and those exhibiting late effects after radiotherapy treatment to evaluate FISH as a method for predicting radiosensitivity.

\subsubsection{Methods}

\subsubsection{Patient Selection and Sample Collection}

The patients for this study have participated in previous studies by these authors. As previously described [87], the patients were selected from an on-going phase 3 clinical trial evaluating the optimal timing of Dose Escalated Radiation (76 Gy) and short course Androgen Deprivation Therapy for intermediate-risk prostate cancer (OTT0101, OHREB \#2001014-01H). 10 patients exhibiting Grade 3 late proctitis (as per the RTOG/EORTC Late Toxicity Scale) [58] were identified as radiosensitive (sensitive), and were matched with 20 Grade 0 patients (with no late proctitis) as controls. Of these 20 patients (used in previous studies), 6 were used as controls for this study. The six control patients were selected from the 20 by a combined ranking of their dicentric 
chromosome assay (DCA) results and the number of cells in $\mathrm{M} 2$, as a fraction of the total cells counted (fM2) values: 5 of the patients were chosen from the least responsive results, while the $6^{\text {th }}$ patient was one of the most responsive. The study was approved by The Ottawa Hospital Research Ethics Board and Health Canada's Research Ethics Board and prior to blood collection, all patients gave informed consent to give a venous blood sample.

\subsubsection{Sample Irradiations and Cell Culture}

Blood samples from each patient were drawn into $10 \mathrm{~mL}$ lithium-heparinized vacutainers (BD, Mississauga, $\mathrm{ON}$ ) and blinded before being sent to the radiobiology laboratory at Health Canada. On arrival, $1.7 \mathrm{~mL}$ of whole blood was aliquoted into two sterilized cryogenic vials (Corning Life Sciences, Lowell MA); a 4 Gy sample and control ( 0 Gy). The 4 Gy sample was irradiated on its side, at room temperature (RT) in a cabinet X-ray (X-RAD320, Precision X-ray, North Branford CT). The irradiation conditions were $250 \mathrm{kV}, 12.5 \mathrm{~mA}$, with a $2 \mathrm{~mm} \mathrm{Al} \mathrm{filter} \mathrm{resulting} \mathrm{in} \mathrm{a} \mathrm{dose} \mathrm{rate} \mathrm{of} 1.7$ $\mathrm{Gy} / \mathrm{min}$ at $50 \mathrm{~cm}$ from the source, as measured using a Radcal 9010 ion chamber (Radcal, Monrovia CA) calibrated at the National Research Council, Ottawa, ON $\left(\mathrm{N}_{\mathrm{K}}=0.992\right.$ Gy/Gy reading at $250 \mathrm{kV}$, assuming air kerma to be equal to dose). Post irradiation, blood samples were incubated at $37^{\circ} \mathrm{C}$ on a rocker for $2 \mathrm{~h}$ prior to culturing.

After incubation, blood was cultured following IAEA recommended methods [65]. Briefly, $1.5 \mathrm{~mL}$ of blood was transferred into the T25 vented culture flasks (VWR, Mississauga, ON) containing $13.5 \mathrm{~mL}$ RPMI 1640 media (Invitrogen, Burlington ON) supplemented with $1 \%$ L-Glutamine pen-strep (Sigma-Aldrich, Oakville ON, 100x), 15\% 
inactivated FBS (Sigma-Aldrich) and 2\% PHA (Invitrogen). The flasks were incubated in a $5 \% \mathrm{CO}_{2}, 37^{\circ} \mathrm{C}$ incubator. $150 \mu \mathrm{L}$ Colcemid (Invitrogen, $10 \mu \mathrm{g} / \mathrm{mL}$ ) was added to the samples at $40 \mathrm{~h}$, and the samples were incubated for another $4 \mathrm{~h}$. The incubation time was reduced from the IAEA methods of $48 \mathrm{~h}$ to $44 \mathrm{~h}$ to reduce the number of cells in second metaphase.

At $44 \mathrm{~h}$, the suspensions were transferred to $15 \mathrm{~mL}$ polypropylene tubes, centrifuged at $200 \mathrm{~g}$ for 8 minutes and the pellet was resuspended in hypotonic $0.075 \mathrm{M}$ $\mathrm{KCl}$ solution at $\mathrm{RT}$ and incubated for 12 minutes. Samples were subsequently fixed and washed repeatedly with $3: 1$ methanol/acetic acid and placed in a $-20^{\circ} \mathrm{C}$ freezer for a minimum of 30 minutes prior to slide preparation

\subsubsection{Slide preparation and staining}

Staining was carried out according to the standard protocol provided by the manufacturer of the probes (Cytocell 1,2,4 Direct Probe, Rainbow Scientific; Windsor CT). The following probes were used: chromosome 1 with (Texas Red spectrum, red signal), chromosome 2 (FITC spectrum, green signal) and chromosome 4 (Texas Red and FITC spectra, resulting in a yellow signal).

Fixed samples were washed twice with fresh Carnoy's fixative ( 3 methanol: 1 acetic acid at RT) and the pellet resuspended. $15 \mu \mathrm{L}$ of cell suspension was dropped on each slide and slides were checked for adequate chromosome spreading.

The slides were soaked in 2x saline-sodium citrate (SSC) buffer (Sigma-Aldrich, $\mathrm{pH} 7.0)$ for 2 minutes, and then dehydrated in a series of ethanol baths $(70 \%, 80 \%$ and $100 \%$ ), each for 2 minutes. $20 \mu \mathrm{L}$ of probe (warmed to RT) was placed on the slide, 
ensuring good coverage, and coverslipped with a $20 \times 24 \mathrm{~mm}$ glass coverslip. The edges of the coverslip were sealed with rubber solution glue and allowed to dry completely. To denature the DNA, the slides were placed in a thermocycler, which heated them to $75^{\circ} \mathrm{C}$ for 2 minutes, and then hybridised at $37^{\circ} \mathrm{C}$ for $24 \mathrm{~h}$.

Post-hybridization, the glue and coverslips were carefully removed and the slides washed in $0.4 \times$ SSC buffer (Sigma-Aldrich, $\mathrm{pH} \mathrm{7.0)}$ at $72^{\circ} \mathrm{C}$ for 2 minutes. The slides were drained and washed in $2 x$ SSC, $0.05 \%$ Tween-20 (Sigma-Aldrich, pH 7.0) at RT for 30 seconds. Again the slides were drained and $20 \mu \mathrm{L}$ of DAPI (4,6-diamidino-2phenylindole) antifade (Cytocell) was applied as a counterstain. The slides were coverslipped and the edges sealed with clear nail polish, and allowed to develop in the dark for 10 minutes.

\subsubsection{Scoring}

The slides were visualized under fluorescence microscopy on a Metafer Slide

Scanning System (Metasystems Group Inc., Watertown MA). For the 0 Gy samples, a minimum of 1000 spreads were scored, while for the 4 Gy samples, a minimum of 100 colour junctions were scored. Spreads were scored for colour junctions, and types of damage including stable (deletions, inversions, insertions) and unstable (dicentrics, rings, acentric fragments) damage involving chromosomes 1,2 and or 4 according to the PAINT system devised by Tucker et al. [89].

Due to the complexity of the damage in the 4 Gy samples, the scoring was kept as simple as possible to maintain a consistent and repeatable result. To that end, the scoring 
method is clarified below and figure 4-1 illustrates examples of how the spreads were scored.
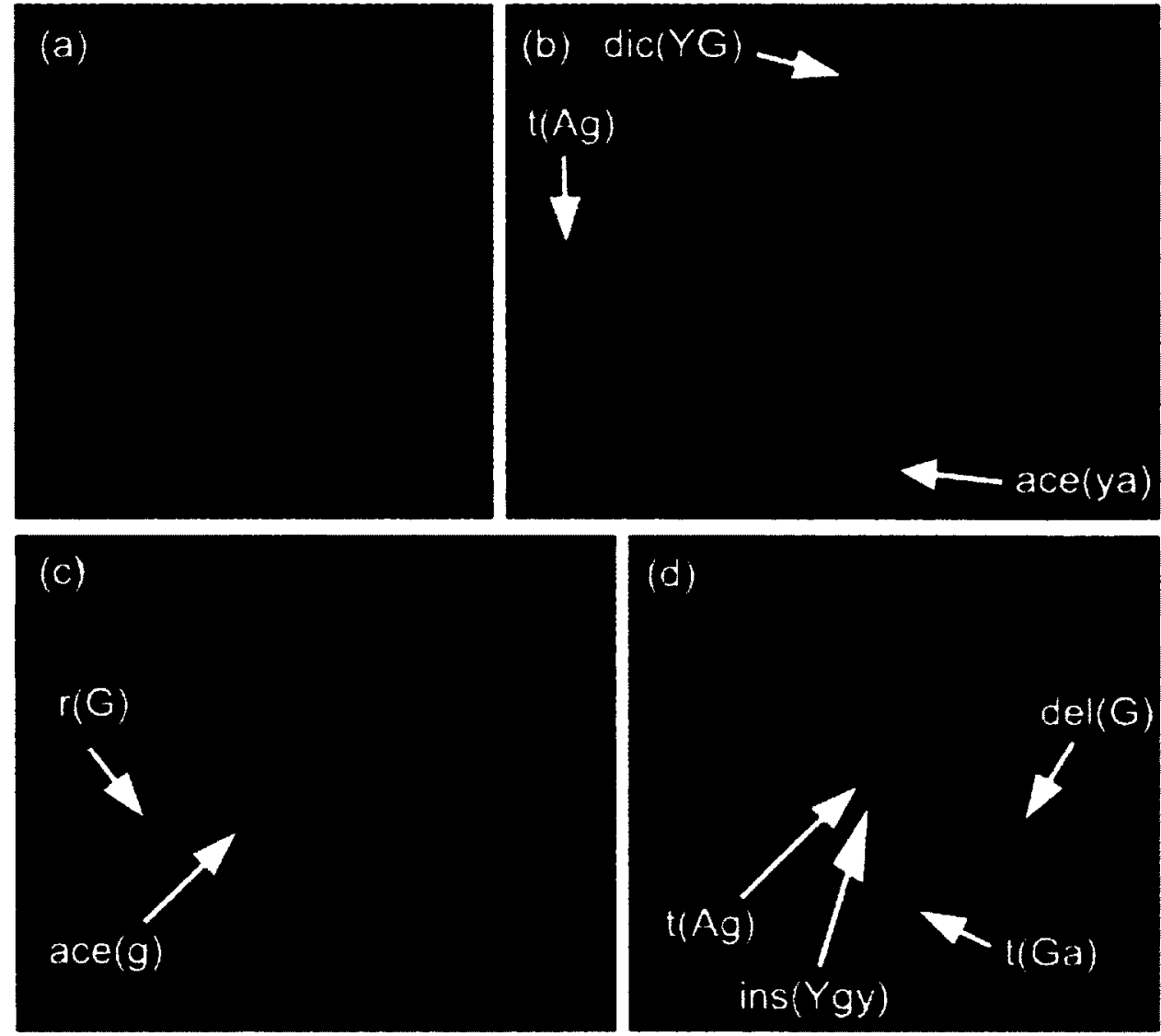

Figure 4-1: Examples of metaphase spreads stained for chromosome 1 (red), 2 (green) and 4 (yellow) with (a) no damage, (b) a dicentric (dic(YG)), an acentric fragment(ace(ya)) and a translocation(t( $\mathrm{Ag}))$, (c) a centric ring(r(G)) and an acentric fragment(ace(g)), and (d) an insertion(ins(Ygy)), a deletion(del(G)), and a reciprocal translocation(t( $\mathrm{Ag})$ and $\mathrm{t}(\mathrm{Ga})$ ). Separating the damage by chromosome, (a) no damage, (b) 1 yellow, 1 green, (c) 1 green and (d) 1 yellow and 2 green. Spreads were captured at 1000x magnification on a Metafer Slide Scanning System (Metasystems Group Inc., Watertown MA) 
A colour junction was scored for any visible junction between two different colours. Only in cases where it was explicitly clear, for instance, a dicentric consisting of both chromosome 1 (RR), was a colour junction counted. Deletions were scored if one of the sister chromosomes was noticeably shorter than the other, or else if there was visible damage and no other source. An inversion was scored if the centromere was clearly identifiable and the p- or q- arms were significantly longer than the chromosome's homologue. Dicentrics were scored as long as part of the dicentric had painted chromosome content. Dicentrics involving two chromosomes of the same colour, for example $R R$, or $R R a$, were scored as a colour junction since it was a clear junction between two chromosomes. An insertion was scored only if it involved a centromere and associated acentric fragment, interrupted by a chromosome of a different colour, for example, Gag, Aga or even YAy. Situations such as gAg or aRa were not counted as insertions. Any acentric fragment with coloured content was counted as an acentric fragment. There was no distinction between a fragment and a "dot". If a spread looked otherwise normal but had a coloured fragment, a deletion was assumed for a corresponding colour, though only in the case of no other obvious source of damage. Finally, damage was also sorted by colour (red, green or yellow, representing chromosomes 1, 2 and 4 respectively). A piece of colour was matched with at least one coloured centromere, to determine how many times a double strand break formed in that particular chromosome. 


\subsubsection{Statistics}

Blood samples from the two cohorts (sensitive and control) were investigated for the following endpoints (per cell) of interest: colour junctions, deletions, insertions, inversions, dicentrics, rings, acentric fragments, and also damage in each of chromosomes 1, 2 and 4. A Poisson regression model was used to determine if there was a difference in rates of aberrations between the two cohorts at $4 \mathrm{~Gy}$, after controlling for background rates (at $0 \mathrm{~Gy}$ ). Background rates of aberrations were used as a covariate in the Poisson regression model to control for any aberrations already present in each individual's blood sample as a result of the patients' previous radiotherapy course. Since two of the individuals from the radio-sensitive status group did not have background rates recorded, a sensitivity analysis was carried out: 1) eliminating their results at the $4 \mathrm{~Gy}$ dose group and 2) imputing their background rate with the average background rate of individuals in the same status group. In this second analysis, degrees of freedom were adjusted to reflect that two observations were imputed. The sensitivity analysis was included to determine the effect of these two individuals on the results, as it is always better to retain information than to eliminate it.

\subsubsection{Results}

As mentioned above, two of the sensitive patients had missing background rates. The results of the sensitivity analysis were comparable; therefore the missing background rates were replaced with the average background rate of their cohort. Table 4-1 presents the results from the Poisson regression model for each of the endpoints listed above. 
Columns 2 and 3 of table 4-1 present the mean and standard deviation, after $4 \mathrm{~Gy}$, of the sensitive and control cohorts.

The data comparing the spread of each cohort as dose versus aberration rate, is presented in figures 4-2 (colour junctions per cell), 4-3 (stable damage per cell), 4-4 (unstable damage per cell) and 4-5 (chromosome damage per cell). 
Table 4-1: Poisson regression analysis results comparing the sensitive and control cohorts for multiple endpoints (per cell) after $4 \mathrm{~Gy}$ in vitro irradiation. The coefficient for the background rate $\beta$ (with standard error (SE)) is an assessment of the correlation between aberrations at $4 \mathrm{~Gy}$ and the background rate. Endpoints were considered to be significant at the 0.05 level and marked with an *.

\begin{tabular}{|c|c|c|c|c|}
\hline & $\begin{array}{c}\text { Sensitive } \\
\text { Population }\end{array}$ & $\begin{array}{c}\text { Control } \\
\text { Population }\end{array}$ & & \\
\hline & $\begin{array}{l}\text { Mean } \\
\text { (SD) }\end{array}$ & $\begin{array}{c}\text { Mean } \\
(\text { SD) }\end{array}$ & $\begin{array}{c}\beta(S E) \text { of } \\
\text { background } \\
\text { rate }\end{array}$ & $\begin{array}{c}F_{(1,11)} \\
\text { (p-value) }\end{array}$ \\
\hline $\begin{array}{l}\text { Colour } \\
\text { Junction }\end{array}$ & $\begin{array}{c}2.4 \\
(0.4) \\
\end{array}$ & $\begin{array}{c}1.9 \\
(0.2)\end{array}$ & $\begin{array}{c}2.1 \\
(1.8)\end{array}$ & $\begin{array}{c}9.62 \\
(0.01)^{*}\end{array}$ \\
\hline \multicolumn{5}{|c|}{ Stable Damage } \\
\hline Deletions & $\begin{array}{c}0.24 \\
(0.06)\end{array}$ & $\begin{array}{c}0.34 \\
(0.05)\end{array}$ & $\begin{array}{l}-26.3 \\
(26.4)\end{array}$ & $\begin{array}{c}9.67 \\
(0.01)^{*}\end{array}$ \\
\hline Insertions & $\begin{array}{c}0.05 \\
(0.03) \\
\end{array}$ & $\begin{array}{c}0.03 \\
(0.03) \\
\end{array}$ & $\begin{array}{r}192 \\
(412) \\
\end{array}$ & $\begin{array}{c}0.7 \\
(0.4) \\
\end{array}$ \\
\hline Inversions & $\begin{array}{c}0.01 \\
(0.01) \\
\end{array}$ & $\begin{array}{r}0.006 \\
(0.009) \\
\end{array}$ & $\begin{array}{c}259 \\
(1099) \\
\end{array}$ & $\begin{array}{c}0.1 \\
(0.8) \\
\end{array}$ \\
\hline \multicolumn{5}{|c|}{ Unstable Damage } \\
\hline Dicentrics & $\begin{array}{c}0.4 \\
(0.1)\end{array}$ & $\begin{array}{c}0.36 \\
(0.06)\end{array}$ & $\begin{array}{c}43.5 \\
(43.9)\end{array}$ & $\begin{array}{c}7.40 \\
(0.02)^{*}\end{array}$ \\
\hline Rings & $\begin{array}{c}0.03 \\
(0.02) \\
\end{array}$ & $\begin{array}{c}0.01 \\
(0.01) \\
\end{array}$ & $\begin{array}{c}-3837 \\
(1930) \\
\end{array}$ & $\begin{array}{c}2.0 \\
(0.2) \\
\end{array}$ \\
\hline Acentrics & $\begin{array}{c}0.8 \\
(0.2)\end{array}$ & $\begin{array}{c}0.65 \\
(0.09)\end{array}$ & $\begin{array}{c}-2.8 \\
(14.1)\end{array}$ & $\begin{array}{c}4.14 \\
(0.07)\end{array}$ \\
\hline \multicolumn{5}{|c|}{ Individual Chromosomes } \\
\hline Chr. 1 & $\begin{array}{r}0.7 \\
(0.1) \\
\end{array}$ & $\begin{array}{c}0.6 \\
(0.2) \\
\end{array}$ & $\begin{array}{l}24.9 \\
(9.6) \\
\end{array}$ & $\begin{array}{c}4.46 \\
(0.06) \\
\end{array}$ \\
\hline Chr. 2 & $\begin{array}{c}0.6 \\
(0.2) \\
\end{array}$ & $\begin{array}{c}0.49 \\
(0.05) \\
\end{array}$ & $\begin{array}{c}6.4 \\
(11.2)\end{array}$ & $\begin{array}{c}4.20 \\
(0.07) \\
\end{array}$ \\
\hline Chr. 4 & $\begin{array}{c}0.4 \\
(0.1)\end{array}$ & $\begin{array}{c}0.47 \\
(0.08)\end{array}$ & $\begin{array}{c}-3.1 \\
(10.7)\end{array}$ & $\begin{array}{c}0.4 \\
(0.5)\end{array}$ \\
\hline
\end{tabular}




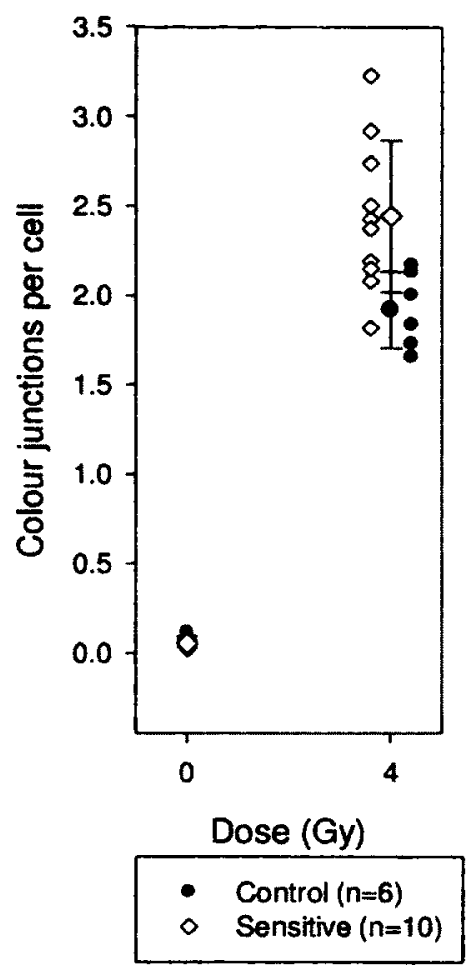

Figure 4-2: Plot illustrating the spread and mean (with standard deviation) of colour junctions per cell for unirradiated and 4 Gy samples in both sensitive (open diamond) and control (closed circle) cohorts. 

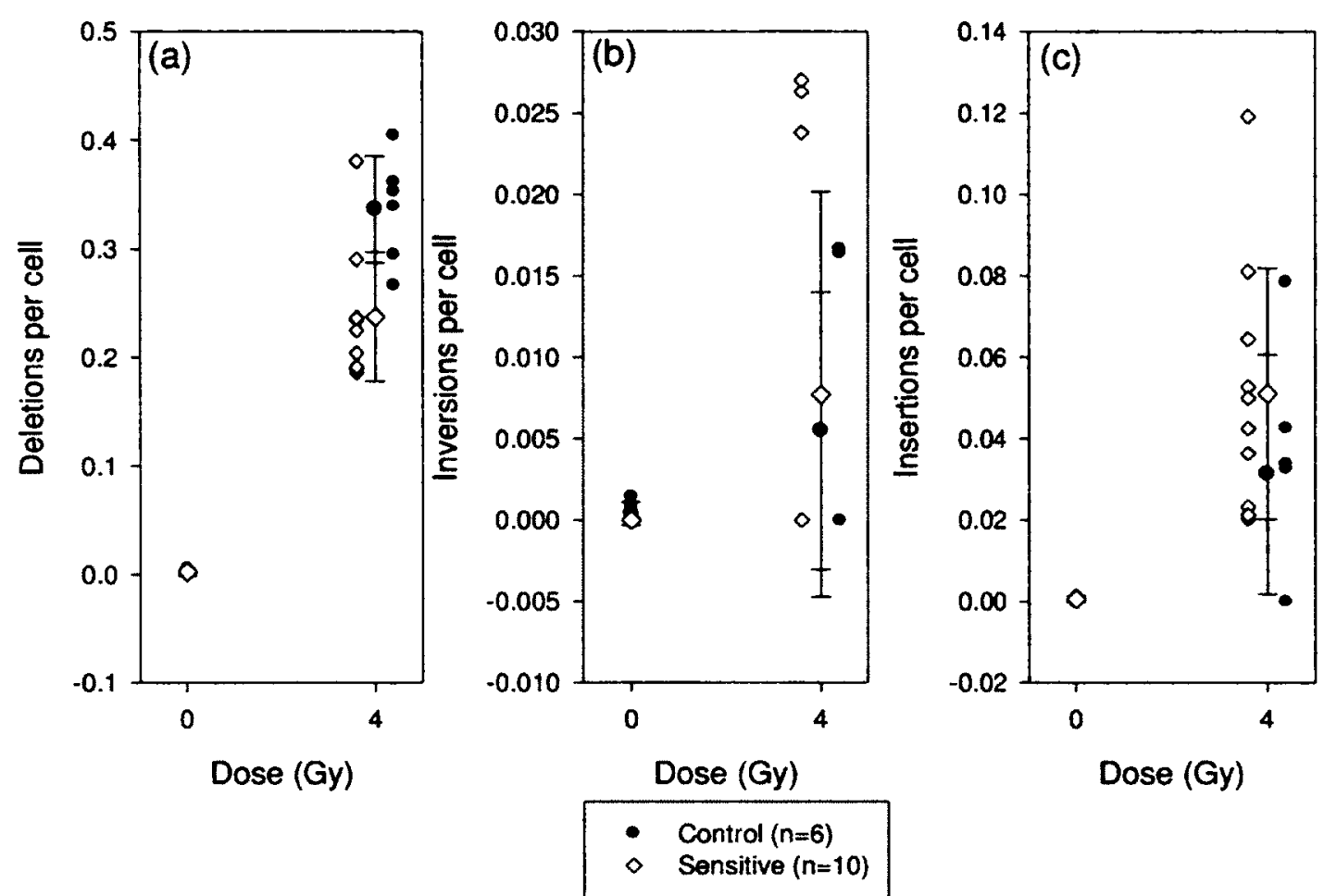

Figure 4-3: Plots illustrating the spread and mean (with standard deviation) of stable damage in both the sensitive (open diamond) and control (closed circle) cohorts. Stable damage is divided into (a) deletions, (b) inversions and (c) insertions. 

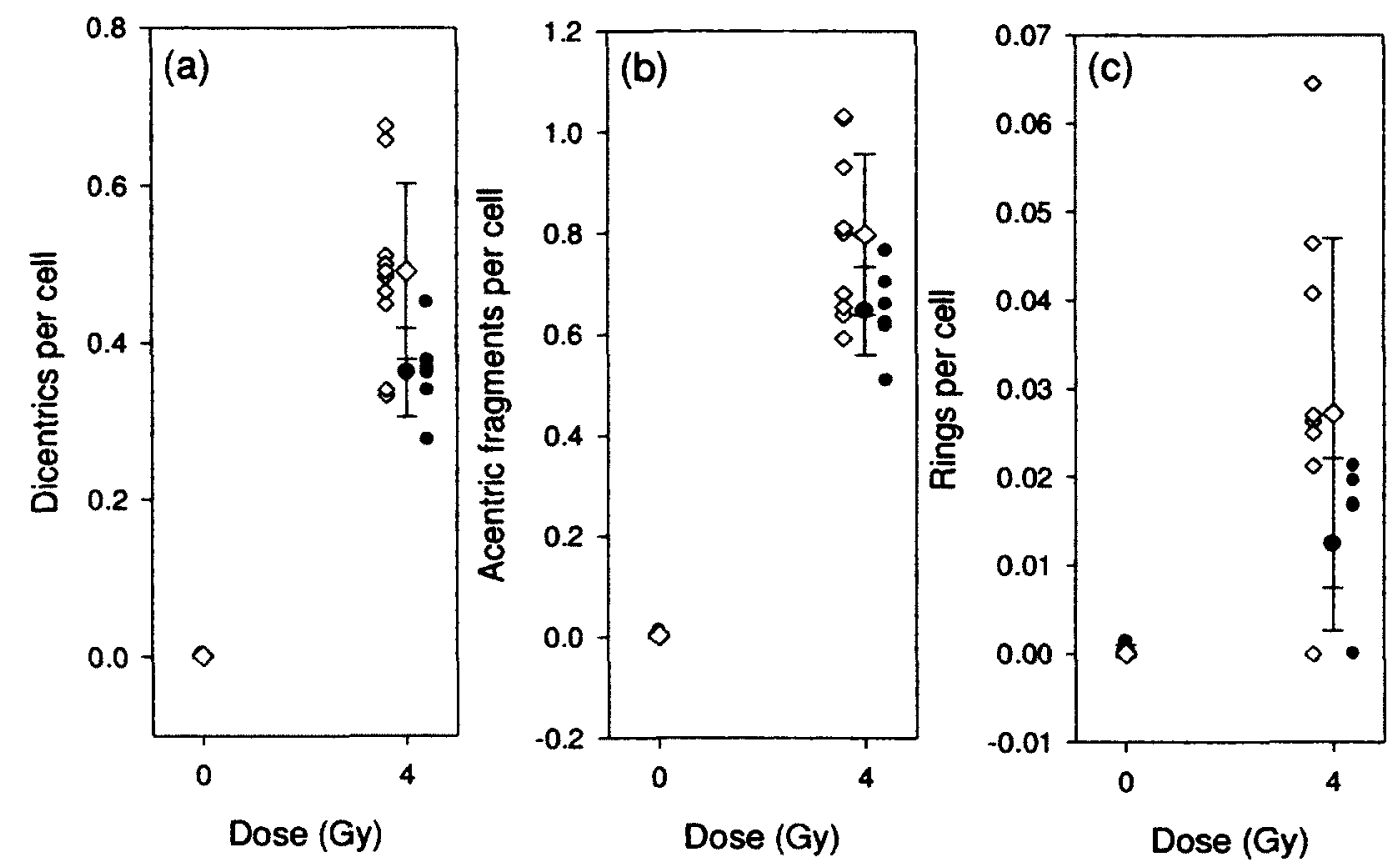

- Control $(n=6)$

- Sensitive $(n=10)$

Figure 4-4: Plots illustrating the spread and mean (with standard deviation) of unstable damage in both the sensitive (open diamond) and control (closed circle) cohorts. Unstable damage is divided into (a) dicentrics, (b) acentric fragments and (c) rings. 

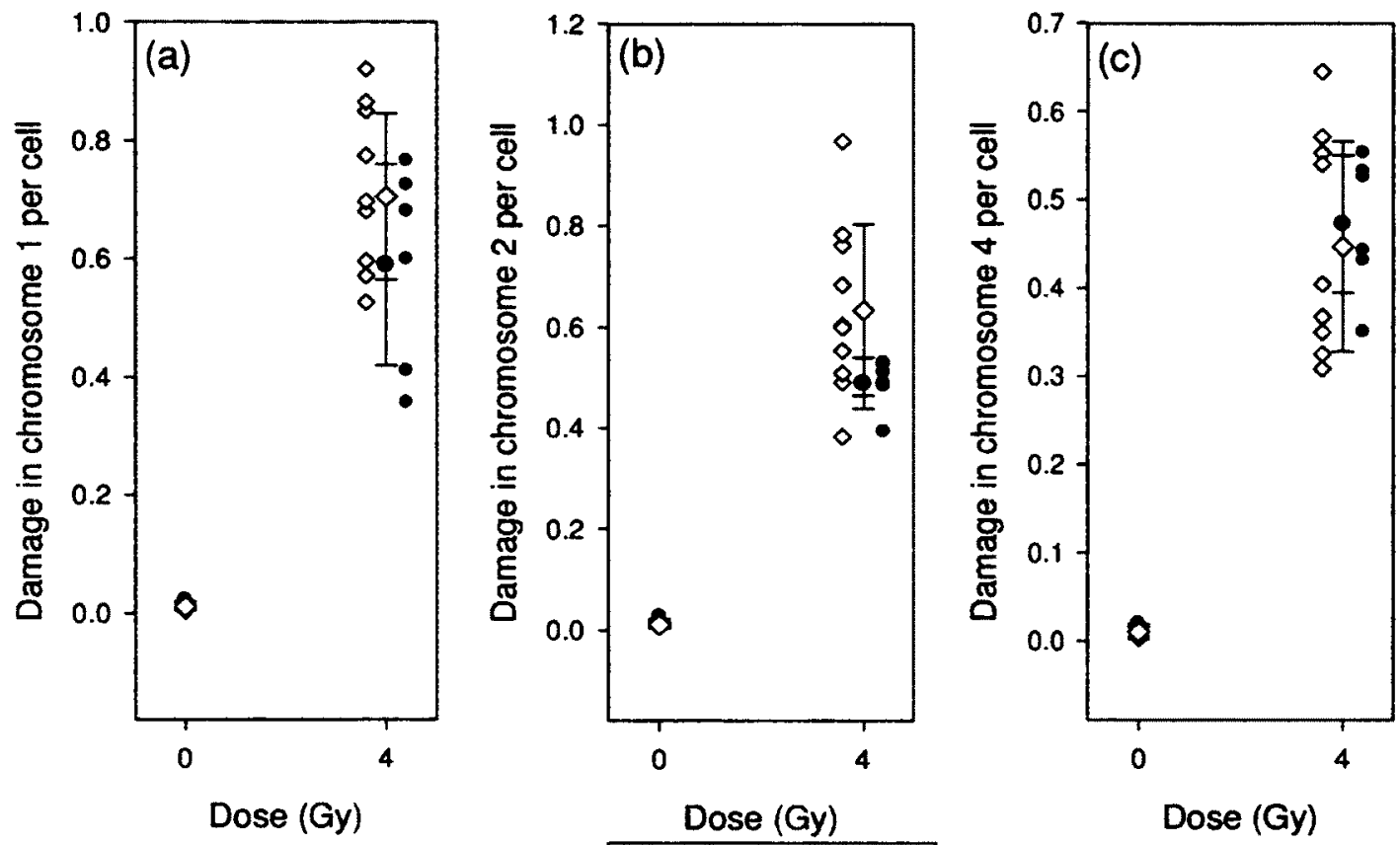

- Control $(n=6)$

- Sensitive $(n=10)$

Figure 4-5: Plots illustrating the spread and mean (with standard deviation) of damage as scored per (a) chromosome 1 (b) chromosome 2 and (c) chromosome 4, in both the sensitive (open diamond) and control (closed square) cohorts.

As previously mentioned, the background rate was used in the analysis as a covariate to control for each patient's rate of aberrations prior to further radiation exposure at $4 \mathrm{~Gy}$. Therefore the coefficient for the background rate $(\beta)$ in table $4-1$ (column 4) can be interpreted as an assessment of the correlation between aberrations at the high dose ( $4 \mathrm{~Gy}$ ) and background rate. The background rate was marginally significant in only one endpoint, damage in chromosome 1 per cell, indicating that higher 
background rates led to higher rates of damage in chromosome 1 at $4 \mathrm{~Gy}$, regardless of sensitivity. For all other endpoints there was no significant correlation between rates of aberration at the high dose and background rate. Note that a Poisson regression model was used to also compare the background rates of aberrations (for each endpoint) between the sensitive and control cohorts: no statistical difference was observed between the background rates (for each endpoint) between the two groups ( $p>0.05$, results not shown).

Comparing the rates of aberrations between the two cohorts (at the high dose), significant differences were observed for the following endpoints: colour junctions per cell $(p=0.01)$, deletions per cell $(p=0.01)$, and dicentrics per cell $(p=0.02)$. In the case of colour junctions and dicentrics per cell, rates were lower among the control patients as compared to sensitive patients. Conversely, rates of deletions per cell were significantly higher among control patients as compared to sensitive patients.

\subsubsection{Discussion}

The purpose of this study was to further investigate the incidence of chromosomal damage in in vitro irradiated lymphocytes from a cohort of prostate cancer patients identified as radiosensitive. Previous work with these patients [87] had identified a correlation between unstable chromosome damage and the occurrence of late normal tissue side effects. Further work, using FISH, was pursued to investigate translocations and other chromosome damage endpoints (both stable and unstable). Despite the difficulty in scoring FISH spreads at high radiation doses (due to more complex damage), previous results from this patient cohort demonstrated the value of evaluating damage 
after a high in vitro dose (4 Gy) when seeking a radiosensitive biomarker. Huber et al. [88], working with $3 \mathrm{~Gy}$ in vitro irradiated samples found some correlations between translocations and acute radiation side effects.

By only painting 3 chromosome pairs (chromosomes 1,2 and 4), the count is limited, but chromosome 1,2 and 4 make up $8.02,7.62$ and $6.23 \%$ of the human genome respectively [71] allowing $21.87 \%$ of the genome to be assessed. Painting more chromosomes would provide more information but could also render analysis too complex to interpret.

Furthermore, ideally only chromosomes in first metaphase should be analysed. Although no indicator of multiple cell cycles was included, incubation time was short enough that most cells would be in first metaphase.

There are several approaches to scoring translocations using FISH probes. Classical scoring methods assume reciprocal translocations, where $t(\mathrm{Ab})$ and $t(\mathrm{Ba})$ make up 1 event. Tucker et al. [89] introduced the PAINT scoring system which does not assume reciprocal translocations. For example, exchanges that are reciprocal are scored as 2 events and a non-reciprocal translocation is scored as 1 event. Since the scoring at high doses is complicated, the PAINT system was used, and events were scored as "colour junctions".

Using this scoring system, three endpoints, colour junctions, deletions and dicentrics per cell, were found to be significant $(p=0.01,0.01,0.02$, respectively). While the mean number of colour junctions and dicentrics per cell were higher in the sensitive cohort as compared to the control, it was interesting to note that the mean number of deletions per cell was found to be lower in the sensitive cohort as compared to control. 
Further investigations would be required to understand the mechanisms behind this process.

Three endpoints, acentric fragments per cell, damage in chromosome 1, and damage in chromosome 2 per cell, had marginally non-significant results $(p=0.07,0.06$, 0.07 , respectively). There were two issues that needed to be considered when evaluating the results from this analysis: sample size, and variability among the sensitive cohort. The sample size in this study was small (6 control and 10 sensitive individuals). With the smaller sample size, the power of the test was decreased because the false negative rate was increased. This led to the second issue; the variability among the status groups. In this study variability at the high dose was large especially among the sensitive individuals. With marginal results, one needs to consider, if these endpoints truly do differ between the two groups or not. The best way to answer this question would be to increase sample size, that is the number of individuals in the study, and not the number of cells scored. Clearly, data from larger cohorts of patients would provide increased statistical power. As well, it is worth further investigating different patient cohorts to determine if these findings can be generalized to patients undergoing radiotherapy for different tumour types.

In conclusion, with 3 endpoints considered to be significant, the analysis of translocations using FISH after in vitro irradiation correlates with clinical response to radiation. This cytogenetic assay should be considered as a predictor of radiosensitivity. 


\section{The $\gamma \mathrm{H} 2 \mathrm{AX}$ Study}

\subsection{Introduction to the $\gamma \mathrm{H} 2 \mathrm{AX}$ study}

This chapter contains the manuscript entitled "Investigating $\gamma H 2 A X$ as a biomarker of radiation sensitivity using flow cytometry methods", as submitted to Radiology Research and Practice (November $4^{\text {th }}, 2012$ ). The manuscript has been edited from the submitted version following revisions requested by examiners at the defense (December $10^{\text {th }}, 2012$ ). The references have been unified for the entire thesis, and are presented at the end of the thesis, in section 7.0 References.

\subsection{Investigating $\gamma \mathrm{H} 2 \mathrm{AX}$ as a biomarker of radiation sensitivity using flow} cytometry methods

Authors: Lindsay A. Beaton(1), Leonora Marro(1), Shawn Malone(2), Sara Samiee(2), Scott Grimes(2), Kyle Malone(2), Ruth C. Wilkins(1)

(1) Environmental and Radiation Health Sciences Directorate, Health Canada, 775 Brookfield Rd. Postal Locator 6303B, Ottawa, ON, Canada

(2) Department of Physics, Carleton University, 1125 Colonel By Dr., Ottawa, ON, Canada

(3) The Ottawa Hospital, Ottawa Hospital Research Institute, University of Ottawa, 501 Smyth Rd., Ottawa, ON, Canada 


\subsubsection{Abstract}

Background and Purpose: This project examined the in vitro $y \mathrm{H} 2 \mathrm{AX}$ response in lymphocytes of prostate cancer patients who had a radiosensitive response after receiving radiotherapy. The goal of this project was to determine whether the $\gamma \mathrm{H} 2 \mathrm{AX}$ response, as measured by flow cytometry, could be used as a marker for radiosensitivity.

Material and Methods: Patients were selected from a randomized clinical trial evaluating the optimal timing of Dose Escalated Radiation and short course Androgen Deprivation Therapy. Of 438 patients, $3 \%$ developed Grade 3 late radiation proctitis and were considered to be radiosensitive. Blood was drawn from 10 of these patients along with 20 matched samples from patients with grade 0 proctitis. Dose response curves up to 10 Gy along with time response curves after $2 \mathrm{~Gy}(0-24 \mathrm{~h})$ were generated for each sample. The $\gamma \mathrm{H} 2 \mathrm{AX}$ response in lymphocytes and lymphocyte subsets was analyzed by flow cytometry.

Results: There were no significant differences between the sensitive and control samples for either the dose course or the time course.

Conclusions: Although $\gamma \mathrm{H} 2 \mathrm{AX}$ response has previously been demonstrated to be an indicator of radiosensitivity, flow cytometry lacks the sensitivity necessary to distinguish any differences between samples from control and radiosensitive patients. 


\subsubsection{Introduction}

The induction and repair of chromosomal damage in irradiated lymphocytes is thought to be a promising predictor of patient sensitivity to ionizing radiation [90]. Since DNA double strand breaks (DSB) are considered to be the critical lesion for DNA damage, the lack of repair, or misrepair, can have severe repercussions. As such, it is important to be able to quantitate the induction and disappearance of DSBs.

Rogakou et al. [24] showed that $\mathrm{H} 2 \mathrm{AX}$ (an electrophoretic isoform of the histone $\mathrm{H} 2 \mathrm{~A})$ is phosphorylated $(\gamma \mathrm{H} 2 \mathrm{AX})$ at the sites of DSBs, and Sedelnikova et al. [90] demonstrated that $\gamma \mathrm{H} 2 \mathrm{AX}$ foci corresponded one to one with DSBs. These results mean that the number of DSBs induced can be measured by counting the number of $\gamma \mathrm{H} 2 \mathrm{AX}$ foci [90]. Furthermore, by staining $\gamma \mathrm{H} 2 \mathrm{AX}$ with a fluorochrome-labelled antibody, these individual foci can be visualized and enumerated by microscopy (spot counting) which is a sensitive but time consuming method. Alternatively, flow cytometry can measure the emitted fluorescence from the $\gamma \mathrm{H} 2 \mathrm{AX}$ foci, which is a less sensitive method however one that provides good population statistics.

In 2004, Olive et al. [73] proposed that the expression of $\gamma \mathrm{H} 2 \mathrm{AX}$, as measured by flow cytometry, could be used as an indicator of tissue radiosensitivity. Rübe et al. [91] studied the $\gamma \mathrm{H} 2 \mathrm{AX}$ response in mice and found that even minor impairments in DSB repair lead to excessive DNA damage accumulation during fractionated irradiation and concluded that this may have a significant impact on normal tissue response in clinical radiotherapy. In addition to induction of repair as a potential indicator, Menegakis et al. [92] investigated residual $\gamma \mathrm{H} 2 \mathrm{AX}$ foci as potential indicators of clonogenic cells and found that after 24 hours, residual $\gamma \mathrm{H} 2 \mathrm{AX}$ foci correlated with clonogenic survival. 
Chua et al. [43] performed a study comparing the efficiency of DSB repair and chromosomal radiosensitivity in ex vivo irradiated blood lymphocytes between sensitive and control patients and found that residual foci measured $24 \mathrm{~h}$ after $4 \mathrm{~Gy}$ were significantly higher in patients considered to be sensitive as compared to controls.

A study by Andrievski et al. [93] noted that lymphocyte subsets CD4, CD8 and $\mathrm{CD} 19$ had varied $\gamma \mathrm{H} 2 \mathrm{AX}$ responses, and proposed that investigating the in vitro response in lymphocyte subsets, CD19 in particular, might prove to be a more sensitive assay.

The goal of this project was to analyze the induction and residual in vitro $\gamma \mathrm{H} 2 \mathrm{AX}$ response in lymphocytes and lymphocyte subsets of patient classified as sensitive or nonsensitive (control) to radiation in order to determine if the lymphocytes or lymphocyte subsets yielded a more sensitive indication of radiation response.

\subsubsection{Materials and Methods}

\subsubsection{Patient Selection and Sample Collection}

Patients for this study were selected from an on-going phase 3 clinical trial (OTT0101, OHREB \#2001014-01H) evaluating the optimal sequencing of radiation and 6 months hormonal therapy in cT1-cT3 prostate cancer (as described previously in Beaton et al. [87]). Briefly, based on the RTOG/EORTC Late Toxicity Scale [58], 10 patients who were identified with Grade 3 late proctitis (sensitive) were matched with 20 Grade 0 patients (control). Table 5-1 (also published in [87]), provides a summary of the patients' clinical characteristics. These patients gave informed consent to give a venous blood sample. The study was approved by The Ottawa Hospital Research Ethics Board and Health Canada's Research Ethics Board. 
Table 5-1: Clinical features of control and radiosensitive groups (same as Table 3-1)

\begin{tabular}{ccccccc}
\hline $\begin{array}{c}\text { Clinical } \\
\text { Group }\end{array}$ & $\begin{array}{c}\text { Age at } \\
\text { diagnosis } \\
\text { (mean and } \\
\text { range) }\end{array}$ & $\begin{array}{c}\text { Pre-Existing } \\
\text { Cardiovascular } \\
\text { Disease/ } \\
\text { Hypertension }\end{array}$ & $\begin{array}{c}\text { Pre- } \\
\text { existing } \\
\text { Type II } \\
\text { Diabetes }\end{array}$ & $\begin{array}{c}\text { Smoker/ } \\
\text { Ex- } \\
\text { Smoker }\end{array}$ & $\begin{array}{c}\text { Mean follow } \\
\text { up time post- } \\
\text { treatment } \\
\text { (years) }\end{array}$ & $\begin{array}{c}\text { Mean } \\
\text { time to } \\
\text { onset of } \\
\text { grade 3 } \\
\text { proctitis } \\
\text { (range) }\end{array}$ \\
\hline Control & $69(60-77)$ & $8 / 20$ & $3 / 20$ & $8 / 20$ & 6 & N/A \\
\hline Sensitive & $73(68-76)$ & $6 / 10$ & $1 / 10$ & $4 / 10$ & 7 & $\begin{array}{c}21 \\
\text { months } \\
\text { (9-41 } \\
\text { months) }\end{array}$ \\
\hline
\end{tabular}

The blood samples, drawn in lithium-heparin tubes (Becton, Dickinson and Co (BD), Mississauga ON), were cultured 1:10 with sterile $15 \%$ complete media (86\% RPMI 1640 (Invitrogen, Burlington ON), 15\% FBS (Sigma-Aldrich, Oakville ON), $1 \% 2 \mathrm{mM}$ L-glutamine (Sigma-Aldrich, 100x)) and kept in a $25 \mathrm{~cm}^{2}$ vented culture flask (VWR, Mississauga, ON). From the culture flask, the blood in media suspension was aliquoted into 19 samples of $1 \mathrm{~mL}$ into $5 \mathrm{~mL}$ flow tubes (BD) and placed on ice. These 19 samples included 6 dose points, 1 unstained control, 3 single colour controls, 1 negative $\gamma \mathrm{H} 2 \mathrm{AX}$ colour control, 1 positive $\gamma \mathrm{H} 2 \mathrm{AX}$ colour control, and 7 Full Minus One (FMO) controls. At least $1 \mathrm{~mL}$ of blood was left in the lithium-heparin tube on a rocker to be used for the time course experiments. Of this $1 \mathrm{~mL}, 100 \mu \mathrm{L}$ was removed and added to $900 \mu \mathrm{L}$ complete media before each of 7 time point samples were irradiated. 


\subsubsection{Irradiation}

The blood samples were irradiated upright, on ice, in a cabinet $X$-ray (XRAD320, Precision X-ray, North Branford CT) at $250 \mathrm{kV}, 12.5 \mathrm{~mA}$, with a $2 \mathrm{~mm} \mathrm{Al}$ filter and $50 \mathrm{~cm}$ from the source. The dose rate was $1.7 \mathrm{~Gy} / \mathrm{min}$ calibrated using a Radcal 9010 ion chamber (Radcal, Monrovia CA) calibrated at $\mathrm{NRC}\left(\mathrm{N}_{\mathrm{K}}=0.992 \mathrm{~Gy} / \mathrm{Gy} \mathrm{y}_{\text {reading }}\right.$ at $250 \mathrm{kV}$, assuming air kerma to be equal to dose). The dose course samples received the following doses; $0,2,4,6,8,10 \mathrm{~Gy}$. The unstained, single colour, negative $\gamma \mathrm{H} 2 \mathrm{AX}$ and negative FMO controls remained unirradiated. The positive $\gamma \mathrm{H} 2 \mathrm{AX}$ and positive FMO controls were exposed to $10 \mathrm{~Gy}$. After irradiation, the samples were left to stand in a water bath at $37^{\circ} \mathrm{C}$, tightly capped, for 1 hour. The time course samples received $2 \mathrm{~Gy}$ each, and were place in a $37^{\circ} \mathrm{C}$ incubator, loosely capped for the following incubation times: $0,0.5,1,2,4,8,24 \mathrm{~h}$, with irradiations being staggered such that all time course samples were processed simultaneously.

\subsubsection{Fixing and Permeabilizing}

After incubation, the samples were fixed and permeabilized using a modified method from Chow et al. [94]. The samples were cold $\left(0^{\circ} \mathrm{C}\right)$ centrifuged for 8 minutes at $300 \mathrm{~g}$. The supernatant was aspirated and the pellet resuspended. $65 \mu \mathrm{L}$ of $10 \%$ formaldehyde, at room temperature (RT), was carefully added and mixed immediately. The samples were incubated at RT for 10 minutes. $1 \mathrm{~mL}$ of cold Triton-X in phosphate buffered saline (PBS) (0.12\% Triton-X $100 \mathrm{w} / \mathrm{v}$, Sigma-Aldrich; 100\% PBS) was then added to each sample, which were again incubated for 30 minutes at RT. The samples were rinsed with $1 \mathrm{~mL}$ of cold wash buffer (96\% PBS, 4\% FBS), mixed, and cold 
centrifuged for 8 minutes at $300 \mathrm{~g}$. The supernatant was aspirated, the pellet resuspended and $1 \mathrm{~mL}$ of cold methanol solution (70\% $\mathrm{MeOH}, 30 \% \mathrm{PBS}, \mathrm{v} / \mathrm{v})$ was added dropwise while vortexing. The samples were maintained on ice, stored at $-40^{\circ} \mathrm{C}$ overnight and processed within 2 days.

\subsubsection{Staining and Flowing Samples}

From the freezer, the samples were resuspended and $1 \mathrm{~mL}$ of cold trisbuffered saline (TBS) was added and mixed. The samples were cold centrifuged for 5 minutes at $400 \mathrm{~g}$, the supernatant aspirated and the pellet resuspended. $1 \mathrm{~mL}$ of cold TST (96\% TBS, 4\% FBS, $0.1 \%$ Triton-X 100) was added to each sample and mixed. The samples were incubated on ice for 10 minutes and then cold centrifuged for 5 minutes at $400 \mathrm{~g}$. After aspirating the supernatant and resuspending the pellet, $1 \mu \mathrm{L}$ of $\gamma \mathrm{H} 2 \mathrm{AX}$-FITC (Millipore, Etobicoke, ON) was added to the required samples and all of the samples were incubated on ice, in the dark, for 2 hours. Thirty minutes prior to the end of incubation, the CD antibodies were also added to the required samples (10 $\mu \mathrm{L}$ CD4-PE (BD), $5 \mu \mathrm{L}$ CD8APC (BD) and $5 \mu \mathrm{L} \mathrm{CD19-PC7} \mathrm{(Beckman} \mathrm{Coulter,} \mathrm{Mississauga,} \mathrm{ON)).}$

Following the 2 hour incubation, $1 \mathrm{~mL}$ cold TBS $+2 \%$ FBS solution was added to all the samples, and they were cold centrifuged for 5 minutes at $400 \mathrm{~g}$. The supernatant was aspirated, and the pellet resuspended in $500 \mu \mathrm{L}$ of cold TBS $+2 \%$ FBS. The samples were stored in the dark on ice until they were run through the flow cytometer.

A gate was drawn around the lymphocyte population based upon characteristic populations in the forward versus side scatter acquisition plots. At least 50,000 lymphocytes were collected. The data was acquired without compensation on a 
FACSCalibur (BD), and compensation and analysis was performed post-acquisition using the software FCS Express (De Novo Software, Los Angeles, CA).

\subsubsection{Statistical Analysis}

In each of the two experiments (dose course, time course), two status groups, sensitive and control populations, were compared. Each experiment investigated the two groups with respect to four endpoints (lymphocytes, CD4, CD8 and CD19). In both of these experiments a two factorial analysis of variance model with randomized complete block design (RCBD) was applied, where patients were nested within each level of status. The two factors are status group (sensitive, control) and dose (or time). The RCBD accounts for individuals blood samples tested at all dose groups or measured at each time point. The interest was investigating if there was a difference in the mean fluorescent intensity for the four endpoints between status groups, as well as if differences between status groups occurred at each dose group or time point.

Linear mixed effects models (LMM) were applied to model the outcome mean fluorescent intensity, where each individual's sample was considered a random block nested within a status group, to control for correlation between samples at the various dose points or at various time points. When the overall F-test from the LMM for the difference between status groups or the interaction between status group and dose or time was observed $(\mathrm{p}<0.05)$, then multiple comparison tests were applied to compare the two status groups at each dose level or time point. Bonferroni corrections were applied for pair-wise comparisons in order to adjust the Type I error rate (the rate of false positives) 
to be less than 0.05 . The endpoints lymphocytes, CD4, CD8 and CD19 were analyzed separately.

The assumptions for LMM were verified using the Anderson-Darling test for normality of residuals, and Bartlett's test for homogeneity of variance across groups. When these assumptions were not satisfied then non-parametric statistics were used.

\subsubsection{Results}

Table 5-2 presents the average and standard deviation of geometric mean fluorescent intensity for CD4, CD8, CD19 and lymphocytes at each dose and status group in the dose course. Figure 5-1 displays the results from the four endpoints CD4, CD8, CD19 and lymphocytes in the dose course. As can be seen in table 5-2 and in figure 5-1, average geometric mean light intensity was similar between the two status groups (sensitive and control) for each of the four endpoints. There were no significant differences observed between the two status groups at each of the respective dose groups ( $p>0.05$ in all endpoints, see table 5-2).

Table 5-3 presents the average and standard deviation of geometric mean fluorescent intensity for CD4, CD8, CD19 and lymphocytes at each time point and status group in the time course. Figure 5-2 displays the results from the four endpoints CD4, CD8, CD19 and lymphocytes in the time course. As can be seen in table 5-3 and in figure 5-2 average geometric mean fluorescent intensity was similar between the two status groups (sensitive and control) for each of the four endpoints. As well there were no significant differences observed between the two status groups at each of the respective time points ( $p>0.05$ in all endpoints, see table 5-3). 
Table 5-2: Comparing control to sensitive groups for the dose course experiment. Entries in table represent the geometric fluorescent intensity of the $\gamma \mathrm{H} 2 \mathrm{AX}$ signal for each status and dose combination.

\begin{tabular}{cccccccc}
\hline \multirow{2}{*}{ Treatment Group } & $\mathbf{0}$ & $\mathbf{2}$ & $\mathbf{4}$ & $\mathbf{6}$ & $\mathbf{8}$ & $\mathbf{1 0}$ \\
\cline { 2 - 7 } & \multicolumn{7}{c}{ CD4 } \\
\hline $\begin{array}{c}\text { Control } \\
(\mathrm{n}=20)\end{array}$ & $\begin{array}{c}8.83 \\
\text { (1.31) }\end{array}$ & $\begin{array}{c}(6.73 \\
\text { (6.93) }\end{array}$ & $\begin{array}{c}53.91 \\
(10.44)\end{array}$ & $\begin{array}{c}75.92 \\
(17.80)\end{array}$ & $\begin{array}{c}101.98 \\
(26.90)\end{array}$ & $\begin{array}{c}117.81 \\
(31.73)\end{array}$ \\
\hline $\begin{array}{c}\text { Sensitive } \\
(\mathrm{n}=10)\end{array}$ & 8.83 & 32.53 & 51.37 & 75.33 & 98.44 & 114.41 \\
& $(2.58)$ & $(7.97)$ & $(11.41)$ & $(17.44)$ & $(19.83)$ & $(30.85)$ \\
\hline
\end{tabular}

Overall status effect: $F_{(1,28)}(p-v a l u e)=0.06(0.81)$

Overall difference between status groups at the various dose groups: $F_{(5,140)}(p$-value $)=0.18(0.97)$

\section{CD8}

$\begin{array}{lcccccc}\text { Control } & 8.25 & 24.82 & 42.00 & 57.09 & 76.31 & 86.12 \\ (\mathrm{n}=20) & (1.50) & (5.86) & (8.89) & (14.41) & (24.05) & (24.94)\end{array}$

\begin{tabular}{ccccccc}
\hline $\begin{array}{c}\text { Sensitive } \\
(\mathrm{n}=10)\end{array}$ & 7.84 & 25.22 & 38.79 & 53.57 & 70.45 & 82.55 \\
& $(1.84)$ & $(5.16)$ & $(6.13)$ & $(11.21)$ & $(16.58)$ & $(19.24)$ \\
\hline \multicolumn{7}{c}{ Overall status effect: $\mathrm{F}_{(1,28)}$ (p-value) $=0.38(0.54)$} \\
\hline
\end{tabular}

Overall difference between status groups at the various dose groups: $F_{(5,140)}(p-v a l u e)=0.33(0.89)$

Table 5-2 continued on the next page 
Table 5-2 continued

\begin{tabular}{|c|c|c|c|c|c|c|}
\hline & \multicolumn{6}{|c|}{ Dose (Gy) } \\
\hline & $\mathbf{0}$ & 2 & 4 & 6 & 8 & 10 \\
\hline & \multicolumn{6}{|c|}{ CD19 } \\
\hline $\begin{array}{l}\text { Control } \\
(\mathrm{n}=20)\end{array}$ & $\begin{array}{c}7.61 \\
(1.59)\end{array}$ & $\begin{array}{l}19.99 \\
(4.81)\end{array}$ & $\begin{array}{l}33.81 \\
(7.90)\end{array}$ & $\begin{array}{c}45.66 \\
(11.69)\end{array}$ & $\begin{array}{c}59.37 \\
(18.40)\end{array}$ & $\begin{array}{c}66.38 \\
(20.61)\end{array}$ \\
\hline \multirow[t]{4}{*}{$\begin{array}{l}\text { Sensitive } \\
(n=10)\end{array}$} & $\begin{array}{c}6.97 \\
(2.15)\end{array}$ & $\begin{array}{l}21.07 \\
(5.73)\end{array}$ & $\begin{array}{l}31.82 \\
(6.39)\end{array}$ & $\begin{array}{l}42.91 \\
(9.79)\end{array}$ & $\begin{array}{c}55.31 \\
(10.43)\end{array}$ & $\begin{array}{r}62.32 \\
(15.43)\end{array}$ \\
\hline & \multicolumn{6}{|c|}{ Overall status effect: $F_{(1,28)}(p$-value $)=0.33(0.57)$} \\
\hline & \multicolumn{6}{|c|}{$\begin{array}{l}\text { Overall difference between status groups at the various dose } \\
\text { groups: } F_{(5,140)}(p \text {-value })=0.42(0.84)\end{array}$} \\
\hline & \multicolumn{6}{|c|}{ Lymphocytes } \\
\hline $\begin{array}{l}\text { Control } \\
(n=20)\end{array}$ & $\begin{array}{c}8.39 \\
(1.29)\end{array}$ & $\begin{array}{l}26.49 \\
(6.17)\end{array}$ & $\begin{array}{l}45.08 \\
(9.49)\end{array}$ & $\begin{array}{c}61.32 \\
(15.44)\end{array}$ & $\begin{array}{c}81.72 \\
(24.08)\end{array}$ & $\begin{array}{c}92.39 \\
(26.90)\end{array}$ \\
\hline $\begin{array}{l}\text { Sensitive } \\
(\mathrm{n}=10)\end{array}$ & $\begin{array}{c}8.32 \\
(2.20)\end{array}$ & $\begin{array}{l}27.61 \\
(6.32)\end{array}$ & $\begin{array}{l}42.10 \\
(7.44)\end{array}$ & $\begin{array}{c}58.83 \\
(11.93)\end{array}$ & $\begin{array}{c}75.97 \\
(14.23)\end{array}$ & $\begin{array}{c}87.49 \\
(21.26)\end{array}$ \\
\hline
\end{tabular}

Overall status effect: $F_{(1,28)}(p-$ value $)=0.29(0.59)$

Overall difference between status groups at the various dose groups: $F_{(5,140)}(p-v a l u e)=0.42(0.84)$ 
Table 5-3: Comparing control to sensitive groups for time course experiments after exposure to $2 \mathrm{~Gy}$ in vitro radiation. Entries in table represent the mean (SD) geometric fluorescent intensity of the $\gamma \mathrm{H} 2 \mathrm{AX}$ signal for each status and time combination.

\begin{tabular}{cccccccc}
\hline \multirow{2}{*}{ Treatment Group } & $\mathbf{0}$ & $\mathbf{0 . 5}$ & $\mathbf{1}$ & $\mathbf{2}$ & $\mathbf{4}$ & $\mathbf{8}$ & $\mathbf{2 4}$ \\
\cline { 2 - 8 } & & \multicolumn{7}{c}{ CD4 } \\
\hline \multirow{2}{*}{ Control $(\mathrm{n}=20)$} & 11.01 & 33.38 & 40.40 & 35.40 & 24.42 & 13.23 & 10.30 \\
& $(3.50)$ & $(8.43)$ & $(11.07)$ & $(8.10)$ & $(6.33)$ & $(2.93)$ & $(2.03)$ \\
\hline Sensitive & 10.80 & 32.18 & 40.41 & 37.91 & 25.87 & 14.25 & 10.26 \\
$(\mathrm{n}=10)$ & $(3.86)$ & $(7.81)$ & $(8.39)$ & $(11.26)$ & $(7.81)$ & $(4.07)$ & $(3.14)$ \\
\hline
\end{tabular}

Overall status effect: $F_{(1,28)}(p$-value $)=0.05(0.82)$

\begin{tabular}{ccccccccc}
\hline & \multicolumn{7}{c}{ Overall difference between status groups at the various time } \\
& \multicolumn{7}{c}{ points: $\mathrm{F}_{(6.167)}(\mathrm{p}$-value $)=0.38(0.89)$} \\
\hline Control & 10.09 & 29.02 & 34.44 & 29.87 & 21.31 & 12.36 & 9.72 \\
$(\mathrm{n}=20)$ & $(3.32)$ & $(7.79)$ & $(9.66)$ & $(7.26)$ & $(5.94)$ & $(3.02)$ & $(2.17)$ \\
\hline Sensitive & 9.13 & 27.27 & 33.18 & 30.29 & 21.26 & 12.70 & 9.37 \\
$(\mathrm{n}=10)$ & $(2.64)$ & $(5.22)$ & $(5.03)$ & $(6.51)$ & $(5.65)$ & $(3.03)$ & $(2.51)$ \\
\hline
\end{tabular}

Overall status effect: $F_{(1,28)}(p$-value $)=0.11(0.74)$

\begin{tabular}{ccccccccc}
\hline & \multicolumn{7}{c}{ Overall difference between status groups at the various time } \\
points: $F_{(6,167)}(\mathrm{p}$-value $)=0.25(0.96)$
\end{tabular}

Overall status effect: $F_{(1,28)}(p-v a l u e)=0.15(0.70)$

Overall difference between status groups at the various time points: $F_{(6.167)}(p$-value) $=0.08(1.00)$

Table 5-3 continued on the next page 
Table 5-3 continued

\begin{tabular}{|c|c|c|c|c|c|c|c|}
\hline & \multicolumn{7}{|c|}{ Time (h) } \\
\hline & 0 & 0.5 & 1 & 2 & 4 & 8 & 24 \\
\hline & \multicolumn{7}{|c|}{ Lymph } \\
\hline $\begin{array}{l}\text { Control } \\
(n=20)\end{array}$ & $\begin{array}{l}10.54 \\
(3.13)\end{array}$ & $\begin{array}{l}30.50 \\
(7.50)\end{array}$ & $\begin{array}{l}36.92 \\
(9.79)\end{array}$ & $\begin{array}{l}32.54 \\
(7.41)\end{array}$ & $\begin{array}{l}22.82 \\
(5.77) \\
\end{array}$ & $\begin{array}{l}13.22 \\
(3.02)\end{array}$ & $\begin{array}{l}10.72 \\
(2.20)\end{array}$ \\
\hline \multirow[t]{3}{*}{$\begin{array}{c}\text { Sensitive } \\
(n=10)\end{array}$} & $\begin{array}{l}10.28 \\
(3.07) \\
\end{array}$ & $\begin{array}{l}29.27 \\
(5.80) \\
\end{array}$ & $\begin{array}{l}36.59 \\
(5.84) \\
\end{array}$ & $\begin{array}{l}33.99 \\
(7.99) \\
\end{array}$ & $\begin{array}{l}23.65 \\
(6.37) \\
\end{array}$ & $\begin{array}{l}14.03 \\
(3.47) \\
\end{array}$ & $\begin{array}{r}10.72 \\
(3.05)\end{array}$ \\
\hline & \multicolumn{7}{|c|}{ Overall status effect: $F_{(1,28)}(p$-value $)=0.01(0.94)$} \\
\hline & \multicolumn{7}{|c|}{$\begin{array}{l}\text { Overall difference between status groups at the various time } \\
\text { points: } F_{(6,167)}(p \text {-value })=0.27(0.95)\end{array}$} \\
\hline
\end{tabular}


(a) Lymphocytes

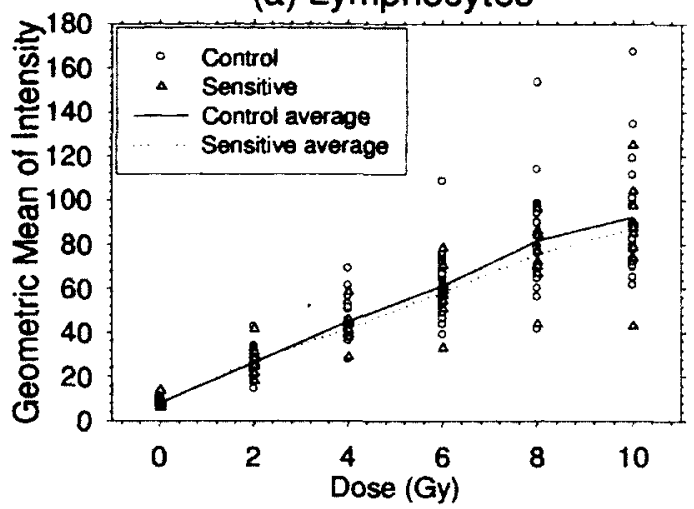

(c) $\mathrm{CD} 8$

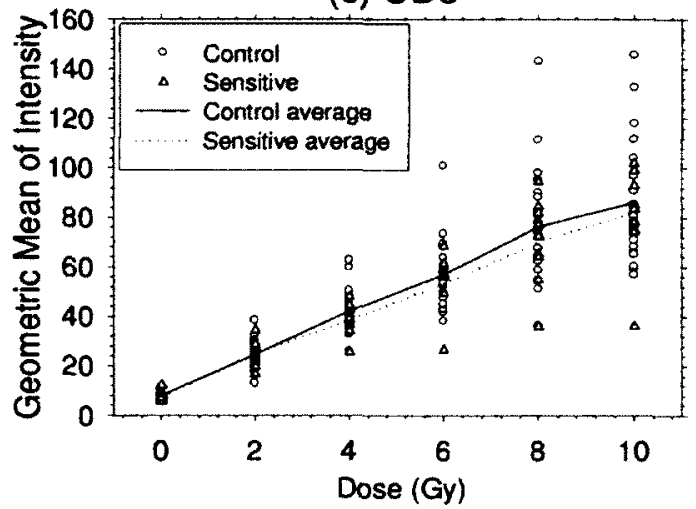

(b) CD4

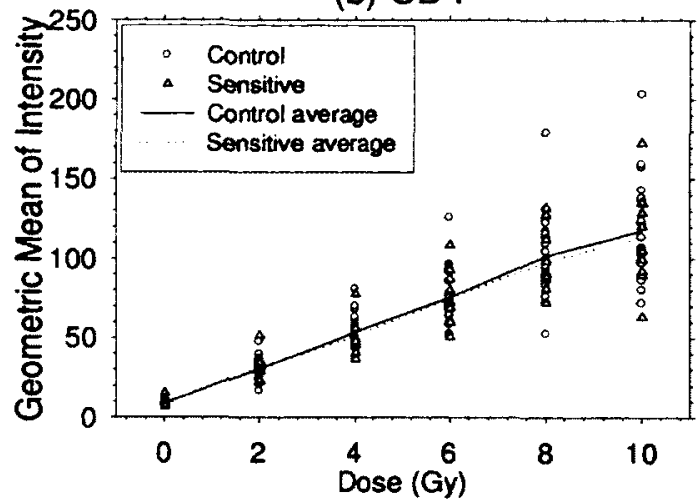

(d) CD19

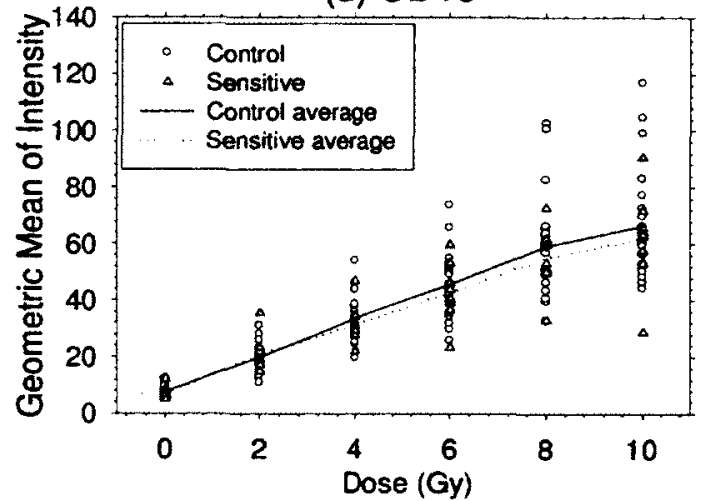

Figure 5-1: Dose course results for lymphocytes (a) and each subset (b, c, d). 
(a) Lymphocytes

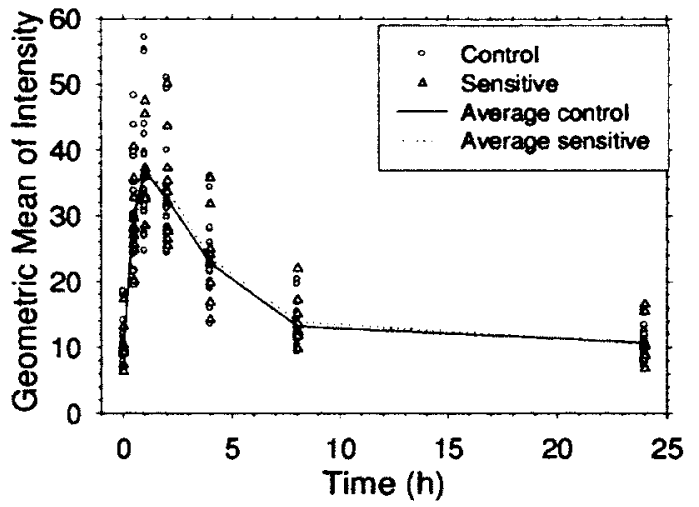

(c) $\mathrm{CD8}$

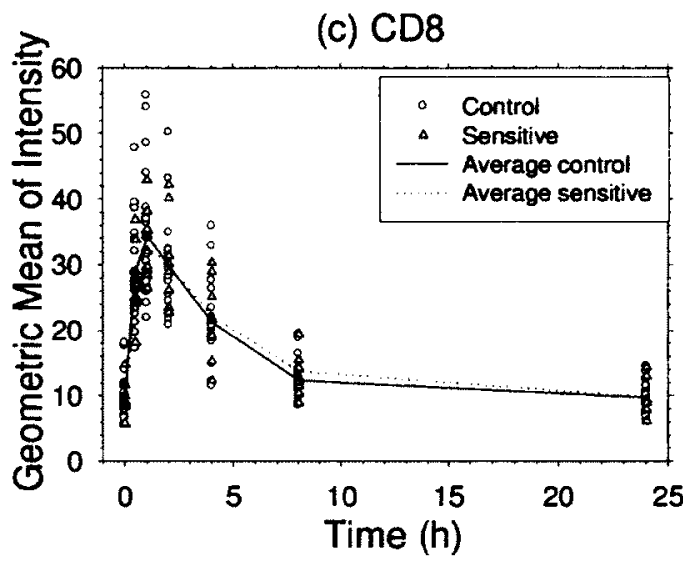

(b) $\mathrm{CD} 4$

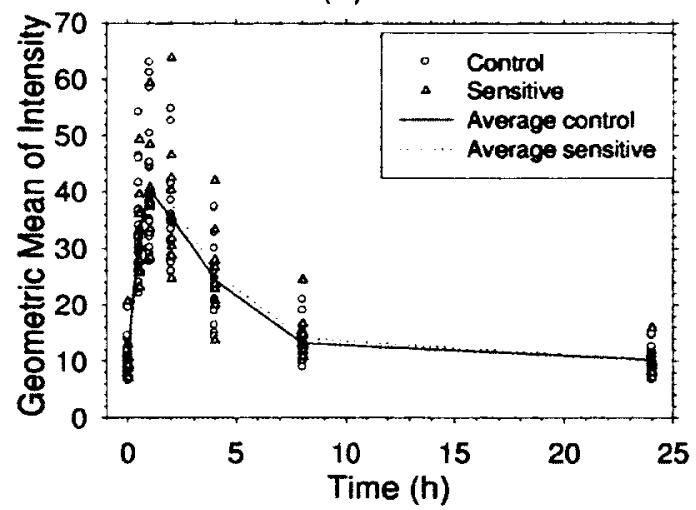

(d) CD19

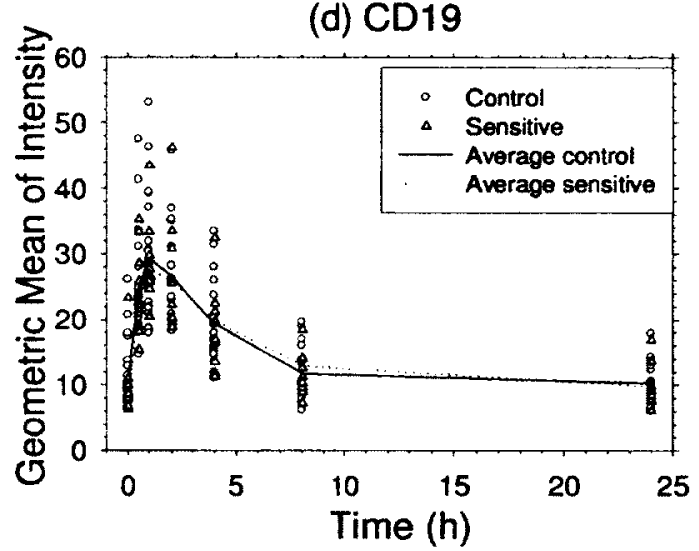

Figure 5-2: Time course results for lymphocytes (a) and each subset (b, c, d).

\subsubsection{Discussion}

Unfortunately, after fairly rigorous examination of the patient samples, with 6 dose points and 7 time points each, there was no significant difference found in either experiment.

Although it is not uncommon to normalize the data to the $0 \mathrm{~Gy}$ or $0 \mathrm{~h}$ time point, it was decided that this could potentially skew the data as those points are just as susceptible to experimental error. It has been shown (see Lew 2007 [95] for a detailed 
example) that when there is correlation between the data, as is the case in this study, the randomized block ANOVA is more powerful than a one-way ANOVA. Despite this, no significant differences were found.

In order to explore the data further, the presence of possible outliers was investigated. Absolute values of studentized residuals were generated for each patient at each dose and time point, and any greater than 2 were considered to be suspect. With some of the points identified as suspect, the statistical analysis was run on the ranks of the data and compared to the original data. By analyzing the ranks, the effect of any large or very small values on the results was removed. The results were the same in each case, indicating that the possible outliers were not masking any differences between the two groups of patients.

Although Menegakis et al. [92] found a correlation between residual $\gamma \mathrm{H} 2 \mathrm{AX}$ foci and clonogenic survival, and Chua et al. [43] found a difference $24 \mathrm{~h}$ after a 4 Gy dose, both performed their analysis by spot counting. While the results of this study were unable to detect any differences between the sensitive and control groups, this may have been a result of the methodology not being sensitive enough. Even with increased counting statistics, the small differences between the groups could not be detected. Higher patient numbers would help increase the sensitivity in detecting differences if they exist. It is also possible that the time and dose points used in this study were not ideal for detecting differences. Chua et al. detected a significant difference 24 h after 4 Gy while our $24 \mathrm{~h}$ point was after $2 \mathrm{~Gy}$. It has previously been seen that differences in radiosensitivity become more apparent when larger amounts of damage have been 
induced in vitro (Beaton et al., [87]). As the same endpoints were not used in this study as in Chua et al., it is difficult to make a direct comparison.

In conclusion, the sensitivity of conventional flow cytometry was insufficient to detect a difference between patients identified as sensitive or control, even when investigating lymphocyte subsets. Further studies will investigate whether an imaging flow cytometer, with increased sensitivity due to imaging capabilities will be capable of distinguishing between the two populations. This technology will combine the sensitivity of spot counting with the advantage of high throughput and better count statistics.

\subsubsection{Acknowledgements}

The authors would like to thank Colin Malone for his work with the patient database. This project was partially funded by the Ottawa Regional Cancer Foundation.

\subsubsection{Conflict of Interest}

The authors declare no conflict of interest. 


\subsection{Further notes with respect to the $\gamma \mathrm{H} 2 \mathrm{AX}$ experiment}

\subsubsection{Reproducibility}

While repeated experiments could not be performed, due to limited blood sample volumes, a comparison could be done between a dose course point ( $2 \mathrm{~Gy}, 1 \mathrm{~h}$ incubation) and a time course point ( $1 \mathrm{~h}$ incubation, $2 \mathrm{~Gy}$ ). These two data points were expected to be similar, as the samples originated from the same patient whole blood sample. The dose course $\gamma \mathrm{H} 2 \mathrm{AX}$ response was plotted patient-by-patient with the time course $\gamma \mathrm{H} 2 \mathrm{AX}$ response, for each of the lymphocyte and lymphocyte subset populations, as shown in figure 5-3. Ideally, the expected result would be a linear response with a slope of +1 which would indicate no differences between the dose and time course samples from the same patient. As shown in figure 5-3, the data follows a linear trend with a positive slope for each of the lymphocyte and lymphocyte subset populations. There appears to be a systematic difference between the $\gamma \mathrm{H} 2 \mathrm{AX}$ response from the time course samples and the dose course sample; this could possibly be explained by the fact that the time course samples were irradiated and processed approximately $24 \mathrm{~h}$ after the dose course samples. 

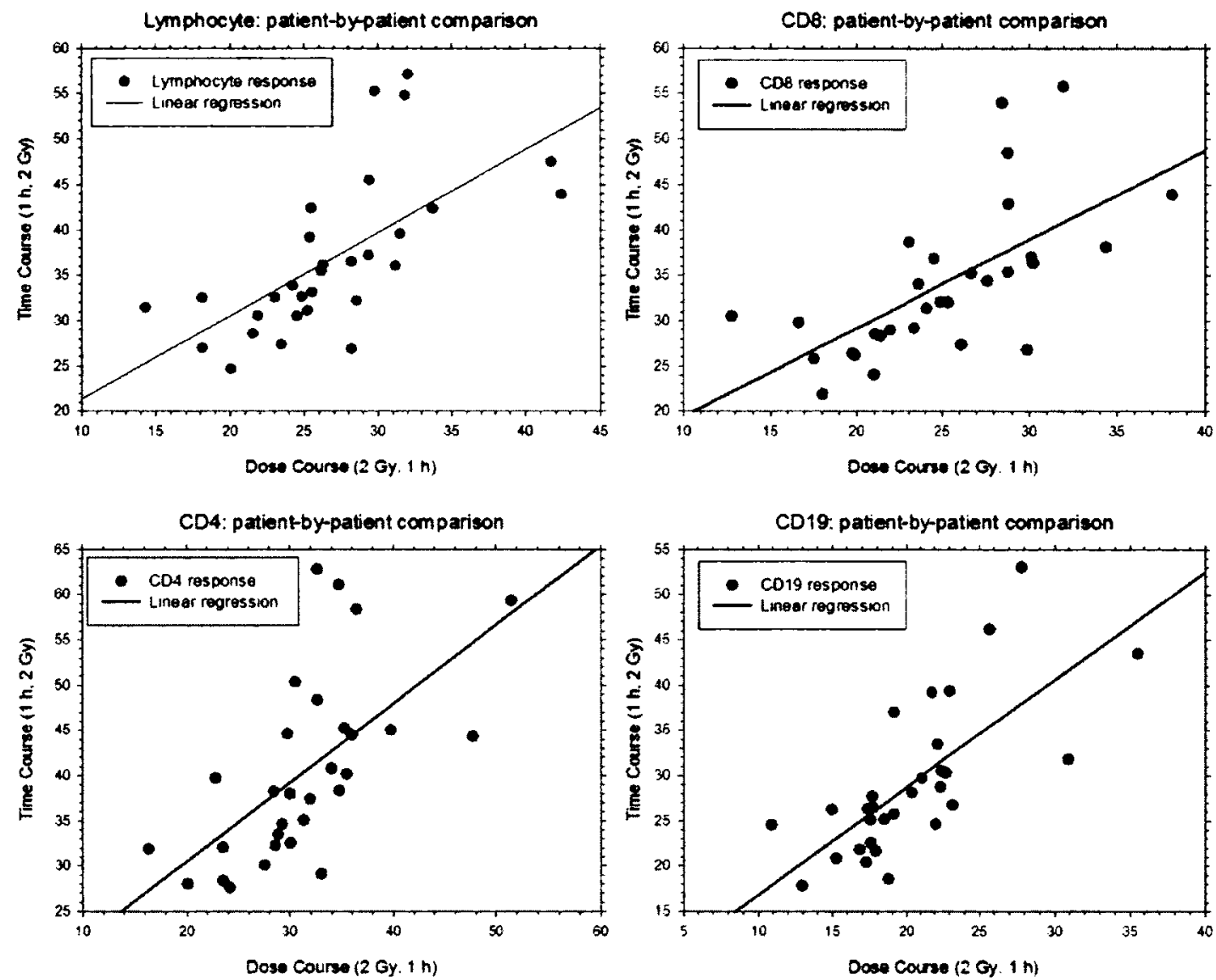

Figure 5-3: Plot of dose course point ( $2 \mathrm{~Gy}, 1 \mathrm{~h}$ ) versus time course point ( $2 \mathrm{~Gy}, 1$ h) for each patient, for each of the lymphocyte and lymphocyte subset (CD4, CD8 and CD19) populations. The data follows a linear trend, as expected, although it shows a systematic difference between the time and dose course.

\subsubsection{Radiation-induced apoptosis}

Based on some of the literature on apoptosis [37;96], the ratio of CD4/CD8 cells was examined from the $\gamma \mathrm{H} 2 \mathrm{AX}$ samples, at $0 \mathrm{~h}, 0 \mathrm{~Gy}$ and $24 \mathrm{~h}$ to see if there was a change in ratio between the control and sensitive groups. Endpoints of interest that were considered in this analysis included the ratios of number of cells CD4/lymphocytes, 
CD8/lymphocytes, CD19/lymphocytes and CD4/CD8. These ratios were only compared between the sensitive and control cohorts at $0 \mathrm{~Gy}, 0 \mathrm{~h}$, and $24 \mathrm{~h}$. The ratios of the number of cells CD4/lymphocytes, CD8/lymphocytes, CD19/lymphocytes were considered to be proportions and therefore the logits of these were analyzed. The ratio of number of cells CD4/CD8 is considered to be a rate, and therefore a Poisson regression model was used to analyze this rate. For these four ratios, the factors of dose or time were not considered in the model for analysis. The aim of the analysis was to compare the ratios between the two cohorts at a specified dose group or time point. Therefore a one way analysis of variance model was used to analyze the logits of CD4/lymphocytes, CD8/lymphocytes, and CD19/lymphocytes, and a similar Poisson regression model was used to analyze the rate $\mathrm{CD} 4 / \mathrm{CD} 8$. Table 5-4 presents the average and standard deviation of the ratios of number of the four endpoints for each cohort at $0 \mathrm{~Gy}, 0 \mathrm{~h}$, and $24 \mathrm{~h}$. The results were statistically similar between the two cohorts $(p>0.05$ in all cases, see table $5-4)$. No significant results were found. 
Table 5-4: Comparing control to sensitive groups for special ratios (DC and TC). Entries in table represent the mean (SD) for each status.

\begin{tabular}{|c|c|c|c|}
\hline \multirow{2}{*}{ Status group } & Dose Course & Time Course & Time Course \\
\hline & 0 Gy, 0 h & $\mathbf{O h}, 2 \mathbf{G y}$ & $24 \mathrm{~h}, 2 \mathrm{~Gy}$ \\
\hline & \multicolumn{3}{|c|}{$\begin{array}{c}\text { CD4/Lymphocytes } \\
\end{array}$} \\
\hline Control $(n=20)$ & $0.43(0.10)$ & $0.49(0.16)$ & $0.51(0.15)$ \\
\hline Sensitive $(n=10)$ & $0.41(0.08)$ & $0.42(0.08)$ & $0.47(0.09)$ \\
\hline \multirow[t]{2}{*}{$F_{(1,28)}(p-v a l u e)$} & $0.2(0.7)$ & $1.15(0.29)$ & $0.1(0.8)$ \\
\hline & \multicolumn{3}{|c|}{ CD8/Lymphocytes } \\
\hline Control $(n=20)$ & $0.19(0.09)$ & $0.21(0.10)$ & $0.22(0.09)$ \\
\hline Sensitive $(n=10)$ & $0.19(0.12)$ & $0.21(0.13)$ & $0.22(0.12)$ \\
\hline \multirow[t]{2}{*}{$F_{(1,28)}(p-v a l u e)$} & $0.2(0.6)$ & $0.1(0.8)$ & $0.01(0.9)$ \\
\hline & \multicolumn{3}{|c|}{ CD19/Lymphocytes } \\
\hline Control $(n=20)$ & $0.10(0.04)$ & $0.08(0.04)$ & $0.07(0.03)$ \\
\hline Sensitive $(n=10)$ & $0.10(0.04)$ & $0.09(0.04)$ & $0.06(0.02)$ \\
\hline \multirow[t]{2}{*}{$F_{(1,28)}(p$-value $)$} & $0.10(0.7497)$ & $0.31(0.5842)$ & $0.03(0.8626)$ \\
\hline & \multicolumn{3}{|c|}{ CD4/CD8 } \\
\hline Control $(n=20)$ & $2.87(1.85)$ & $2.82(1.44)$ & $2.66(1.25)$ \\
\hline Sensitive $(n=10)$ & $3.14(2.12)$ & $2.86(2.09)$ & $2.69(1.57)$ \\
\hline$F_{(1,28)}(p$-value $)$ & $0.13(0.7247)$ & $0.00(0.9447)$ & $0.00(0.9575)$ \\
\hline
\end{tabular}




\section{Statistical Analysis}

\subsection{Summary of individual experiments}

In this work, various cytogenetic and DNA damage endpoints were measured in blood samples taken from sensitive and control prostate cancer patients. These blood samples were divided between 3 different in vitro radiation experiments; DCA (0 and 6 Gy), FISH ( 0 and $4 \mathrm{~Gy}$ ) and $\gamma \mathrm{H} 2 \mathrm{AX}(0$ to $10 \mathrm{~Gy}$ with a $1 \mathrm{~h}$ incubation time and 0 to $24 \mathrm{~h}$ with a 2 Gy dose). Table 6-1 is a summary of the final test statistics from each of these endpoints comparing the two status groups (control and sensitive).

The DCA experiment measured dicentric chromosomes, excess fragments and fraction of cells in second metaphase (fM2) in 0 Gy samples (for background rates) and again after exposure to $6 \mathrm{~Gy}$ ). All three endpoints were found to be significantly different at the 6 Gy dose. The chromosome aberration endpoints (dicentrics and excess fragments per cell) were analyzed using a Poisson regression model, while the fM2 endpoint was analyzed with a logistic regression model. The results of this experiment are examined in Chapter 3 section 3.2.5 Results.

The FISH experiment measured colour junctions, deletions, dicentrics, rings, acentric fragments, insertions, inversions, and amount of damage in each of chromosome 1,2 and 4 in 0 Gy samples (for background rates) and again after exposure to $4 \mathrm{~Gy}$. Three endpoints (colour junctions, deletions and dicentrics) were found to be significantly different. The endpoints were analyzed using a Poisson regression model. The results of this experiment are examined in Chapter 4 section 4.2.5 Results.

The $\gamma \mathrm{H} 2 \mathrm{AX}$ experiment measured the in vitro $\gamma \mathrm{H} 2 \mathrm{AX}$ response in lymphocytes and lymphocyte subsets (CD4, CD8 and CD19). The endpoints for both the dose course 
(0 - 10 Gy with 1 hour incubation) and time course (0-24 h at $2 \mathrm{~Gy})$, for lymphocyte and lymphocyte subsets (CD4, CD8 and CD19) were analyzed using a linear mixed effect model. The results of this experiment are examined in Chapter 5 section 5.2.4 Results.

Table 6-1: Summary of the final test statistics from the DCA and FISH endpoints comparing the two status groups (control and sensitive). Test statistics from the $\gamma \mathrm{H} 2 \mathrm{AX}$ are not shown as they were not found to be significant. There were no significant differences between the groups at the background $(0 \mathrm{~Gy})$ level. Significance levels are denoted by asterisks, where $*, * *$ and $* * *$ correspond to $\mathrm{p}$-values $\leq 0.05,0.01$ and 0.001 respectively.

\begin{tabular}{ccccc}
\hline & & \multicolumn{2}{c}{ Challenge Dose (4 or 6 Gy) } \\
\hline Assay & Endpoint & \multicolumn{2}{c}{ Status } & \multirow{2}{*}{ p-value } \\
\hline \multirow{3}{*}{ DCA } & Dicentrics & $2.91(0.32)$ & $3.26(0.31)$ & $0.03^{*}$ \\
\cline { 2 - 5 } & Excess Fragments & $1.43(0.37)$ & $2.27(0.23)$ & $<0.0001^{* * *}$ \\
\cline { 2 - 5 } & Fraction in M2 & $0.46(0.09)$ & $0.27(0.10)$ & $0.0007^{* * *}$ \\
\hline \multirow{5}{*}{ Colour junctions } & $1.9(0.2)$ & $2.4(0.4)$ & $0.01^{* *}$ \\
\cline { 2 - 5 } & Deletions & $0.34(0.05)$ & $0.24(0.06)$ & $0.01^{* *}$ \\
\cline { 2 - 5 } & Insertions & $0.03(0.03)$ & $0.05(0.03)$ & 0.4 \\
\cline { 2 - 5 } & Inversions & $0.006(0.009)$ & $0.01(0.01)$ & 0.8 \\
\cline { 2 - 5 } & Dicentrics & $0.36(0.06)$ & $0.4(0.1)$ & $0.02^{*}$ \\
\cline { 2 - 5 } & Acentric fragments & $0.65(0.09)$ & $0.8(0.2)$ & 0.07 \\
\cline { 2 - 5 } & Rings & $0.01(0.01)$ & $0.03(0.02)$ & 0.2 \\
\cline { 2 - 5 } & Chromosome 1 & $0.6(0.2)$ & $0.7(0.1)$ & 0.06 \\
\cline { 2 - 5 } & Chromosome 2 & $0.49(0.05)$ & $0.6(0.2)$ & 0.07 \\
\cline { 2 - 5 } & Chromosome 3 & $0.47(0.08)$ & $0.4(0.1)$ & 0.5 \\
\hline
\end{tabular}




\subsection{Building a classifier: discriminant analysis}

\subsubsection{Building the data set}

To build the initial data set to be used for a discriminant analysis, all endpoints that were significant at the $10 \%$ level were used. As there was no statistical difference in the dose or time course between the control and sensitive groups in the in vitro $\gamma \mathrm{H} 2 \mathrm{AX}$ response in lymphocytes and lymphocyte subsets endpoints ( $p>0.10$, in all cases).

To have a complete data set, data from all endpoints from each patient had to be present in order to use the patient's data to develop the discriminant function. In the FISH study, due to resource limitations, only 6 control patients were included. Therefore the FISH endpoints were removed from the discriminant function to avoid discarding the 14 control patients that were not used in the FISH study.

The remaining endpoints to be used in developing the discriminant analysis were therefore dicentrics per cell, excess fragments per cell and fM2. As was observed in the univariate analysis of each of these three endpoints, there was no difference in the background rates between the control and sensitive cohorts. Therefore only the results from the 6 Gy endpoints were used in the discriminant analysis data set. The independent variables of the model included dicentrics per cell, excess fragments per cell, and $\mathrm{fM} 2$, while the dependent variable was sensitivity status (control $=0$ and sensitive $=1$ ).

Table 6-2 presents some simple descriptive statistics for the endpoints dicentrics per cell, excess fragments per cell, and fM2 in each of the status groups. At the bottom of table 6-2 is a simple test of equality of group means. Each of the tests compared the outcome between the two cohorts, and the results were significant $(p<0.05)$. The multivariate statistic Wilk's Lambda, a measure of how well the model was able to 
discriminate between the two groups, was equal to $0.32(p<0.0001)$. All of which suggests that there is strong evidence that these variables are able to distinguish between the two status groups.

Table 6-2: Descriptive statistics and test of equality of group means

\begin{tabular}{ccccccc}
\hline & \multicolumn{2}{c}{ Dicentrics } & \multicolumn{2}{c}{ Excess fragments } & \multicolumn{2}{c}{ fM2 } \\
\hline & Mean & SD & Mean & SD & Mean & SD \\
\hline Control $(\mathrm{n}=20)$ & 2.91 & 0.32 & 1.43 & 0.37 & 0.46 & 0.09 \\
\hline Sensitive $(\mathrm{n}=10)$ & 3.26 & 0.31 & 2.27 & 0.23 & 0.27 & 0.1 \\
\hline Total $(\mathrm{n}=30)$ & 3.03 & 0.36 & 1.71 & 0.52 & 0.4 & 0.13 \\
\hline $\begin{array}{c}\text { Test of equality of } \\
\text { group means } \\
\mathrm{F}_{(1,28)} \text { (p-value) }\end{array}$ & $8.33(0.0074)$ & $42.96(<0.0001)$ & $25.54(<0.0001)$ \\
\hline
\end{tabular}

\subsubsection{Linear discriminant analysis}

Linear discriminant analysis (LDA), an adaptation of Fisher's linear discriminant [97], is a method to discriminate (or classify) two or more groups. The main idea is to transform a multivariate observation into a univariate observation such that the new univariate observations were separated as much as possible. Fisher suggested a linear combination of the multivariate data to create the new univariate observations.

The number of discriminant functions is always 1 less the number of groups in the dependent variable. In this case there are only two cohorts in the dependent variable (sensitive, control), and therefore there is only one discriminant function.

The canonical correlation is the multiple correlation between the predictors and the discriminant function. With only one function, it provides an index of overall model fit which is interpreted as being the proportion of variance explained $\left(R^{2}\right)$. In the present 
study the canonical correlation was 0.82 , and suggested that the model explained $68 \%$ $\left(0.82^{2} \times 100 \%\right)$ of the variation in the grouping variable i.e., whether a person is in the control or sensitive cohort. The likelihood ratio (0.32), equal to Wilk's Lambda, indicated that the discriminant function was highly significant $(\mathrm{p}<0.0001)$ and provided a measure of the proportion of total variability not explained. Therefore the discriminant function explained $68 \%$ of the variation in the grouping variable, and $32 \%$ remained unexplained by the function.

Table 6-3 provides an index of the importance of each predictor like standardized regression coefficients do in multiple regression (see table 6-3, column 2). The absolute value of the coefficient is an indicator of importance in the discriminant model, with larger values indicating increased significance. In the present data set, excess fragments per cell was the strongest predictor $(b=0.87$ ), while low (due to the negative sign) fM2 cells $(b=-0.63)$ was next in importance as a predictor. These two variables, with large coefficients, stood out as those that strongly predict allocation to the two status groups (sensitive and control).

Table 6-3: Standardized canonical discriminant function coefficients.

\begin{tabular}{ccc}
\hline Variable & $\begin{array}{c}\text { Canonical } \\
\text { coefficients }\end{array}$ & $\begin{array}{c}\text { Canonical structure } \\
\text { matrix correlation }\end{array}$ \\
\hline Dicentrics per cell & -0.42 & 0.38 \\
\hline $\begin{array}{c}\text { Excess fragments per } \\
\text { cell }\end{array}$ & 0.87 & 0.85 \\
\hline $\mathrm{fM} 2$ cells & -0.63 & -0.66 \\
\hline
\end{tabular}

The canonical structure matrix table is another way of indicating the relative importance of the predictors, and can be seen in the third column of table 6-3. The 
structure matrix correlations are considered to be more accurate than the standardized canonical discriminant function coefficients. These represent correlations of each variable with each discriminant function (sometimes referred to as structure coefficients or discriminant loadings). Variables having an absolute correlation greater than 0.30 , are considered important predictors. Therefore, as seen in the results, both excess fragments per cell $(0.85)$ and $\mathrm{fM} 2$ cells $(-0.66)$ are considered to be very important, whereas dicentrics per cell $(0.38)$ is a marginally important predictor.

In order to evaluate the accuracy of the discriminant model, the data is often split into two subsets, a randomly selected test set, and the rest of the data called a training data set. The test data set is used to validate the model built with the training data set. Since the number of observations in the current data set was limited to a total of $30 ; 10$ sensitive and 20 controls. Rather than split the limited data into training and testing sets, the validity of the function could still be assessed by using a cross-validation technique. In cross-validation, each observation is removed from the data set, a discriminant model built with the remaining data, and then the model tested on the removed observation. Each observation is removed in this way in turn, and the final results combined for the entire data set. Table 6-4 presents the results from a cross validation analysis. Of the observations that should have been classified as a control, $15 \%$ were misclassified as sensitive, and $10 \%$ of the sensitive were misclassified as controls. Assuming that patients had a $3 \%$ (from the population studied for these experiments, defined as case 1) to $10 \%$ (from the literature, [77], defined as case 2) probability of ranking as sensitive, then the probability of misclassification was $15 \%$. 
Table 6-4: Cross validation summary using linear discriminant function. Case 1 assumes a $3 \%$ probability of sensitive patients (based upon the population studied for this thesis, while case 2 assumes a $10 \%$ probability of sensitive patients [77]).

\begin{tabular}{c|ccc}
\hline & \multicolumn{3}{|c}{$\begin{array}{c}\text { Number of } \\
\text { observations (\%) } \\
\text { classified into each } \\
\text { status group }\end{array}$} \\
\hline Status group & Control & Sensitive & Total \\
Control & $17(85 \%)$ & $3(15 \%)$ & 20 \\
Sensitive & $1(10 \%)$ & $9(90 \%)$ & 10 \\
Total & $18(60 \%)$ & $12(40 \%)$ & 30 \\
\multicolumn{4}{|c|}{ Probability of misclassification } \\
Misclassification rate & 0.15 & 0.1 & \\
Case 1 & 0.97 & 0.03 & 0.149 \\
Case 2 & 0.90 & 0.10 & 0.145 \\
\hline
\end{tabular}

The results of the cross-validation were also plotted in figure 6-1. 


\section{Linear discriminant analysis with cross-validation}

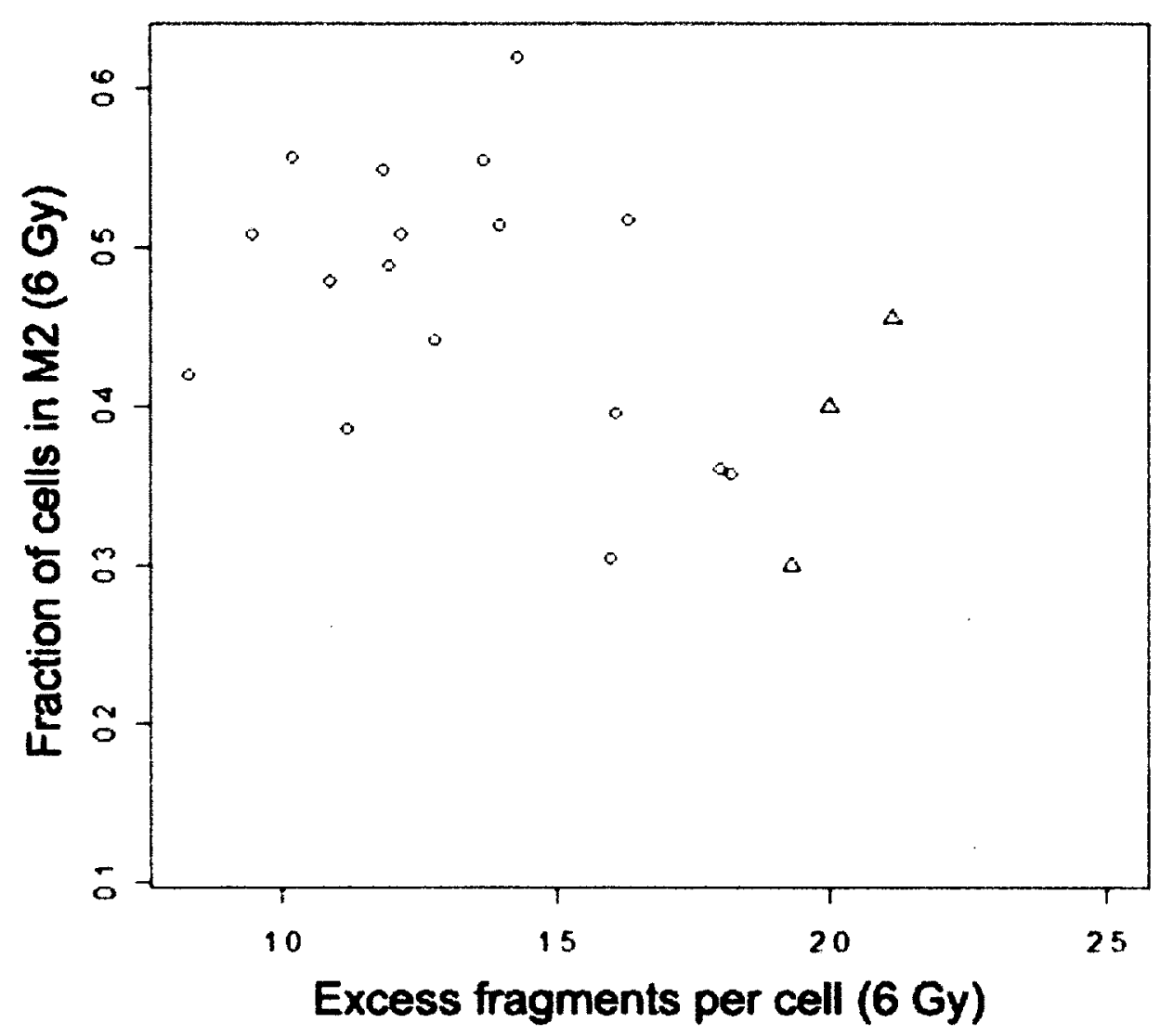

Figure 6-1: Scatter plot of the two most significant factors of the linear discriminant function, excess fragments per cell and fM2, after $6 \mathrm{~Gy}$. Red symbols represent true sensitive samples, black represent controls. Open triangles represent predicted sensitive values, and open circles predicted controls.

Ideally the correlation between the independent variables should be low, as is common in all multivariate analysis, and helps to avoid problems of multi-colinearity, which could skew the results. In the case of the three independent variables chosen in the 
previous section, dicentrics per cell were highly correlated with both excess fragments per cell (correlation $=0.50, \mathrm{p}=0.006)$ and $\mathrm{fM} 2$ cells $($ correlation $=-0.57, \mathrm{p}=0.0014)$. Furthermore, a stepwise discriminant analysis indicated that the most significant variables in predicting which status group a patient belonged to included excess fragments per cell and fM2 cells. Dicentrics per cell were not included by the stepwise discriminant function. By removing the variable from the discriminant model, the correlation only dropped to $65 \%$ from $68 \%$. This indicated that the variable dicentrics per cell did not add any additional value to the discriminant function.

\subsection{Conclusions}

Discriminant models, like all multivariate models, generally become more powerful in being able to distinguish between groups when the sample sizes are large in each group, from which the discriminant function was developed. The limitation of a discriminant model is if the two populations are overlapped, and the variability is too large, then no data set will distinguish the populations entirely. The only two variables really necessary for the discriminant analysis were excess fragments per cell and fM2 cells. The variable dicentrics per cell did not improve the power of the discriminant function in predicting or discriminating between the two status groups. It should also be noted that, in general, the group sizes of the dependent variable (i.e. sensitivity status) should be at least five times the number of independent variables. If only the two variables are used, in this case, the number of sensitive observations (10) is in fact five times the number of independent variables used in the model. 
The results of the discriminant analysis show a reasonable ability to predict the classification of a patient, given the limited data set. It is recommended that more data be collected to strengthen the analysis. 


\section{General Discussion}

There is a large variation in the individual patient response to the radiation that patients receive during cancer therapy. For many years, attempts have been made to identify a marker for radiosensitivity so that treatments could be tailored to the individual response of each patient. This research has focused on endpoints measured in lymphocytes that will provide some insight into biomarkers of radiation sensitivity and help advance this area of research.

\subsection{Summary of thesis findings and limiting factors}

The dicentric chromosome assay (DCA) allows for the identification of unstable damage due to the exposure of ionizing radiation. As discussed in Chapter 3, three endpoints, (dicentrics per cell, excess fragments per cell and the percentage of cells in second metaphase (fM2)) were found to be significant indicators of radiosensitivity. Fluorescent in situ hybridization (FISH) has the benefit of adding colour to the chromosomes, allowing junctions between damaged and subsequently repaired chromosomes to be visualized. These experiments identified an additional three endpoints (colour junctions, deletions and dicentrics per cell) that were significant indicators of radiosensitivity. Two of the DCA endpoints, excess fragments per cell and $\mathrm{fM} 2$, were combined using a linear discriminant analysis to develop a classifier with a misclassification rate of $15 \%$. These results indicate that chromosome damage measured after relatively high doses (6 and 4 Gy respectively) of in vitro radiation could provide a biomarker of radiosensitivity. 
The measure of $\gamma \mathrm{H} 2 \mathrm{AX}$ is an indication of DNA double strand breaks (DSBs). It can be used to track the induction and repair of these DSBs, both of which were measured by performing dose response and time course experiments. While the results of these $\gamma \mathrm{H} 2 \mathrm{AX}$ experiments (Chapter 5 section 5.2.4 Results) were not statistically significant, they could be an indication that the use of flow cytometry alone is not sensitive enough to distinguish between the sensitive and control patients. These experiments will be followed up with further investigations of a combined spot-counting and fluorescence-measurement technique, using imaging flow cytometry to acquire more information about each sample. This is discussed further in 7.1.1 Null results and suggested improvements.

Nevertheless, if the results of several of the more significant endpoints are combined, they could provide a stronger indication of an individual's response to radiotherapy. As discussed in Chapter 6, the most significant, independent endpoints should be used in multivariate analysis to help obtain a stronger classifier. Currently, due to sample size limitations, the two best variables to use for discriminant analysis are excess fragments per cell and fM2. As these two variables account for $65 \%$ of the variance in the model, using them, and assuming unequal variance, provides the model with the least probability of misclassification. With cross-validation, the linear discriminant model had a misclassification rate of approximately $15 \%$.

While this study has focused solely on prostate cancer patients, to limit interpatient variability, it would be valuable for future studies to investigate these same endpoints in different patient cohorts to see if there is a similar result. This would help to confirm these lymphocyte assays as general bioindicators of radiosensitivity, not limited 
to just one type of cancer. As noted in the DCA discussion (Chapter 4), similar results for the dicentric chromosome and excess fragment endpoints have already been found in breast cancer patients by Chua et al. et al.[43], as well as Borgmann et al. [42].

\subsubsection{Null results and suggested improvements}

With regards to the negative results in the $\gamma \mathrm{H} 2 \mathrm{AX}$ assay, this study showed a large interpatient variability in $\gamma \mathrm{H} 2 \mathrm{AX}$ response, even in the baseline signal. This is not unexpected, as Ismail et al. [98] used a flow cytometry method to measure $\gamma \mathrm{H} 2 \mathrm{AX}$ signal in unfixed white blood cells, and also found a significant variation in the level of $\gamma \mathrm{H} 2 \mathrm{AX}$ expressed that did not correlate with DNA damage. They proposed that the number of $\gamma \mathrm{H} 2 \mathrm{AX}$ molecules produced per DSB, and therefore the size of foci, varied among individuals; this would be detectable by fluorescence intensity measurement (for example with flow cytometry) but not with $\gamma \mathrm{H} 2 \mathrm{AX}$ foci counting techniques (which is independent of brightness). Chua et al. [43] found a significant correlation between residual DNA damage in irradiated blood lymphocytes and late normal tissue response to breast radiotherapy. Similar to this study, Chua et al. looked at both residual DNA damage by counting $\gamma \mathrm{H} 2 \mathrm{AX}$ foci after $24 \mathrm{~h}$ as well as counting excess aberrations per cell, such as excess acentric fragments after $6 \mathrm{~Gy}$. The major difference between the two studies was in the $\gamma \mathrm{H} 2 \mathrm{AX}$ analysis. Chua et al. examined two dose points at two time points: $0.5 \mathrm{~Gy}$ at $0.5 \mathrm{~h}$ and $4 \mathrm{~Gy}$ at $24 \mathrm{~h}$ after irradiation and found a significant difference in the two groups (sensitive and control) after $24 \mathrm{~h}$ after $4 \mathrm{~Gy}$. In our study, 7 time points were examined at the same dose ( $2 \mathrm{~Gy} ; 0,0.5,1,2,4,8$ and $24 \mathrm{~h}$ ) and 6 dose

point at the same time $(1 \mathrm{~h} ; 0,2,4,6,8,10 \mathrm{~Gy})$. Our study also used flow cytometry 
methods, examining the fluorescent intensity of approximately 50,000 lymphocytes per sample, as compared to Chua et al. who counted $\gamma \mathrm{H} 2 \mathrm{AX}$ foci in at least 50 cells per sample. The study by Finnon et al. [57] examining multiple gene expression and chromosome damage endpoints also examined $\gamma \mathrm{H} 2 \mathrm{AX}$ response by flow cytometry and found that the sensitive patients could not be distinguished from controls. This indicates that either the spot counting methods are more sensitive; and that the flow method is not quite sensitive enough to differentiate between the two populations, or that a higher dose is required to reveal differences in damage induced to cells from the two populations of patients. Future studies will develop a method that uses a combination of intensity and spot counting technique, such as that possible with an imaging flow cytometer. This would allow for the acquisition of more information on both the number of DSBs as well as the intensity of each focus.

\subsubsection{Patient selection and limitations of sample size}

Our study was limited by the number of radiosensitive patients available and willing to participate. A patient was identified as radiosensitive if they were a Grade 3 patient (using the RTOG/EORTC score (see Appendix A), specifically those patients requiring cauterization of colonic lesions). Of the 13 patients identified as Grade 3,1 passed away and 2 declined to participate. All patients were selected from the same clinical trial to minimize interpatient variability; keeping to patients within this strictly controlled clinical study resulted in patients of a similar age, gender and with very similar treatment protocols, and dose volume histograms. Comparable studies, such as Chua et 
al. [43] had similar sample sizes: 14 (7 sensitive and 7 controls). Future studies of other patient cohorts will help to increase the number of samples. 


\subsubsection{Confounding factors: treatment errors and treatment target volume}

The most evident confounding factor would be treatment error, and while this is always a possibility with complex treatments such as radiation therapy, the improvements in dose delivery and treatment planning are meant to reduce treatment errors. Nonetheless, patients are still exhibiting a varied response to treatment, and more severe long-term side effects are still in evidence.

It is also important to consider the treatment target volume, which could be a confounding factor when determining if a patient is to be considered radiosensitive. If this parameter is not consistently defined among patients, it could have an effect on the late normal tissue side effects. Livsey et al. [99] investigated differences in target volume definition in prostate cancer by asking several oncologists to define the clinical target volume (CTV1) and prostate volume (CTV2) and compared the plans amongst them. The results indicated that the smallest variance was noted at the most critical boundaries (for example rectum-prostate, bladder-prostate). These critical boundaries are the ones most likely to have the greatest effect on normal tissue toxicity. The authors concluded that interclinician outlining differences had less clinical relevance than expected indicating that definition of the CTV would not be a confounding factor for side effects.

\subsubsection{Missing data points}

When dealing with biological samples, it is not uncommon for unexpected sample issues to arise. As noted in the DCA discussion (Chapter 3), for patient 5, there were no countable spreads in the 0 Gy sample, while the $6 \mathrm{~Gy}$ sample did have spreads. The method control sample was checked, and no problems were detected, therefore it was 
concluded that patient 5 had slower cycling cells and therefore $48 \mathrm{~h}$ was not sufficient for the 0 Gy sample.

In the FISH experiments (Chapter 4), the samples from patients 8 and 10 did not have enough cells at 0 Gy to do any FISH analysis. These patients did have samples at 4 Gy, and were done to maximize the amount of information that could be gathered from sensitive patients.

\subsubsection{Inter-scorer variability}

To address the issue of scoring variability between scorers, adherence to a rigid set of counting rules was important. Intralaboratory comparisons were done to ensure that similar results were seen within the same set of slides (less than $5-10 \%$ ). This was important for both the DCA and FISH assays, as the scoring was done manually. It was not critical for the $\gamma \mathrm{H} 2 \mathrm{AX}$ assay as automated analysis was performed.

\subsection{Further work with assorted patient populations}

In order to further test the feasibility of these endpoints as predictors of radiation response, it would be beneficial to test the significant endpoints in additional patients. Those with other types of cancer as well as non-cancer patient cohorts who undergo radiotherapy such as arterial venal malformation (AVM) would be of interest. AVMs are not a cancerous tumour, but rather a benign malformation, often found in the brain, and pose a risk of rupture. If the AVM cannot be removed surgically, patients undergo stereotactic radiosurgery (SRS) to ablate it. This procedure is performed at the Ottawa Hospital. In most cases, this is a successful treatment, but unfortunately, a few patients 
are sensitive to the high dose of radiation and suffer from severe late normal tissue effects (radionecrosis) [100]. These patients would be prime candidates for a test of their radiosensitivity prior to treatment. Embarking on a new study also gives the opportunity to collect patient samples prior to radiotherapy and perform prospective studies.

\subsection{Application of assay(s) in the clinic}

Early research in radiosensitivity biomarkers often focused on fibroblast studies. Fibroblasts are grown from skin biopsies, which are more invasive and painful for the patient and may leave scars. The fibroblasts then have to be grown in culture, which is time consuming (a few weeks at best) and the samples can be sensitive to cell culture conditions. Brock et al. [34] discussed the issues involved with getting precise and accurate survival assay results, and noted that it would be necessary to combine survival data from at least three independent experiments to obtain an $\mathrm{SF}_{2}$ with $5 \%$ error or less. As each assay takes approximately 3-4 weeks, even overlapping schedules would result in a long turnaround time for results. They also noted a wide interpatient variability with respect to cell yield and fibroblast growth rate, morphology and cloning efficiency. These variations further complicate $\mathrm{SF}_{2}$ assays, and can lead to long delays and inconclusive results. Conversely, lymphocyte samples are considered to be more stable and easy to acquire. As well, the samples can simply be stimulated by PHA in culture to begin to cycle. The lymphocyte assays, especially the DCA, are very well established for

biodosimetry; they take 4 or 5 days to complete, depending on the dose and scoring methods, and a response could be available within a week. If a radiosensitivity assay 
were to use both DCA and FISH endpoints, the samples could be processed simultaneously, without causing a delay in the response time.

\subsubsection{Predictive assays}

It is clear from the many studies that have been done, that identifying a biomarker of radiation sensitivity to predict late normal tissue response has been a challenge. In 2002, Russell and Begg [101] published an editorial outlining the difficulties and confounding factors, both biological/laboratory factors such as cell type used, dose, dose rate, type of medium, consistent quality of the medium, plating time and use of feeder cells, as well as clinical factors such as total dose and fractionation schedule. They concluded that gene expression profiling would lead to an improved understanding of the underlying mechanisms of normal tissue reactions to radiation. They noted that the predictive power of pre-treatment expression profiling had been shown for tumours, and that proof of concept studies had recently been done. Unfortunately, the use of genetic profiling is still not used in clinical practice, and there is still a need for a relatively quick and cost-efficient bioindicator that could be used in the clinic.

Thus there are still valuable insights to be had from the investigation of chromosome aberrations, which help to provide context for the molecular mechanisms. Bailey et al. and Bedford published a review in 2006 [102] which summarized the contributions of studies of chromosomal aberrations following ionizing radiation and the insights these studies provided on the associated DNA repair processes involved. They concluded that a complementary approach of studying cytogenetic aberrations to provide context to the molecular mechanisms would be the most beneficial approach. 
Long term reactions to radiotherapy have a lasting impact on the quality of life of patients post-treatment. It is particularly relevant to patients with treatable disease with a longer life expectancy. With improvements in radiotherapy equipment and treatment planning, dose-escalation is more widely accepted, but without a proper idea of the effects on the normal tissue exposed, even to minimized doses, there could be an increased number of patients with grade 3 toxicity due to radiosensitivity, as opposed to toxicity due to treatment error/margins.

\subsection{Concluding remarks}

With improvements in planning and treatment technologies, individual patient sensitivity becomes increasingly significant to predicting patient outcomes. As mentioned in section 7.1.3 Confounding factors, the risk of adverse side effects from the treatment is being reduced as the treatment plans become more finely tuned, and the beam targeting increasingly becomes more precise and accurate. Thus individual radiosensitivities will begin to account for a larger proportion of the adverse side effects of radiotherapy. Based on the results of these three studies, it is suggested that chromosome damage assays, both DCA and FISH, be used to test patient lymphocytes for indications of individual radiosensitivity. Work should be done to further validate these results in other patient cohorts to determine if the results translate to other tumour types. As well, future work should include the start of a predictive study, where samples are obtained and tested from cancer patients prior to treatment, and the patient followed in a long-term study to note any late normal tissue toxicity. 
Identification of a predictive assay will enable the tailoring of radiation therapy to each individual allowing patients who are radiosensitive to ionizing radiation to have their doses reduced and be spared of the toxic effects to normal tissues. Conversely, those who are resistant to radiation can be given higher doses, resulting in better cure rates. Overall, this will have an impact not only on the cure rate and lifespan of these patients, but also on their quality of life. 


\section{References}

[1] H. B. Stone, C. N. Coleman, M. S. Anscher, and W. H. McBride, "Effects of radiation on normal tissue: consequences and mechanisms," Lancet Oncol., vol. 4, no. 9, pp. 529-536, Sept.2003.

[2] D. J. Brenner, "Fractionation and late rectal toxicity," Int. J. Radiat. Oncol. Biol. Phys., vol. 60, no. 4, pp. 1013-1015, Nov.2004.

[3] B. Emami, J. Lyman, A. Brown, L. Coia, M. Goitein, J. E. Munzenrider, B. Shank, L. J. Solin, and M. Wesson, "Tolerance of normal tissue to therapeutic irradiation," Int. J. Radiat. Oncol. Biol. Phys., vol. 21, no. 1, pp. 109-122, 1991.

[4] P. J. McKinnon, "ATM and ataxia telangiectasia," EMBO. Rep., vol. 5, no. 8, pp. 772-776, Aug.2004.

[5] C. C. Dvorak and M. J. Cowan, "Radiosensitive severe combined immunodeficiency disease," Immunol. Allergy Clin. North Am., vol. 30, no. 1, pp. 125-142, Feb.2010.

[6] A. R. Gennery, M. A. Slatter, A. Bhattacharya, D. Barge, S. Haigh, M. O'Driscoll, R. Coleman, M. Abinun, T. J. Flood, A. J. Cant, and P. A. Jeggo, "The clinical and biological overlap between Nijmegen Breakage Syndrome and Fanconi anemia," Clin. Immunol., vol. 113, no. 2, pp. 214-219, Nov.2004.

[7] S. M. Bentzen and J. Overgaard, "Patient-to-Patient Variability in the Expression of Radiation-Induced Normal Tissue Injury," Semin. Radiat. Oncol., vol. 4, no. 2, pp. 68-80, Apr.1994.

[8] T. A. Buchholz, "Finding our sensitive patients," Int. J. Radiat. Oncol. Biol. Phys., vol. 45, no. 3, pp. 547-548, Oct. 1999.

[9] D. Azria, M. Betz, C. Bourgier, W. J. Sozzi, and M. Ozsahin, "Identifying patients at risk for late radiation-induced toxicity," Crit Rev. Oncol. Hematol., Sept.2010.

[10] G. P. Raaphorst, S. Malone, G. Alsbeih, L. Souhani, E. Szumacher, and A. Girard, "Skin fibroblasts in vitro radiosensitivity can predict for late complications following AVM radiosurgery," Radiother. Oncol., vol. 64, no. 2, pp. 153-156, Aug.2002.

[11] C. N. Andreassen, J. Alsner, and J. Overgaard, "Does variability in normal tissue reactions after radiotherapy have a genetic basis--where and how to look for it?," Radiother. Oncol., vol. 64, no. 2, pp. 131-140, Aug.2002.

[12] J. W. Denham and M. Hauer-Jensen, "The radiotherapeutic injury--a complex 'wound'," Radiother. Oncol., vol. 63, no. 2, pp. 129-145, May2002. 
[13] D. T. Goodhead, "Initial events in the cellular effects of ionizing radiations: clustered damage in DNA," Int. J. Radiat. Biol., vol. 65, no. 1, pp. 7-17, Jan. 1994.

[14] J. F. Ward, "The complexity of DNA damage: relevance to biological consequences," Int. J. Radiat. Biol., vol. 66, no. 5, pp. 427-432, Nov.1994.

[15] P. Pfeiffer, W. Goedecke, and G. Obe, "Mechanisms of DNA double-strand break repair and their potential to induce chromosomal aberrations," Mutagenesis, vol. 15 , no. 4, pp. 289-302, July 2000.

[16] C. Richardson, M. E. Moynahan, and M. Jasin, "Double-strand break repair by interchromosomal recombination: suppression of chromosomal translocations," Genes Dev., vol. 12, no. 24, pp. 3831-3842, Dec.1998.

[17] P. Pfeiffer, W. Goedecke, S. Kuhfittig-Kulle, and G. Obe, "Pathways of DNA double-strand break repair and their impact on the prevention and formation of chromosomal aberrations," Cytogenet. Genome Res., vol. 104, no. 1-4, pp. 7-13, 2004.

[18] K. Rothkamm, I. Kruger, L. H. Thompson, and M. Lobrich, "Pathways of DNA double-strand break repair during the mammalian cell cycle," Mol. Cell Biol., vol. 23, no. 16, pp. 5706-5715, Aug.2003.

[19] E. Mladenov and G. Iliakis, "Induction and repair of DNA double strand breaks: the increasing spectrum of non-homologous end joining pathways," Mutat. Res., vol. 711 , no. 1-2, pp. 61-72, June2011.

[20] C. Redon, D. Pilch, E. Rogakou, O. Sedelnikova, K. Newrock, and W. Bonner, "Histone H2A variants H2AX and H2AZ," Curr. Opin. Genet. Dev., vol. 12, no. 2, pp. 162-169, Apr.2002.

[21] A. Celeste, O. Fernandez-Capetillo, M. J. Kruhlak, D. R. Pilch, D. W. Staudt, A. Lee, R. F. Bonner, W. M. Bonner, and A. Nussenzweig, "Histone H2AX phosphorylation is dispensable for the initial recognition of DNA breaks," Nat. Cell Biol, vol. 5, no. 7, pp. 675-679, July2003.

[22] O. Fernandez-Capetillo, A. Lee, M. Nussenzweig, and A. Nussenzweig, "H2AX: the histone guardian of the genome," DNA Repair (Amst), vol. 3, no. 8-9, pp. 959967, Aug.2004.

[23] E. P. Rogakou, D. R. Pilch, A. H. Orr, V. S. Ivanova, and W. M. Bonner, "DNA double-stranded breaks induce histone $\mathrm{H} 2 \mathrm{AX}$ phosphorylation on serine $139, " \mathrm{~J}$. Biol. Chem., vol. 273, no. 10, pp. 5858-5868, Mar.1998.

[24] E. P. Rogakou, C. Boon, C. Redon, and W. M. Bonner, "Megabase chromatin domains involved in DNA double-strand breaks in vivo," J. Cell Biol., vol. 146, no. 5, pp. 905-916, Sept. 1999. 
[25] O. A. Sedelnikova, E. P. Rogakou, I. G. Panyutin, and W. M. Bonner, "Quantitative detection of (125)IdU-induced DNA double-strand breaks with gamma-H2AX antibody," Radiat. Res., vol. 158, no. 4, pp. 486-492, Oct.2002.

[26] D. R. Pilch, O. A. Sedelnikova, C. Redon, A. Celeste, A. Nussenzweig, and W. M. Bonner, "Characteristics of gamma-H2AX foci at DNA double-strand breaks sites," Biochem. Cell Biol., vol. 81, no. 3, pp. 123-129, June2003.

[27] A. Kinner, W. Wu, C. Staudt, and G. Iliakis, "Gamma-H2AX in recognition and signaling of DNA double-strand breaks in the context of chromatin," Nucleic Acids Res., vol. 36, no. 17, pp. 5678-5694, Oct.2008.

[28] Alberts B, Bray D, Lewis J, Raff M, Roberts K, and Watson JD, Molecular biology of the cell. New York: Garland, 1994.

[29] N. G. Burnet, J. Nyman, I. Turesson, R. Wurm, J. R. Yarnold, and J. H. Peacock, "Prediction of normal-tissue tolerance to radiotherapy from in-vitro cellular radiation sensitivity," Lancet, vol. 339, no. 8809, pp. 1570-1571, June 1992.

[30] F. B. Geara, L. J. Peters, K. K. Ang, J. L. Wike, and W. A. Brock, "Prospective comparison of in vitro normal cell radiosensitivity and normal tissue reactions in radiotherapy patients," Int. J. Radiat. Oncol. Biol. Phys., vol. 27, no. 5, pp. 1173$1179,1993$.

[31] A. E. Kiltie, J. B. Barber, R. Swindell, A. J. Ryan, C. M. West, J. H. Hendry, and B. Magee, "Lack of correlation between residual radiation-induced DNA damage, in keratinocytes assayed directly from skin, and late radiotherapy reactions in breast cancer patients," Int. J. Radiat. Oncol. Biol. Phys., vol. 43, no. 3, pp. 481487, Feb. 1999.

[32] A. E. Kiltie, A. J. Ryan, R. Swindell, J. B. Barber, C. M. West, B. Magee, and J. $H$. Hendry, "A correlation between residual radiation-induced DNA double-strand breaks in cultured fibroblasts and late radiotherapy reactions in breast cancer patients," Radiother. Oncol., vol. 51, no. 1, pp. 55-65, Apr.1999.

[33] J. Peacock, A. Ashton, J. Bliss, C. Bush, J. Eady, C. Jackson, R. Owen, J. Regan, and J. Yarnold, "Cellular radiosensitivity and complication risk after curative radiotherapy," Radiother. Oncol., vol. 55, no. 2, pp. 173-178, May2000.

[34] W. A. Brock, S. L. Tucker, F. B. Geara, I. Turesson, J. Wike, J. Nyman, and L. J. Peters, "Fibroblast radiosensitivity versus acute and late normal skin responses in patients treated for breast cancer," Int. J. Radiat. Oncol. Biol. Phys., vol. 32, no. 5, pp. 1371-1379, 1995.

[35] N. E. Crompton, R. Miralbell, H. P. Rutz, F. Ersoy, O. Sanal, D. Wellmann, S. Bieri, P. A. Coucke, G. C. Emery, Y. Q. Shi, H. Blattmann, and M. Ozsahin, "Altered apoptotic profiles in irradiated patients with increased toxicity [see 
comments]," Int. J. Radiat. Oncol. Biol. Phys., vol. 45, no. 3, pp. 707-714, Oct.1999.

[36] J. B. Barber, C. M. West, A. E. Kiltie, S. A. Roberts, and D. Scott, "Detection of individual differences in radiation-induced apoptosis of peripheral blood lymphocytes in normal individuals, ataxia telangiectasia homozygotes and heterozygotes, and breast cancer patients after radiotherapy," Radiat Res, vol. 153, no. 5 Pt 1, pp. 570-578, May2000.

[37] R. C. Wilkins, B. C. Kutzner, M. Truong, and J. R. McLean, "The effect of the ratio of $\mathrm{CD} 4+$ to $\mathrm{CD} 8+\mathrm{T}$-cells on radiation-induced apoptosis in human lymphocyte subpopulations," Int. J. Radiat. Biol., vol. 78, no. 8, pp. 681-688, Aug.2002.

[38] M. Ozsahin, N. E. Crompton, S. Gourgou, A. Kramar, L. Li, Y. Shi, W. J. Sozzi, A. Zouhair, R. O. Mirimanoff, and D. Azria, "CD4 and CD8 T-lymphocyte apoptosis can predict radiation-induced late toxicity: a prospective study in 399 patients," Clin. Cancer Res., vol. 11, no. 20, pp. 7426-7433, Oct.2005.

[39] K. Schnarr, D. Boreham, J. Sathya, J. Julian, and I. S. Dayes, "Radiation-Induced Lymphocyte Apoptosis to Predict Radiation Therapy Late Toxicity in Prostate Cancer Patients," Int. J. Radiat. Oncol. Biol. Phys., Jan.2009.

[40] L. A. Henriquez-Hernandez, R. Carmona-Vigo, B. Pinar, E. Bordon, M. Lloret, M. I. Nunez, C. Rodriguez-Gallego, and P. C. Lara, "Combined low initial DNA damage and high radiation-induced apoptosis confers clinical resistance to longterm toxicity in breast cancer patients treated with high-dose radiotherapy," Radiat. Oncol., vol. 6, p. 60, 2011.

[41] U. Hoeller, K. Borgmann, M. Bonacker, A. Kuhlmey, A. Bajrovic, H. Jung, W. Alberti, and E. Dikomey, "Individual radiosensitivity measured with lymphocytes may be used to predict the risk of fibrosis after radiotherapy for breast cancer," Radiother. Oncol., vol. 69, no. 2, pp. 137-144, Nov.2003.

[42] K. Borgmann, U. Hoeller, S. Nowack, M. Bernhard, B. Roper, S. Brackrock, C. Petersen, S. Szymczak, A. Ziegler, P. Feyer, W. Alberti, and E. Dikomey, "Individual radiosensitivity measured with lymphocytes may predict the risk of acute reaction after radiotherapy," Int. J. Radiat. Oncol. Biol. Phys., vol. 71, no. 1, pp. 256-264, May2008.

[43] M. L. Chua, N. Somaiah, R. A'Hern, S. Davies, L. Gothard, J. Yarnold, and K. Rothkamm, "Residual DNA and chromosomal damage in ex vivo irradiated blood lymphocytes correlated with late normal tissue response to breast radiotherapy," Radiother. Oncol., vol. 99, no. 3, pp. 362-366, June2011.

[44] E. C. Bourton, P. N. Plowman, D. Smith, C. F. Arlett, and C. N. Parris, "Prolonged expression of the gamma-H2AX DNA repair biomarker correlates 
with excess acute and chronic toxicity from radiotherapy treatment," Int. J. Cancer, vol. 129, no. 12, pp. 2928-2934, Dec.2011.

[45] J. Werbrouck, R. K. De, L. Beels, A. Vral, E. M. Van, N. W. De, and H. Thierens, "Prediction of late normal tissue complications in RT treated gynaecological cancer patients: potential of the gamma-H2AX foci assay and association with chromosomal radiosensitivity," Oncol. Rep., vol. 23, no. 2, pp. 571-578, Feb.2010.

[46] J. Werbrouck, F. Duprez, N. W. De, and H. Thierens, "Lack of a correlation between gammaH2AX foci kinetics in lymphocytes and the severity of acute normal tissue reactions during IMRT treatment for head and neck cancer," Int. $J$. Radiat. Biol., vol. 87, no. 1, pp. 46-56, Jan.2011.

[47] G. I. Terzoudi, V. I. Hatzi, C. Donta-Bakoyianni, and G. E. Pantelias, "Chromatin dynamics during cell cycle mediate conversion of DNA damage into chromatid breaks and affect formation of chromosomal aberrations: biological and clinical significance," Mutat. Res., vol. 711, no. 1-2, pp. 174-186, June2011.

[48] G. E. Pantelias and G. I. Terzoudi, "A standardized G2-assay for the prediction of individual radiosensitivity," Radiother. Oncol., vol. 101, no. 1, pp. 28-34, Oct.2011.

[49] J. P. Banath, S. H. MacPhail, and P. L. Olive, "Radiation sensitivity, H2AX phosphorylation, and kinetics of repair of DNA strand breaks in irradiated cervical cancer cell lines," Cancer Res., vol. 64, no. 19, pp. 7144-7149, Oct.2004.

[50] C. N. Andreassen, "Can risk of radiotherapy-induced normal tissue complications be predicted from genetic profiles?," Acta Oncol, vol. 44, no. 8, pp. 801-815, 2005.

[51] C. Badie, S. Dziwura, C. Raffy, T. Tsigani, G. Alsbeih, J. Moody, P. Finnon, E. Levine, D. Scott, and S. Bouffler, "Aberrant CDKN1A transcriptional response associates with abnormal sensitivity to radiation treatment," Br. J. Cancer, vol. 98 , no. 11 , pp. 1845-1851, June2008.

[52] J. A. Meador, S. A. Ghandhi, and S. A. Amundson, "p53-Independent Downregulation of Histone Gene Expression in Human Cell Lines by High- and Low-LET Radiation," Radiat. Res., vol. 175, no. 6, pp. 689-699, June2011.

[53] O. K. Rodningen, A. L. Borresen-Dale, J. Alsner, T. Hastie, and J. Overgaard, "Radiation-induced gene expression in human subcutaneous fibroblasts is predictive of radiation-induced fibrosis," Radiother. Oncol., vol. 86, no. 3, pp. 314-320, Mar.2008.

[54] C. M. West, M. J. McKay, T. Holscher, M. Baumann, I. J. Stratford, R. G. Bristow, M. Iwakawa, T. Imai, S. M. Zingde, M. S. Anscher, J. Bourhis, A. C. Begg, K. Haustermans, S. M. Bentzen, and J. H. Hendry, "Molecular markers 
predicting radiotherapy response: report and recommendations from an International Atomic Energy Agency technical meeting," Int. J. Radiat. Oncol. Biol. Phys., vol. 62, no. 5, pp. 1264-1273, Aug.2005.

[55] M. Baumann, T. Holscher, and A. C. Begg, "Towards genetic prediction of radiation responses: ESTRO's GENEPI project," Radiother. Oncol., vol. 69, no. 2, pp. 121-125, Nov.2003.

[56] A. Y. Ho, D. P. Atencio, S. Peters, R. G. Stock, S. C. Formenti, J. A. Cesaretti, S. Green, B. Haffty, K. Drumea, L. Leitzin, A. Kuten, D. Azria, M. Ozsahin, J. Overgaard, C. N. Andreassen, C. S. Trop, J. Park, and B. S. Rosenstein, "Genetic predictors of adverse radiotherapy effects: the Gene-PARE project," Int. $J$. Radiat. Oncol. Biol. Phys., vol. 65, no. 3, pp. 646-655, July2006.

[57] P. Finnon, S. Kabacik, A. Mackay, C. Raffy, R. A'Hern, R. Owen, C. Badie, J. Yarnold, and S. Bouffler, "Correlation of in vitro lymphocyte radiosensitivity and gene expression with late normal tissue reactions following curative radiotherapy for breast cancer," Radiother. Oncol., vol. 105, no. 3, pp. 329-336, Dec.2012.

[58] J. D. Cox, J. Stetz, and T. F. Pajak, "Toxicity criteria of the Radiation Therapy Oncology Group (RTOG) and the European Organization for Research and Treatment of Cancer (EORTC)," Int. J. Radiat. Oncol. Biol. Phys., vol. 31, no. 5, pp. 1341-1346, Mar.1995.

[59] O. Nairz, F. Merz, H. Deutschmann, P. Kopp, H. Scholler, F. Zehentmayr, K. Wurstbauer, G. Kametriser, and F. Sedlmayer, "A strategy for the use of imageguided radiotherapy (IGRT) on linear accelerators and its impact on treatment margins for prostate cancer patients," Strahlenther. Onkol., vol. 184, no. 12, pp. 663-667, Dec.2008.

[60] D. J. Brenner, A. A. Martinez, G. K. Edmundson, C. Mitchell, H. D. Thames, and E. P. Armour, "Direct evidence that prostate tumors show high sensitivity to fractionation (low alpha/beta ratio), similar to late-responding normal tissue," Int. J. Radiat. Oncol. Biol. Phys., vol. 52, no. 1, pp. 6-13, Jan.2002.

[61] D. J. Brenner, "Hypofractionation for prostate cancer radiotherapy--what are the issues?," Int. J. Radiat. Oncol. Biol. Phys., vol. 57, no. 4, pp. 912-914, Nov.2003.

[62] W. Dorr and J. H. Hendry, "Consequential late effects in normal tissues," Radiother. Oncol., vol. 61, no. 3, pp. 223-231, Dec.2001.

[63] B. G. Gardner, A. L. Zietman, W. U. Shipley, U. E. Skowronski, and P. McManus, "Late normal tissue sequelae in the second decade after high dose radiation therapy with combined photons and conformal protons for locally advanced prostate cancer," J. Urol., vol. 167, no. 1, pp. 123-126, Jan.2002. 
[64] A. R. Mclean and C. A. Michie, "In vivo estimates of division and death rates of human T lymphocytes," Proc. Natl. Acad. Sci. U. S. A, vol. 92, no. 9, pp. 37073711 , Apr.1995.

[65] IAEA, "Cytogenetic Dosimetry: Applications in Preparedness for and Response to Radiation Emergencies," IAEA, Vienna,EPR-Biodose 2011, 2011.

[66] P. C. Nowell, "Phytohemagglutinin: an initiator of mitosis in cultures of normal human leukocytes," Cancer Res., vol. 20, pp. 462-466, May1960.

[67] P. S. Moorhead, P. C. Nowell, W. J. Mellman, D. M. Battips, and D. A. Hungerford, "Chromosome preparations of leukocytes cultured from human peripheral blood," Exp. Cell Res., vol. 20, pp. 613-616, Sept.1960.

[68] P. Perry and S. Wolff, "New Giemsa method for the differential staining of sister chromatids," Nature, vol. 251, no. 5471, pp. 156-158, Sept.1974.

[69] A. T. Sumner and H. J. Evans, "Mechanisms involved in the banding of chromosomes with guinacrine and Giems. II. The interaction of the dyes with the chromosomal components," Exp. Cell Res., vol. 81, no. 1, pp. 223-226, Sept.1973.

[70] D. Pinkel, T. Straume, and J. W. Gray, "Cytogenetic analysis using quantitative, high-sensitivity, fluorescence hybridization," Proc. Natl. Acad. Sci. U. S. A, vol. 83, no. 9, pp. 2934-2938, May1986.

[71] K. L. Johnson, J. D. Tucker, and J. Nath, "Frequency, distribution and clonality of chromosome damage in human lymphocytes by multi-color FISH," Mutagenesis, vol. 13, no. 3, pp. 217-227, May1998.

[72] J. D. Tucker, W. F. Morgan, A. A. Awa, M. Bauchinger, D. Blakey, M. N. Cornforth, L. G. Littlefield, A. T. Natarajan, and C. Shasserre, "A proposed system for scoring structural aberrations detected by chromosome painting," Cytogenet. Cell Genet., vol. 68, no. 3-4, pp. 211-221, 1995.

[73] P. L. Olive and J. P. Banath, "Phosphorylation of histone H2AX as a measure of radiosensitivity," Int. J. Radiat. Oncol. Biol. Phys., vol. 58, no. 2, pp. 331-335, Feb.2004.

[74] M. Roach, III, "Reducing the toxicity associated with the use of radiotherapy in men with localized prostate cancer," Urol. Clin. North Am., vol. 31, no. 2, pp. 353-366, May2004.

[75] S. M. Bentzen, W. Dorr, M. S. Anscher, J. W. Denham, M. Hauer-Jensen, L. B. Marks, and J. Williams, "Normal tissue effects: reporting and analysis," Semin. Radiat. Oncol., vol. 13, no. 3, pp. 189-202, July2003. 
[76] S. M. Bentzen, M. Overgaard, and J. Overgaard, "Clinical correlations between late normal tissue endpoints after radiotherapy: implications for predictive assays of radiosensitivity," Eur. J Cancer, vol. 29A, no. 10, pp. 1373-1376, 1993.

[77] L. B. Marks, E. D. Yorke, A. Jackson, R. K. Ten Haken, L. S. Constine, A. Eisbruch, S. M. Bentzen, J. Nam, and J. O. Deasy, "Use of normal tissue complication probability models in the clinic," Int. J. Radiat. Oncol. Biol. Phys., vol. 76, no. 3 Suppl, p. S10-S19, Mar.2010.

[78] N. G. Burnet, J. Nyman, I. Turesson, R. Wurm, J. R. Yarnold, and J. H. Peacock, "The relationship between cellular radiation sensitivity and tissue response may provide the basis for individualising radiotherapy schedules," Radiother. Oncol., vol. 33, no. 3, pp. 228-238, 1994.

[79] S. Neubauer, J. Dunst, and E. Gebhart, "The impact of complex chromosomal rearrangements on the detection of radiosensitivity in cancer patients," Radiother. Oncol., vol. 43, no. 2, pp. 189-195, May1997.

[80] K. Borgmann, B. Roper, R. El-Awady, S. Brackrock, M. Bigalke, T. Dork, W. Alberti, E. Dikomey, and J. Dahm-Daphi, "Indicators of late normal tissue response after radiotherapy for head and neck cancer: fibroblasts, lymphocytes, genetics, DNA repair, and chromosome aberrations," Radiother. Oncol., vol. 64, no. 2, pp. 141-152, Aug.2002.

[81] C. M. West, S. A. Elyan, P. Berry, R. Cowan, and D. Scott, "A comparison of the radiosensitivity of lymphocytes from normal donors, cancer patients, individuals with ataxia-telangiectasia (A-T) and A-T heterozygotes," Int. J. Radiat. Biol., vol. 68, no. 2, pp. 197-203, Aug. 1995.

[82] D. C. Lloyd, R. J. Purrott, and E. J. Reeder, "The incidence of unstable chromosome aberrations in peripheral blood lymphocytes from unirradiated and occupationally exposed people," Mutat. Res., vol. 72, no. 3, pp. 523-532, Aug.1980.

[83] P. Vodicka, Z. Polivkova, S. Sytarova, H. Demova, M. Kucerova, L. Vodickova, V. Polakova, A. Naccarati, Z. Smerhovsky, M. Ambrus, M. Cerna, and K. Hemminki, "Chromosomal damage in peripheral blood lymphocytes of newly diagnosed cancer patients and healthy controls," Carcinogenesis, vol. 31, no. 7, pp. 1238-1241, July2010.

[84] K. Borgmann, U. Hoeller, S. Nowack, M. Bernhard, B. Roper, S. Brackrock, C. Petersen, S. Szymczak, A. Ziegler, P. Feyer, W. Alberti, and E. Dikomey, "Individual radiosensitivity measured with lymphocytes may predict the risk of acute reaction after radiotherapy," Int. J. Radiat. Oncol. Biol. Phys., vol. 71, no. 1, pp. 256-264, May2008.

[85] M. Fernet and J. Hall, "Predictive markers for normal tissue reactions: fantasy or reality?," Cancer Radiother., vol. 12, no. 6-7, pp. 614-618, Nov.2008. 
[86] J. B. Barber, W. Burrill, A. R. Spreadborough, E. Levine, C. Warren, A. E. Kiltie, S. A. Roberts, and D. Scott, "Relationship between in vitro chromosomal radiosensitivity of peripheral blood lymphocytes and the expression of normal tissue damage following radiotherapy for breast cancer," Radiother. Oncol., vol. 55, no. 2, pp. 179-186, May2000.

[87] L. A. Beaton, C. L. Ferrarotto, L. Marro, S. Samiee, S. Malone, S. Grimes, K. Malone, and R. C. Wilkins, "Chromosome damage and cell proliferation rates in in vitro irradiated whole blood as markers of late radiation toxicity after prostate radiotherapy," Int. J. Radiat. Oncol. Biol. Phys., 2012. http://dx.doi.org/10.1016/j.ijrobp.2012.09.026

[88] R. Huber, H. Braselmann, H. Geinitz, I. Jaehnert, A. Baumgartner, R. Thamm, M. Figel, M. Molls, and H. Zitzelsberger, "Chromosomal radiosensitivity and acute radiation side effects after radiotherapy in tumour patients--a follow-up study," Radiat. Oncol., vol. 6, p. 32, 2011.

[89] J. D. Tucker, W. F. Morgan, A. A. Awa, M. Bauchinger, D. Blakey, M. N. Cornforth, L. G. Littlefield, A. T. Natarajan, and C. Shasserre, "PAINT: a proposed nomenclature for structural aberrations detected by whole chromosome painting," Mutat. Res., vol. 347, no. 1, pp. 21-24, June 1995.

[90] O. A. Sedelnikova, D. R. Pilch, C. Redon, and W. M. Bonner, "Histone H2AX in DNA damage and repair," Cancer Biol. Ther, vol. 2, no. 3, pp. 233-235, May2003.

[91] C. E. Rube, A. Fricke, J. Wendorf, A. Stutzel, M. Kuhne, M. F. Ong, P. Lipp, and C. Rube, "Accumulation of DNA double-strand breaks in normal tissues after fractionated irradiation," Int. J. Radiat. Oncol. Biol. Phys., vol. 76, no. 4, pp. 1206-1213, Mar.2010.

[92] A. Menegakis, A. Yaromina, W. Eicheler, A. Dorfler, B. Beuthien-Baumann, H. D. Thames, M. Baumann, and M. Krause, "Prediction of clonogenic cell survival curves based on the number of residual DNA double strand breaks measured by gammaH2AX staining," Int. J. Radiat. Biol., vol. 85, no. 11, pp. 1032-1041, Nov.2009.

[93] A. Andrievski and R. C. Wilkins, "The response of gamma-H2AX in human lymphocytes and lymphocytes subsets measured in whole blood cultures," Int J Radiat Biol, vol. 85, no. 4, pp. 369-376, Apr.2009.

[94] S. Chow, D. Hedley, P. Grom, R. Magari, J. W. Jacobberger, and T. V. Shankey, "Whole blood fixation and permeabilization protocol with red blood cell lysis for flow cytometry of intracellular phosphorylated epitopes in leukocyte subpopulations," Cytometry A, vol. 67, no. 1, pp. 4-17, Sept.2005.

[95] M. Lew, "Good statistical practice in pharmacology. Problem 2," Br. J. Pharmacol., vol. 152, no. 3, pp. 299-303, Oct.2007. 
[96] E. Bordon, L. A. Henriquez-Hernandez, P. C. Lara, B. Pinar, C. RodriguezGallego, and M. Lloret, "Role of CD4 and CD8 T-lymphocytes, B-lymphocytes and Natural Killer cells in the prediction of radiation-induced late toxicity in cervical cancer patients," Int. J. Radiat. Biol., vol. 87, no. 4, pp. 424-431, Apr.2011.

[97] S. J. Press and S. Wilson, "Choosing between Logistic Regression and Discriminant Analysis,", 73 ed 1977, pp. 699-705.

[98] I. H. Ismail, T. I. Wadhra, and O. Hammarsten, "An optimized method for detecting gamma-H2AX in blood cells reveals a significant interindividual variation in the gamma-H2AX response among humans," Nucleic Acids Res., vol. 35 , no. 5, p. e36, 2007.

[99] J. E. Livsey, J. P. Wylie, R. Swindell, V. S. Khoo, R. A. Cowan, and J. P. Logue, "Do differences in target volume definition in prostate cancer lead to clinically relevant differences in normal tissue toxicity?," Int. J. Radiat. Oncol. Biol. Phys., vol. 60 , no. 4 , pp. $1076-1081$, Nov. 2004.

[100] E. B. Dinca, L. P. de, J. Yianni, J. Rowe, M. W. Radatz, D. Preotiuc-Pietro, and A. A. Kemeny, "Gamma Knife surgery for pediatric arteriovenous malformations: a 25-year retrospective study," J. Neurosurg. Pediatr., vol. 10, no. 5, pp. 445-450, Nov.2012.

[101] N. S. Russell and A. C. Begg, "Editorial radiotherapy and oncology 2002: predictive assays for normal tissue damage," Radiother. Oncol., vol. 64, no. 2, pp. 125-129, Aug.2002.

[102] S. M. Bailey and J. S. Bedford, "Studies on chromosome aberration induction: what can they tell us about DNA repair?," DNA. Repair. (Amst. ), vol. 5, no. 9-10, pp. 1171-1181, Sept.2006. 


\section{Appendix A - Late Radiation Morbidity Scoring Schema}

The RTOG/EORTC late radiation morbidity scoring schema [58], with grade 0 (not listed) for all tissues corresponding to no side effects, and grade 5 (not listed) for selected tissues corresponding to death directly related to radiation effects.

\begin{tabular}{|c|c|c|c|c|}
\hline \multicolumn{5}{|c|}{ RTOG/EORTC LATE Radiation Morbidity } \\
\hline Tissue & Grade 1 & 2 & 3 & 4 \\
\hline $\begin{array}{l}\text { Small/Large } \\
\text { intestine }\end{array}$ & $\begin{array}{l}\text { Mild diarrhea; } \\
\text { mild cramping; } \\
\text { bowel } \\
\text { movement } 5 \\
\text { times daily; } \\
\text { slight rectal } \\
\text { discharge or } \\
\text { bleeding }\end{array}$ & $\begin{array}{l}\text { Moderate diarrhea } \\
\text { and colic; bowel } \\
\text { movement }>5 \\
\text { times daily; } \\
\text { excessive rectal } \\
\text { mucus or } \\
\text { intermittent } \\
\text { bleeding }\end{array}$ & $\begin{array}{l}\text { Obstruction } \\
\text { or bleeding, } \\
\text { requiring } \\
\text { surgery }\end{array}$ & $\begin{array}{c}\text { Necrosis / } \\
\text { perforation fistula }\end{array}$ \\
\hline Bladder & $\begin{array}{l}\text { Slight epithelial } \\
\text { atrophy; minor } \\
\text { telangiectasia } \\
\text { (microscopic } \\
\text { hematuria) }\end{array}$ & $\begin{array}{l}\text { Moderate } \\
\text { frequency; } \\
\text { generalized } \\
\text { telangiectasia; } \\
\text { intermittent } \\
\text { macroscopic } \\
\text { hematuria }\end{array}$ & $\begin{array}{c}\text { Severe } \\
\text { frequency \& } \\
\text { dysuria; } \\
\text { severe } \\
\text { telangiectasia } \\
\text { (often with } \\
\text { petechiae); } \\
\text { frequent } \\
\text { hematuria; } \\
\text { reduction in } \\
\text { bladder } \\
\text { capacity } \\
\text { (<150 cc) }\end{array}$ & $\begin{array}{l}\text { Necrosis/contracted } \\
\text { bladder (capacity < } \\
100 \mathrm{cc} \text { ); severe } \\
\text { hemorrhagic } \\
\text { cystitis }\end{array}$ \\
\hline
\end{tabular}

